\title{
PE Teachers' Perceptions of Technology-Related Learning Experiences: A Qualitative Investigation
}

\author{
Jun-Hyung Baek
}

Follow this and additional works at: https://researchrepository.wvu.edu/etd

\section{Recommended Citation}

Baek, Jun-Hyung, "PE Teachers' Perceptions of Technology-Related Learning Experiences: A Qualitative Investigation" (2016). Graduate Theses, Dissertations, and Problem Reports. 5140.

https://researchrepository.wvu.edu/etd/5140

This Dissertation is protected by copyright and/or related rights. It has been brought to you by the The Research Repository @ WVU with permission from the rights-holder(s). You are free to use this Dissertation in any way that is permitted by the copyright and related rights legislation that applies to your use. For other uses you must obtain permission from the rights-holder(s) directly, unless additional rights are indicated by a Creative Commons license in the record and/ or on the work itself. This Dissertation has been accepted for inclusion in WVU Graduate Theses, Dissertations, and Problem Reports collection by an authorized administrator of The Research Repository @ WVU.

For more information, please contact researchrepository@mail.wvu.edu. 
PE Teachers' Perceptions of Technology-Related Learning Experiences: A Qualitative Investigation

Jun-Hyung Baek, Ms.Ed.

Dissertation submitted to the College of Physical Activity and Sport Sciences

at West Virginia University

in partial fulfillment of the requirements for the degree of

Doctor of Philosophy in Kinesiology

With an emphasis

in

Coaching and Teaching Studies

Emily Jones, Ph.D., Chair.

Sean Bulger, Ed.D.

Andrea Taliaferro, Ph.D.

Malayna Bernstein, Ph.D.

Mete Akcaoglu, Ph.D.

College of Physical Activity and Sport Sciences

\author{
Morgantown, West Virginia \\ 2016
}

Keywords: technology integration, physical education teacher education, professional development program, barriers, strategies

Copyright 2016 Jun-Hyung Baek 


\section{ABSTRACT \\ PE Teachers' Perceptions of Technology-Related Learning Experiences: A Qualitative Investigation}

\section{Jun-Hyung Baek, M.S.}

Background/Purpose: Educational organizations, such as National Association for Sport and Physical Education (NASPE) and International Society for Technology in Education (ISTE), established technology-related standards indicating the knowledge and skills necessary for teachers to integrate technology. Such standards have challenged teacher education programs to restructure existing PETE program to prepare teachers to have knowledge, skills, and dispositions necessary for successful technology integration (Jones, Bulger, \& Wyant, 2012). Yet, physical education (PE) teachers frequently reported that they still do not feel sufficiently prepared to incorporate technology into their classroom (Juniu, Shonfeld, \& Ganot, 2013). Thus, the purpose of this study was to examine in-service PE teachers' past learning experiences to integrate technology from three mediated learning situations and their perceptions of them. Methods/Analysis: Twelve PE teachers, who were enrolled in the Master's PETE program at a rural mid-Atlantic university were invited to participate in this current study based on the results of the Stage of Adoption of Technology (SAT) survey (Christensen, 1997). All participants completed an individual audio-recorded, structured interview regarding their past technologyrelated learning experiences in the three mediated learning situations. Inductive content analysis was used to examine the emergent themes (Elo \& Kyngas, 2008). Trustworthiness of the data was established through member check, investigator triangulation, and peer debriefing. Results: With regard to technology-related learning experiences, the inductive content analysis revealed six learning sources: a) sport and exercise science coursework, b) discipline-specific pedagogy coursework, c) general teacher education coursework, d) school-wide technology workshops, e) discipline-specific technology workshops, f) discipline-specific technology coursework. Two overarching themes emerged from the interview data regarding participants' perceptions of those learning experiences: a) technology-centric/focused experience, and b) hands-on technology experience and observations. Conclusion: Since the level of teachers' knowledge and technology use are different, there should be various learning activities to address the different needs of teachers. The following technology integration training strategies would be appropriate: a) faculty education to model meaningful technology integration examples, b) self-exploration for deep understanding of technology, c) providing situation-based learning for extending learned knowledge, d) university collaboration with local K-12, and e) creating a learning community. 


\section{Dedication}

First of all, I would like to dedicate all my work to my parents who have raised me and have given me unending support and encouragement. You are the persons who have given me strength and wisdom that help me overcome all difficulties that I have had throughout studying in the United States. I also would like to dedicate to my beloved fiancé Mirim Lee. You have always been with me to support and encourage me. Without you, I do not think I can achieve this much. Thank you! 


\section{Acknowledgements}

I am very grateful to West Virginia University faculty members in the Department of Coaching and Teaching Studies, who have guided and supported me throughout this dissertation journey. Especially I would like to thank Dr. Emily Jones who have always been there to guide and support me to accomplish this long journey. I really thank you for your wisdom, kindness, and guidance that you have provided while I am completing my dissertation. You spent so much time with me to review the paper and guide and support me to go through this dissertation process. You have played a critical role in my professional journey. I don't believe I can achieve this much without your guidance, support and wisdom.

I also greatly appreciate the work of all my other committee members: Dr. Sean Bulger, Dr. Andrea Taliaferro, Dr. Malayna Bernstein, and Dr. Mete Akcaoglu, for contributions and ceaseless support throughout this dissertation process. You all have provided me with insight, which enabled me to complete my dissertation successfully. All of your wisdom served as an inspiration for my dissertation work.

I also would like to thank my friends: Luciana Braga and Adam Keath. Luciana Braga has always been helpful giving me good advice as a colleague and mentor. Adam Keath helped me collect and analyze my dissertation and encouraged me to complete all the work that I had. You are my true friend and great colleague who I will continuously collaborate.

Lastly, I would like to thank my parents and fiancé, Mirim Lee who always believe in me and encourage me to achieve my goals. Without all of your beliefs and support, how can I achieve this much? All of your love and care strengthened and enabled me to accomplish this journey. 


\section{Table of Contents}

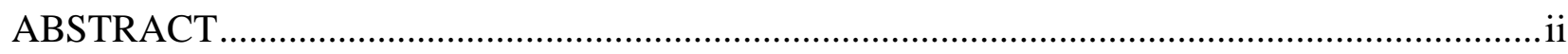

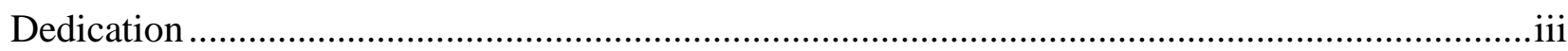

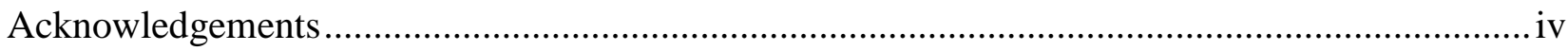

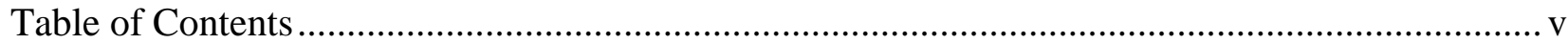

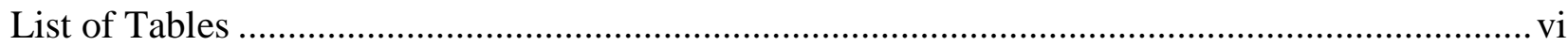

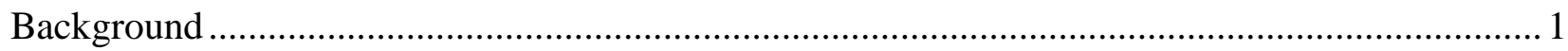

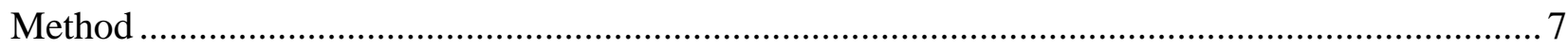

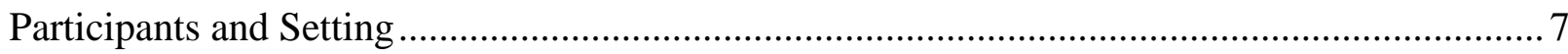

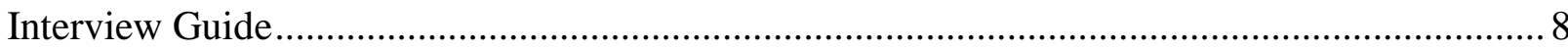

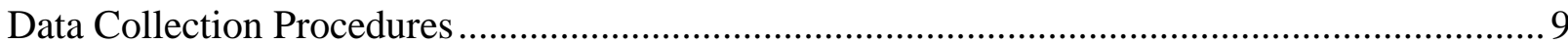

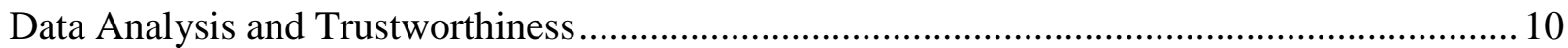

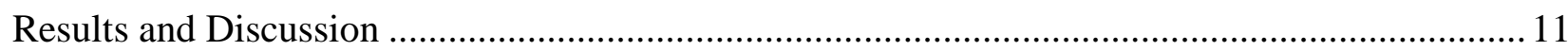

Technology-Related Learning Experiences ................................................................ 12

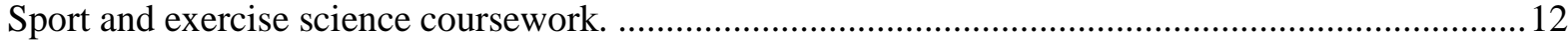

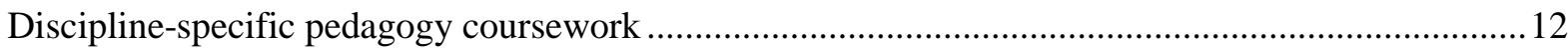

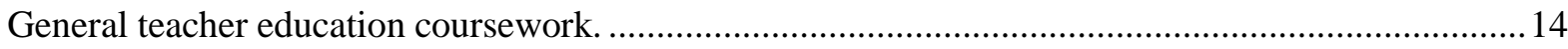

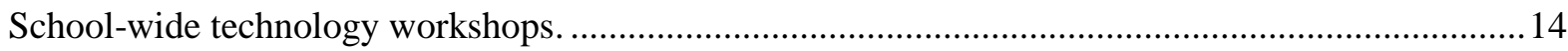

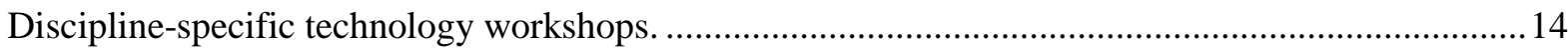

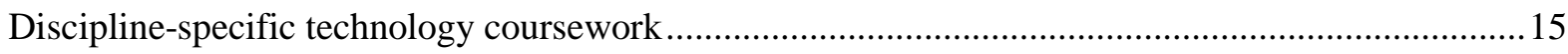

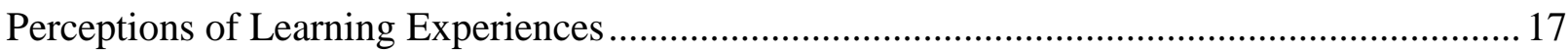

Technology-centric learning experiences ................................................................................... 17

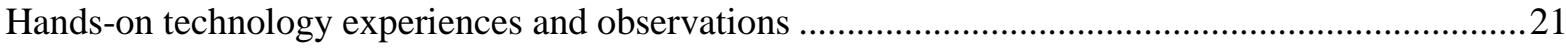

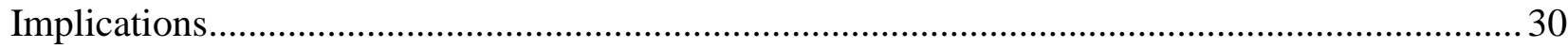

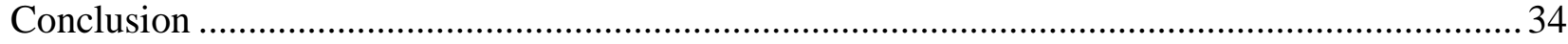

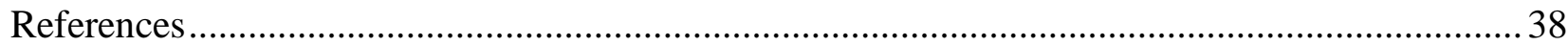

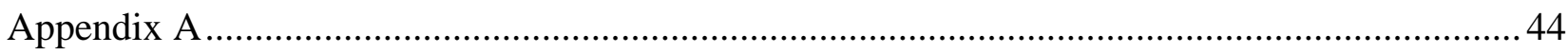

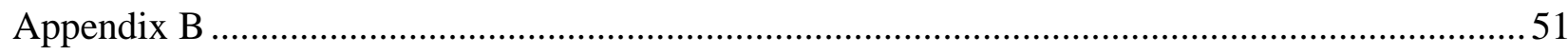

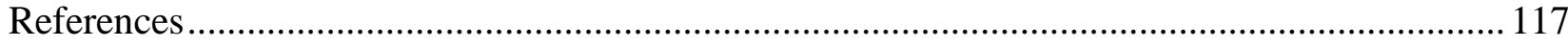

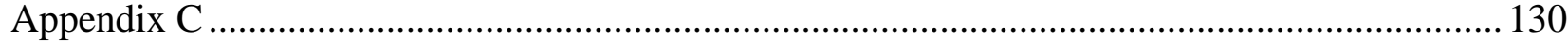

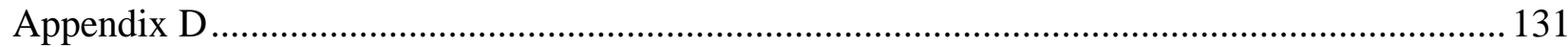

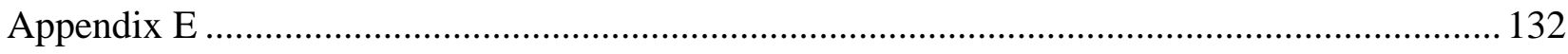




\section{List of Tables}

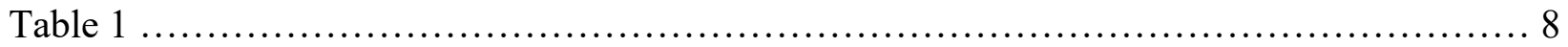

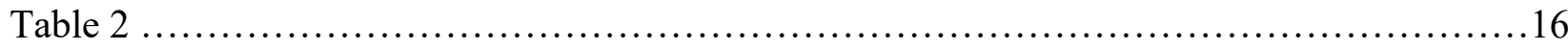

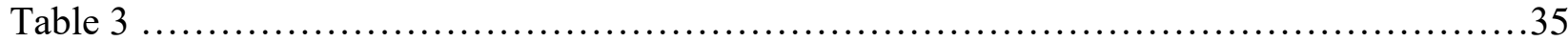




\section{Background}

Those who are involved in education have encouraged physical education (PE) teachers to integrate technology in their pedagogy because of technology's potential to enhance teaching effectiveness and students' learning (Jones, Bulger, \& Wyant, 2012). Nevertheless, many teachers reported they have had difficulty integrating technology despite the fact that technologies are available in nearly all K-12 public schools in the United States (National Center for Education Statistics, 2010).

Educational organizations, such as National Association for Sport and Physical Education [NASPE] and International Society for Technology in Education [ISTE], established technologyrelated standards indicating knowledge and skills necessary for teachers to integrate technology. These standards have challenged teacher education programs to restructure or enhance existing curriculum to prepare teachers to have the knowledge, skill, and dispositions to incorporate technology effectively in teaching (Jones et al., 2012). Yet, studies have reported that pre/inservice PE teachers often do not feel sufficiently prepared to incorporate technology into their classroom in meaningful ways (Gibbone, Rukavia, \& Silverman, 2010; Juniu, Shonfeld, \& Ganot, 2013; Liang, Walls, Hicks, Clayton, \& Yang, 2006). Although this finding highlights the importance of developing quality physical education teacher education (PETE) programs and professional development programs (PDP) designed to better prepare pre/in-service PE teachers with the necessary skills and knowledge necessary to integrate technology into their PE classes, to date there are a lack of studies investigating how pre/in-service PE teachers are trained to utilize technologies for teaching and learning in these programs.

With a growing number of technologies are available in the market, many PE professionals have, in recent years, begun to introduce the application of various technologies 
into PE classrooms. Such technologies include, but are not limited to, pedometers, heart rate monitors, physical activity watches, IPads, various mobile apps, and video games (Beighle, Morgan \& Pangrazi, 2004; Block, 2008; Phillips, Rodenbecka, \& Clegga, 2014). If these technologies are used properly in PE classes, they have the potential to affect teachers' teaching practice and, consequently, student learning. For example, a few studies have suggested the positive impacts of technology-integrated PE environments on learners' motivation, knowledge (movement concepts) (Legrain, Gillet, Gernigon, \& Lafreniere, 2015), physical activity (PA) levels, and psychological aspects of PA behavior (Melton, Bland, Harris, Kelly, \& Chandler, 2015). However, PE teachers' use of technology in their classrooms remains infrequent. The relative absence of technology in PE classes are due to numerous barriers that PE teachers face in the process of technology integration, such as the unique content (human movement) and contexts (gymnasium and playground); limited budgets; large class sizes; lack of training and support; ambivalent beliefs and attitudes toward the value of incorporating technology; and lack of knowledge, skill and confidence to adapt technology into their pedagogy (Gibbone et al., 2010; Liang, et al., 2006). These barriers significantly influence pre/in-service PE teachers' efforts to integrate technology in their classroom.

\section{Barriers to Technology Integration}

The aforementioned barriers can be categorized into two types: first order and second order barriers. First-order barriers refer to obstacles that externally influence teachers' use of technology in the classroom, which include lack of access to technologies, budget, insufficient time to learn technological skills, lack of time for lesson planning, inadequate technical and administrative support, and class size (Ertmer, 1999, Ertmer, Paul, Molly, Eva, \& Denis, 1999: Gibbone et al., 2010). Second-order barriers relate to factors which internally influence teachers' 
technology use including knowledge, skills, self-efficacy, and pedagogical beliefs and attitudes. Although these two types of barriers significantly influence teachers' technology integration efforts, second-order barriers, such as teachers' beliefs toward technology use in teaching PE and knowledge necessary for technology integration, are more critical to address than first-order barriers if successful and meaningful integration is to occur (Ertmer, 1999, 2005; Hixon \& Buckenmeyer, 2009).

School administrators and policy makers often believe that technology integration will automatically follow if first-order barriers are eliminated (Ertmer, 1999; Hixon \& Buckenmeyer, 2009). The removal of first-order barriers, however, does not in and of itself guarantee effective technology integration. For teachers to integrate technology, teachers' beliefs and attitude toward technology must be changed. If teachers do not view technologies as valuable instructional tools to enhance teaching and learning, they are less likely to integrate such technologies, regardless of any access to technology and support they may have (Cuban, Kirkpatrick, \& Peck, 2001; Ertmer, 1999).

A formative period, which is also known as the "apprenticeship socialization period," plays a critical role in the development of PE teachers' attitudes and beliefs towards technological integration. The "apprenticeship socialization period" refers to the time that teachers spent as a K-12 student before entering professional training programs (Lortie, 1975). During this period, pre-service teachers informally learn a great deal about teaching and learning and start to develop their personal teaching values, beliefs, and philosophies through their experience. Teachers' attitude and beliefs constructed during this period influence how teachers perceive and use technology in the classroom (Ertmer \& Ottenbreit-Leftwich, 2010). Wyant, Jones, and Bulger (2015) found that existing beliefs of pre-service PE teachers constructed 
during K-12 years could be an impediment to shaping their beliefs about technology use in PE classroom and their subsequent teaching. Thus, there should be efforts to train pre/in-service PE teachers to have positive beliefs about the use of technology in PE and to perceive the educational value of technology integration.

In addition to teachers' attitudes and beliefs towards technology integration, teachers' knowledge concerning technology integration has a significant impact on their decision to integrate technology. According to Mishra and Koehler (2006), successful technology integration requires teachers to have three different knowledge types: (a) technological knowledge (TK) understanding of various technologies that can support teaching, (b) pedagogical knowledge (PK)- understanding of various pedagogical methods that facilitate learning, and (c) content knowledge $(\mathrm{CK})$ - understanding of contents being taught. Although these three knowledge types are critical for successful technology integration, a more important knowledge is a teacher's understanding of the dynamic interaction and relationship of the three knowledge types within the dynamic classroom content (TCK, TPK, and TPACK).

Despite the importance of other types of knowledge, many university courses and PDPs still primarily focus on training TK (Mishra \& Koehler, 2006). Certainly, being knowledgeable about technology is critical for teachers to integrate technology, but merely knowing how to operate technologies is not sufficient to enable teachers to infuse technology in their pedagogy (Ertmer \& Ottenbreit-Leftwich, 2010). To effectively and efficiently integrate technology, teachers have to a) understand how theoretical concepts can be changed by using technology, b) understand what makes the concept difficult or easy to learn, and c) understand how technologies can help to teach or learn the concept better. (Koehler \& Mishra, 2009). If any of these knowledge types is missing, teachers may not be able to successfully incoporate technology to 
enhance teaching and learning. This TPACK framework has been used by TEPs and PDPs as a guideline to structure courses and learning experiences aimed to equip pre/in-service teachers with the ability to integrate technology into their instruction (Abbitt, 2011).

\section{Strategies to Train Pre/In-service Teachers for Technology Integration}

Within the field of general education (GE), teacher educators have suggested several technology integration training methods that they have implemented to prepare pre/in-service teachers to navigate the first and second order barriers. Such methods include: a) single courses focusing on technology integration, b) access to technology, c) infusion of technology across teacher education program curriculum, d) use of modeling, e) field-based experience, f) use of mentor teachers, g) collaboration between university and public schools, h) faculty education about technology integration, i) use of multimedia, j) workshops, k) combination of the aforementioned methods and 1) activity type model (Brush et al., 2003; Kay, 2006; Harris, Mishra, \& Koehler, 2009). These methods have been found effective in preparing technologically competent pre/in-service teachers who are capable of integrating technology into their teaching (Harris et al., 2009; Kay, 2006). However, few investigators have examined the methods that PETE programs or PDPs actually use to train pre/in-service PE teachers to utilize technology in teaching and their effectiveness to address and overcome barriers to successful and meaningful technology integration.

Jones et al. (2012) stated that PETE programs in several universities had implemented some of the training methods similar to what has been previously described to train pre-service PE teachers to better integrate instructional technologies. However, specific information regarding how these programs have trained pre/in-service PE teachers to integrate technology, and the extent to which the PE teachers believe such programs have been effective in enabling 
them to use instructional technology in the classroom is unknown. An empirical study by Wyant, et al. (2015) found that a single course applying multiple technology integration methods (e.g. hands-on learning, access to technology, and modeling) can be an effective method in developing pre-service PE teachers' knowledge, particularly TK and TPK, and positive attitudes toward technology integration in PE classes. However, the existence of only one study on the topic provides insufficient evidence of the type and quality of instruction needed to ensure that pre/in-service PE teachers feel adequately prepared to implement effectively.

It is critical to understand whether pre/in-service PE teachers believe programs from which they were trained were effective in adequately developing their knowledge, skills, and beliefs to effectively incorporate technology within their teaching practices. This dearth of research may be related to the flawed assumption that technology integration training methods used in general teacher education programs or PDPs, necessarily work in PE settings. Unfortunately, the technology integration training methods used by general teacher educators may not be effective in preparing PE teachers who teach unique content areas (e.g. body movement) in unique contexts (e.g. learning environment: gymnasium). Therefore, there is a need to investigate effective training methods to prepare technologically competent pre/inservice PE teachers for successful technology integration.

\section{Purpose of Study}

The purpose of this current study was to examine in-service PE teachers' past learning experiences to integrate technology across three mediated learning situations (undergraduate and graduate PETE program, PDPs, and PETE graduate program). 


\section{Research Questions}

Two questions guided the focus of this investigation; First, what types of technologyrelated learning experiences did in-service PE teachers have in their mediated learning situations? Second, how did in-service PE teachers perceive their learning experiences within mediated learning situations to influence their attitudes, beliefs, knowledge, and skills in using technology in a PE setting?

\section{Method}

\section{Participants and Setting}

Second and third-year students $(\mathrm{n}=19)$ enrolled in the Master's PETE program at a rural, mid-Atlantic university, were invited to participate in the study. The students took a graduate course focused on instructional technology in sport and physical education as a degree requirement prior to this current study. The course was designed to a) introduce students to a variety of instructional technologies in sport and physical education settings, and b) demonstrate technology integration strategies that enhance instructional efficiencies, and student learning, and professional engagement. All participants completed the instructional technology in sport and physical education course before the study was conducted. Therefore, each had the potential to provide rich information regarding their technology-related learning experiences within the graduate program.

Of the 19 students enrolled in the course, twelve (11 males and 1 female) were selected for the current study based on their responses to a Stage of Adoption of Technology (SAT) survey (Christensen, 1997) (Appendix D). The SAT survey was used to select participants who indicated a wide range in their use of instructional technology. The reliability of the SAT survey has been tested and demonstrated a high test-retest reliability estimate (.91) (Christensen \& 
Knezek, 2001). The SAT survey was used because of an assumption that differing levels of technological usage might provide a broader, more diverse range of perspectives on participants' technology-related learning experiences. All participants graduated from an undergraduate PETE program between 2007 and 2012. At the time of the interviews, all participants were concurrently employed in public schools across the United States and enrolled in a PETE master's program. Participants' average age was 31 years old, and the mean teaching experience was 3.8 years.

Table 1

\begin{tabular}{|c|c|c|c|c|c|c|}
\hline Participant & Gender & $\begin{array}{l}\text { Undergraduate } \\
\text { Graduation Year }\end{array}$ & $\begin{array}{l}\text { Years of } \\
\text { Teaching }\end{array}$ & Age & $\begin{array}{l}\text { Stage of Adoption } \\
\text { of Technology }\end{array}$ & $\begin{array}{l}\text { Geographic } \\
\text { Region }\end{array}$ \\
\hline Jacob & Male & 2009 & 5 & 29 & 1 & South \\
\hline Daniel & Male & 2009 & 2 & 26 & 2 & South \\
\hline Ethan & Male & 2013 & 3 & 25 & 3 & South \\
\hline Annie & Female & 2014 & 1 & 25 & 4 & South \\
\hline Michael & Male & 2007 & 7 & 29 & 4 & South \\
\hline William & Male & 2011 & 2 & 43 & 4 & South \\
\hline Alexander & Male & 2010 & 3 & 27 & 5 & South \\
\hline Joseph & Male & 2012 & 3 & 45 & 5 & West \\
\hline Matthew & Male & 2012 & 2 & 26 & 6 & South \\
\hline Ryan & Male & 2010 & 7 & 38 & 6 & South \\
\hline Christopher & Male & 2010 & 5 & 27 & 6 & Northeast \\
\hline Anthony & Male & 2009 & 5 & 27 & 6 & Northeast \\
\hline
\end{tabular}

\section{Interview Guide}

Narrative interviews were used to understand current PE teachers' technology-related learning experiences in their undergraduate and PETE graduate programs as well as PDPs. The narrative interviews were used because this method was believed the best method to understand, describe, and explain particular events or experiences of participants over a period and to capture the meaning that participants assign to the events or experiences (Bernstein, 2009; Bold, 2011). 
Twelve master's students participated in an individual audio-recorded, structured narrative interviews (Appendix E), which lasted approximately 60 -90 minutes for each interview. An interview guide including twenty open-ended questions was used to address participants' technology-related learning experiences in three learning situations. A narrative interview guide was created with careful consideration given to the elements of a "narrative" interview as described by Bold (2011), including a particular focus on people, action, certainty, and context. Such elements are crucial considerations when attempting to understand participants' experiences and perceptions regarding the issue at hand in a deep and meaningful manner (Bold, 2011). For instance, when asking follow up or probe questions, participants were asked to describe their experiences in detail, "like exactly when it happened, where it happened, what happened, who was involved, what you did with the technology, and what you were thinking and feeling at that moment?" These detailed descriptions allowed the researcher to understand critical factors (e.g. social and cultural factors) (Clandinin, 2006) influencing participants' experiences with and values, beliefs, and attitudes towards technology integration in their PE classes. Prior to the narrative interview, the validity of interview questions was performed by experts in qualitative research methodology and piloted with three physical education teachers to check for clarity and understanding. Based on a result of the pilot testing, interview questions were slightly revised.

\section{Data Collection Procedures}

After IRB permission had been obtained, the lead researcher sent out a cover letter describing the study aims and confidentiality procedures to potential participants via email. A list of all PETE master's students was obtained from the professor teaching the Instructional Technology in Sport and Physical Education course. Individuals agreeing to participate in the 
study were asked to first complete the SAT survey. The results of the SAT survey revealed that all participants' SAT level were well distributed across the six levels outlined on the instrument. Based on the results of the SAT survey the researcher purposefully selected 12 out of 19 participants across all stages of technology adoption. The purposefully selected participants were then contacted by email, and one-on-one structured interviews were scheduled. The interview guide was attached to the introductory email for participant review. Prior to the interviews, a research assistant with experience in qualitative research was recruited to assist with data collection and analysis. Thus, two researchers were trained to conduct the narrative interviews.

At the commencement of each interview, the researchers reiterated the purpose of the study, and reminded participants that all responses were confidential and anonymous and attempted to build rapport to ensure comfort and allow for an open dialogue and discussion. The interviewer concluded the interview by summarizing important information (e.g. feeling and meaning that participants assigned to the experience) and verifying whether the interviewer understood the information correctly. Follow-up with individual participants was initiated by the researcher in the event clarification on particular points arose during data analysis. In return for study participation, participants received a $\$ 20$ gift card.

\section{Data Analysis and Trustworthiness}

All interviews were transcribed verbatim by a professional transcriber to ensure the accuracy of the interview transcript. The transcribed interviews were analyzed using inductive content analysis to identify patterns or themes emergent from the data (Elo \& Kyngas, 2008). Three levels of analyses including a) open coding, b) axial coding and c) selective coding were performed to gather a detailed picture of the information obtained during data collection process (Corbin \& Strauss, 2008). First the transcripts were read through without judging the content to 
gain a general sense of the data, and open coding was conducted on the second reading. Throughout the open coding process, significant information (e.g. events related to learning about technology or technology integration and participants' perception of such learning) was coded. Codes with similar meanings were identified and categorized. For example, codes related to beliefs (e.g. irrelevance to teach PE, negative attitude toward the use of technology in PE, and positive beliefs about the use of technology) were categorized and labeled accordingly . A constant comparative technique was utilized for the purpose of examining the consistency and relatedness of the data (Glaser \& Strauss, 1967). After creating several categories, researchers established relationships between categories and found themes emerged from the data.

To enhance the trustworthiness of the data several recommended strategies, namely a) member checks, b) investigator triangulation, and c) peer debriefing, were employed (Pitney \& Parker, 2009). Member checks were accomplished by sending participants a transcription of their interview and asking them to indicate the extent to which the transcript accurately represented their experiences, perceptions, feelings, and thoughts regarding the research questions. Multiple analyst triangulation and peer debriefing session were also performed to establish trustworthiness.

\section{Results and Discussion}

The purpose of this study was two-fold. First, this study investigated what types of technology-related learning expereinces PE teachers recall from across their undergraduate and graduate education, and in-service professional development programs. Second, this study sought to understand how PE teachers perceived their experiences within three mediated learning 
situations influenced their attitudes, beliefs, knowledge, and skills of using technology in PE settings. Findings are organized by research question.

\section{Technology-Related Learning Experiences}

Concerning the first research question, the qualitative analysis revealed six sources of technology-related learning experiences across the three mediated learning situations (e.g., undergraduate, graduate, and in-service professional development programs). These include a) sport and exercise science coursework b) discipline-specific pedagogy coursework, c) general teacher education coursework, d) school-wide technology workshops, e) discipline-specific technology workshops, and f) discipline-specific technology coursework. Table 2 provides an overview of the technology-related experience learning sources.

Sport and exercise science coursework. Participants described technology being incorporated into the undergraduate sport and exercise science coursework such as exercise physiology, biomechanics, and motor development. Specifically, technology was used by instructors to demonstrate scientific principles and concepts related to human movement. The technology was also described as a tool used by students to fulfill required assignments and learning activities. For example, one participant stated, "In Motor Development, we used pedometers to see how we could track movements between a six-year-old, versus a 38-year old, versus a 96-year-old in a couple of labs where they [participants] came in” (Anthony). Technology-related learning experiences within these courses were hands-on and utilized technology tools to teach, reinforce, or evaluate discipline-specific content knowledge.

Discipline-specific pedagogy coursework. Across undergraduate and PETE graduate programs, participants recalled technology learning experiences within discipline-specific pedagogy courses such as physical education instructional methods, curriculum in physical 
education, and sport pedagogy. Primary technologies identified during these courses included digital video and audio recording devices, movement analysis software and mobile applications (i.e., Coach's Eyes, Dartfish), and presentation software. Participants described digital video and audio recording devices being used to capture instructional teaching episodes which they would view and analyze specific teacher and student behaviors. Two examples are provided below:

"In Sport Pedagogy [undergraduate course], we had to learn the different models of teaching Physical Education. We taught in groups of three. One group would teach, one group would video the group, and then another group would participate. So that's the way that we use technology, and that was how we used iPads to video. And then we had to go back and watch the video after the class and record what occurred during the class, so basically coding what the teacher was doing and what the students were doing." (Annie)

"We had to code our own teaching. So we had some video cameras out and microphones. We would code a 40-minutes lesson and see how much encouragement, positive feedback, corrective feedback, off-task and on-task behaviors [graduate course]." (Ethan)

Movement and skill analysis software programs were tools integrated within undergraduate PEpedagogy courses as tools used by students to critically examine skill performance and identify specific, corrective feedback for learners.

"In Net Wall Games (undergraduate course) and the Tennis course (undergraduate course), we used Dartfish, which at the time was a biomechanics generator, angle generator. So we were able to record out tennis serve and to see if our elbows were bent, our knees were in the wrong position, so we're able to analyze our body positions rather than just our movements." (Anthony)

Participants described graduate-level PE pedagogy instructors' use of presentation software programs (e.g. Prezi, Microsoft PowerPoint, Keynote) to represent content such as physical education instructional methods. After content was presented by the instructor, students were tasked with designing and delivering lessons using specific instructional approaches. This use of technology, albeit somewhat traditional, enhanced the delivery of discipline-specific pedagogical knowledge and was complementary to the application and evaluation of student pedagogical and pedagogical content knowledge. 
General teacher education coursework. Participants described enrolling in

undergraduate computer competency courses that were required for degree completion. Instruction and hands-on experiences within the courses focused on the basic functions of personal computing software such as Microsoft Word, Excel, and PowerPoint. Participants described a direct instruction as the primary instructional method used within the courses. For instance, Daniel commented:

"We had to take a computer competency class, and it was basically just a review of Microsoft Word, Excel, learning all the formulas...... basically we just modeled whatever the instructor showed us. He would [provide an] example of a formula, and we'd calculate it too" (Daniel).

School-wide technology workshops. As in-service teachers, participants described attending technology-specific workshops hosted in their respective schools and school districts. Topics of the workshops focused on the introduction of web-based resources and software programs tailored for specific subject areas, namely math, reading, and language arts.

Participants perceived these school-wide professional development workshops to be informative, but irrelevant for physical educators.

Discipline-specific technology workshops. Another source of technology-related learning described by the participants were discipline-specific workshops and conferences. Examples included state, regional, and national physical education professional conferences. Workshop sessions were typically short in duration and provided attendees a basic overview of a specific technology's features and functions, and then one or two ideas/examples as to how one could use the tool(s) in a teaching and learning setting - typically in health or physical education. The technologies were varied but included tools such as Apple iPad applications, YouTube, pedometers, and exergaming. Instructional methods used by the presenters were often lecturebased with limited activity or hands-on experiences. For example, Annie recalled: 
"it may be a 50-minute workshop on how to use the iPad in physical education and different ways that you could use it. So they showed a couple different applications.... went through the settings, and gave you an example how they use it in the classroom. It was just a sit-down session, so there was no activity" (Annie).

Discipline-specific technology coursework. Participants depicted technology-related learning experiences within a graduate-level discipline-specific technology course. A primary purpose of the course was to explore ways physical education teachers can use technology tools to increase instructional efficiencies and enhance student learning and engagement. Learning activities described by participants included hands-on exploration of different technology tools, observation of technology use and application within physical education and sport scenarios, and idea sharing with colleagues during peer-led technology-enhanced PE lessons. Delivered in a blended (hybrid) format, course activities were structured using several instructional approaches including self-exploration, hands-on application, situation-based learning, peer modeling, formal lecture, and peer and instructor debriefing.

Regarding self-exploration the participants commented, "[the instructor] didn't say 'okay you press the green button to turn it on.' Instead, [she said] 'this is what you're going to have and go explore and play with it"” (Annie). Jacob described, "she wanted us to explore it [technology] by ourselves...rather than her just showing us and saying how you do it, and ask us to repeat what she just said to us." Participants described an assignment that required them to plan and deliver a technology-enhanced PE lesson to their peers. The following comment describes the learning activity:

"After researching the technology and writing about the technology, we had the opportunity to teach the technology to our peers. And in a conference style, you would walk in [presentation room], and you would learn about a technology for about 30 minutes and then you would have the chance to practice that technology a little bit with the person who researched the technology. So, my technology was the Fitbit, which is a calorie counter, step counter, etc. I researched it and then I had to prepare a presentation to show to my peers and my peers had the opportunity to learn technology through me." (Chris) 
Table 2

Characteristics of Technology-Related Experience Learning Sources

$\begin{array}{lll}\text { Mediated Learning Learning Source } & \text { Characteristics } \\ \text { Situation } & \end{array}$

\section{Situation}

\begin{tabular}{ll}
\hline Undergraduate PETE & $\begin{array}{l}\text { Sport and exercise science } \\
\text { coursework }\end{array}$ \\
Program &
\end{tabular}

- Discipline-specific technologies presented within exercise physiology, biomechanics, and motor development courses

- Application of discipline specific technology used to fulfill class assignments

Discipline-specific pedagogy coursework

General Teacher Education Coursework
- Use of digital video technologies to analyze teaching behaviors

- Use of movement analysis tools and software to analyze skill performance

- Word processing and production software programs presented used to fulfil class assignments

- Focused on function and operation aspect of the programs

- Primary instructional methods and strategies employed: Lecture and modeling

\begin{tabular}{ll}
\hline Professional & School-wide technology \\
Development Programs & workshops
\end{tabular}

Development Programs workshops

Discipline-specific technology workshops

- Introduction to educational websites and software programs

- Subject-specific instructional resources provided for math, reading, and language arts educators

- Focused on features and functions of the websites and software programs

- Introduction to technologies conducive to physical education settings

- Primary instructional method and strategy employed: Lecture

- Focused on teaching function and operational aspect of technology

- Introduction to basic ideas for technology integration in the gymnasium

\section{Graduate PETE}

program
Discipline-specific
technology coursework

Discipline-specific pedagogy coursework
- Introduction to technologies conducive to physical education settings

- Primary instructional methods and strategies employed: Didactic lecture; Selfexploration Hands-on application; Peer modeling

- Use of presentation software and digital video technologies

- Use of digital video technologies to analyze teaching behaviors 
Along with delivery of technology-enhanced PE lesson, participants were required to integrate technology in one of their PE units in their respective school as a follow-up class assignment. In the assignment, participants were required to secure technologies through grant proposal and to plan, implement, and analyze a technology-enhanced unit. This contextually situated-learning allowed participants not only to transfer the knowledge and skills built from the class but also to have firsthand observation on how technology can influence their pedagogy. For example, Annie described her experience:

"There was one credit follow up to the technology class. We had to apply for a grant [to secure technology]. I used I Pads and each person could choose [technology] whatever they want. So like Justin did, the Read and Ride program. He got bikes and did that for his class. But, for mine I used the videos. I had to write lesson plans of how I would incorporate the iPads for my students to use. Once I finished those lesson plans, I had to teach them. After I thaught them, I had to reflect upon the lesson and how the technology was used. So basically I had to teach my students not only how to use the iPad and how to use the video." (Annie)

Participants also indicated the course instructor provided feedback and technology integration ideas during the planning stage of their technology-enhanced PE lesson assignment. Specific insights regarding technology uses in PE setting were shared through the instructor's personal experiences teaching with technology.

\section{Perceptions of Learning Experiences}

In terms of the research question two, two overarching themes emerged from the interview data: a) technology-centric experiences and b) hands-on experience and modeling/observation. Each theme is described in further detail below.

Technology-centric learning experiences. The interview data revealed that in general the primary focus of many technology-related learning sources in two mediated learning situations (undergraduate and PDP) was on developing participants' technological knowledge (TK), rather than technology's role in teaching and learning in PE content (e.g. TCK, TPK, and 
TPACK). Regardless of the type of technology introduced, instructors leading the course(s) or PDPs spent a significant amount of time instructing on the functions and operational aspects of the technologies themselves, instead of practical or useful applications to teaching and/or physical education content. A participant noted, "[the course] was just to teach you how to use them, not to use them for teaching or anything" (Ethan). Another participant commented, "they did teach us how to use it [technology], but we never had to go into a classroom and actually use it with the students. It was more of the knowledge base for us to improve out student's skill performance" (Anthony). These techno-centric, basic-function approaches to teaching how to use technologies seemed to lead to dissatisfied and unfulfilled professional learners. One participant described:

"they [workshop presenters] were great with the technology as how it pertained to them, but they couldn't show us how to use it where it would be beneficial for us...... They [specific workshops] were informative, but they didn't really show me anything that I could use in my [PE] class" (William).

Certainly, the general teacher education courses and PDPs were good sources for participants to develop technological knowledge and confidence around technology but were not sufficient in developing other knowledge types (TPK, TCK, and TPACK). During the interviews, participants suggested limited ability, willingness, or effort to make a conceptual connection between the technologies they engaged with during their general teacher education courses and school-wide technology workshops, and the teaching functions associated with delivering physical education. For example, participants used phrases such as " $[\mathrm{I}]$ never thought I would use Excel" and "I didn't think about applying it [to my teaching]" when reflecting on the influence technology-related learning experinces on their professional teaching practices. This inability to connect the features and fuctions of general technologies to the physical education setting prompted some participants to seek technologies that aligned more closely with the 
learning outcomes of physical education. Participants frequently described the technologies they learned from general teacher education courses and school-wide technology workshops as "irrelevant" to the PE-context or included "nothing about PE." Such beliefs made them consider their learning experiences "not useful", "boring," or "not eye opening." This issue can be attributed to the technology-centric focus of the courses and workshops, and lack of discussion of how instrctional content and pedagogy can be changed by the application of technology (TCK and TPK).

Certainly, developing technical skills and comfort with technology are crucial for successful technology integration because technical skill is one of the biggest barriers to technology integration (Ertmer, 1999) and teachers cannot integrate technology if they don't know how to operate it. However, a development of one knowledge type alone is not sufficient. As Koehler and Mishra (2009) stated, meaningful and successful technology integration can only take place when teachers develop three core knowledge bases (TK, PK, and CK) that are used either in a pair or triadic fashion (TPK, TCK, and TPACK). If there is a deficiency in any of these knowledge types, successful and meaningful technology integration does not occur (Pamuk, 2012). That is, all seven knowledge types (TK, PK, CK, PCK, TPK, TCK, and TPACK) are valuable and need to be developed for successful technology integration.

Among these knowledge types, development of TPK is particularly important because it relates to teachers' understanding of how technology influences teaching and learning and their ability to connect technology to instruction (Koehler \& Mishra, 2009). First, a teachers' understanding of technology's role in his/her teaching has an impact on one's beliefs toward technology integration. Teachers' beliefs about technology use are a powerful barrier to technology integration because of the strong relationship with behavior (Ertmer, 2005). If 
teachers are uncertain about technology's role in their instruction and its value to student learning, they will be less likely to use it. In the current study, participants described negative beliefs toward technology in teaching physical education. When asked about their beliefs on technology use in physical education, some described technology as an "unnecessary tool" or "not worth it." Such beliefs can be a significant barrier to technology integration. Therefore, intentionality is needed in developing mediated learning experiences that focus on value-added uses of technology within discipline-specific teaching and learning settings that are complementary to the instruction of 'how-to' use technological tools. Further, technology-related learning experiences should, when possible, be reflective of the unique constraints and challenges of the teaching and learning environment, student learning outcomes, and differentiation of instructional and pedagogical approaches in physical education.

Another reason for the importance of TPK development is related to the ability to connect technologies into teaching. As Koehler and Mishra stated, (2009), most software programs and technologies used in education (e.g. personal computing software, podcasts, social media, etc.) are designed for the purpose of business, communication, or social networking, rather than for educational purposes. To incorporate such technologies in teaching, teachers need to develop the ability to think beyond what the technologies can do, how the technologies are commonly used, and reconfigure the tools for a customized pedagogical purpose (e.g., TPK) (Koehler \& Mishra, 2009; Mishra, Koehler, Zellner, \& Kereluik, 2012). Nevertheless, this current study found that many general teacher education courses and PDPs tended to focus on training technology skills without developing technological pedagogical knowledge (TPK), technological content knowledge (TCK), and technological pedagogical content knowledge (TPACK). Although possessing technological skill is important for successful technology integration, there must be 
sufficient opportunities for pre/in-service teachers to develop, apply, refine TCK and TPK within formal teacher training programs and continuing professional development experiences. Specific strategies to develop TCK, TPK, and TPACK in mediated learning situations are discussed in the implications section.

Hands-on technology experiences and observations. Throughout the data, hands-on experiences and observations appeared to be factors significantly influencing participants' beliefs, attitude, skills, and knowledge to integrate technology in teaching. Four sub-themes emerged include a) limited exposure to technology in K-12 PE, b) knowledge and confidence through vicarious experiences, c) hands-on technology experiences, and d) change in knowledge, self-efficacy, and pedagogy.

Limited exposure to technology in K-12 PE. Participants consistently brought up their past PE experience during K-12 years, which seemed to have a significant impact on their perspective and beliefs about technology in PE settings. During the interview participants consistently used phrases "never seen" and "never used" to describe the virtual absence of technology in their K-12 PE classes. For example, Ryan stated "there was no technology in the physical education that I had in high school......We never really had any chance to incorporate technology into class." This absence of technology during K-12 years appeared to lead them to believe technology as "a tool taking away activity time" or "not a necessary component of physical education." That is, the lack of technology experience during K-12 PE class might be influential in informing participants' view of technology as a potentially valuable instructional tool in enhancing student learning. One participant commented

"I felt like it [technology] would take away from activity time when I was a freshman. My prior experience in physical education as a student [K-12], I feel like my Phys Ed teachers were very, very good at getting me moving. They had not used very much technology at all" (Chris). 
Such comments clearly indicate that one's previous experiences with technology could represent a substantial threat to their views of the value of technology in PE settings, which is consistent with what Jones et al. (2012) stated:

"one may speculate that observations of meaningful technology integration during acculturation would instill a positive belief toward technology as a valued instructional tool for learners whereas observations of no or obscure technology use may cultivate less favorable perceptions of technology as a tool for learning" (p.211).

Several previous studies highlighted the importance of the period before one's entry into a teacher education program (Ertmer, 2005; Ertmer \& Ottenbreit-Leftwich, 2010; Hutchinson, 1993; Jones et al., 2012; Lortie, 1975). According to the studies, pre-service teachers develop a considerable amount of beliefs about teaching and learning from their experiences as K-12 students, which influence their pedagogical beliefs, value, and the adoption of particular practice including the use of technology. What they see, hear, and do during K-12 years have a potential to impact what pre-service teachers learn in their teacher education programs and how they subsequently teach once they become educator themselves (Hutchinson, 1993). Ertmer (2005) stated that teachers might learn or receive information when it is corresponding to their preexisting belief. If beliefs constructed during K-12 years are not favorable for technology use in the PE setting, then training relative to technology integration within teacher education programs may have a limited impact on pre-service teachers' pedagogical beliefs. Thus, some actions to allow K-12 students to experience technology-integrated PE classes should occur. To do so, greater collaboration is needed among teacher educators and K-12 schools to expose technologies K-12 students in PE. Providing workshops teaching funding sources (e.g. DonorsChoose) and technology integration ideas will allow PE teachers to secure technologies and to provide meaningful technolgy-integrated PE lessons to K-12 students. 
Knowledge and confidence through vicarious experiences. Throughout the mediated learning situations explored within this study, participants described opportunities to observe others (e.g. professors, instructors of PDPs, or peers) integrating technology within PE and sportbased contexts. The participants' observation of technology-rich PE lessons seemed to play a positive role on broadening their perspective, beliefs, and knowledge about technology use and its application in physical education (TK, TCK, TPK, and TPACK). One participant noted:

"She [instructor] showed us how to use them and how they have been effectively implemented [in PE setting]. It's real life, real world application and that's what I think is really opened up [my eyes], 'oh, I can do this in my class.'” (Matthew)

These vicarious expereinces with technology allowed participants to see how others used technology to enhance teaching and learning, to witness how others maneuvered through challenges related to technology integration, and to experience achievement of learning outcomes through the intentional use of technology within the classroom. Specifically, participants spoke about the value of observing their peers use technology in movement contexts and the benefits of idea sharing and peer collaboration in regards to technology use. Michael noted that:

"I didn't realize that how much current Phys Ed teachers are using technology. Until that point [graduate course], I had understood that people were learning about it and they're saying that they were using it. But I'd never seen it applied. So to see my cohort in a sense actually applying the things that they were learning, using, and doing was a really neat way to know that technology is actually being used as oppose to just learning about them and then thrown back on the shelf. Taking the tech class opened me up a whole new world that technology is positive and it does bring a lot to the table as far as physical education goes..... [after watching my peers' technology integration] I felt like I needed to get with it because if these people were doing awesome things with technology, why aren't I? I got to see 'hey, you know this is how I can use it. This is how you use that technology and this is how it's going to improve your program' and I'm all about improving my program, so I use technology a little bit now." (Michael)

Some participants revealed their ambivalence toward technology in PE throughout their undergraduate and in-service stages. However, consistent with previous studies, these data 
suggest that vicarious experiences with technology that includes observing others use technology successfully and meaningfully, can have a positive impact on their beliefs and attitudes towards technology as a teaching tool. This is especailly true when the individual modeling (e.g.peer) is perceived to have a similar ability level. Previous studies stated that vicarious experiences are powerful and can promote change in beliefs, confidence, and practice, and increase teachers' perception of the needs of technology integration (Ertmer, 2005; Zhao \& Cziko, 2001).

Participants also placed value on the knowledge of their peers. Just as the peer observations provided opportunities to see how others integrate technologies, participants also indicated that it enhanced their knowledge and awareness of technology's use, function, and potential contributions to pedagogy and content (TPK, TCK, and TPACK). Prior to the peer observations, individuals described themselves as "ignorant" or "narrow-minded" relative to the use and value of technology in teaching PE. Such notions appeared to change after they described the peer observations and interactions within the discipline-specific technology course. Participants' remarks elucidate increased awareness of technology's role in teaching after trusted others (peers) shared ideas and incorporated technology into learning scenarios that were focused on PE-specific learning outcomes and objectives. Phrases such as "awesome ideas that I wouldn't get anywhere else," "some ideas that I may not have thought of," and "see many simple ways to use technology" that reflected the positive influence of the peer observation on TPK. Jacob stated:

"I didn't know how much I could do so that it [seeing my peers integrating technology] was very meaningful to me using like Wii and Xbox in a classroom because I always looked at it as only two people could use it. That's a waste of time in a class of 40 kids. I saw how you could have everyone doing it and just rotate around..... That was very meaningful because I saw how you could use it for bigger groups than just a one or two players in control." 
Teachers' perspective about teaching with technology may be limited to their own experience. If teachers don't have experience or limited experience integrating technology, this would confine their perspective to picture what a technology-rich classroom looks like and how technology can be integrated in classroom, which can decrease the likelihood of technology use (Marra, 2004). As stated earlier, teacher's TPK is important, especially for PE teachers because technologies that are widely used in classroom settings are often less conducive to the environmental contraints of teaching in the gymnasium and are not inuititively aligned with the content standards and objectives of physical education. For these reasons, PE teachers often have difficulty in excogitating how the technologies can be integrated effectively and efficiently in PE setting. For physical educators to utilize the technologies in PE context, they must have a deep understanding of the unique teaching and learning context, developmental needs of their learners, and potential benefits and limitations of technologies in regards to how they will impact the instructional approaches and content delivered in the gymnaisum. In other words, physical educators must develop discipline-specific TPK, or PE-TPK. If this knowledge type is not sufficiently developed, physical educators will not be able to effectively use technologies for students' learning. In this current study, participants were able to broaden their perspective on technology integration through peer modeling which we contend that PE-TPK were developed.

Although this current study found that observation of technology integration would be a good learning source to change and expand pre/in-service teachers' view on teaching and learning with technology as well as knowledge necessary to integrate technology (TPK, TCK, and TPACK), merely seeing others integrating technology may not be effective in increasing teachers' perception of the needs of technology integration and ideas to integrate technology. More important would be observing good examples of technology integration. If the model does 
not demonstrate meaningful and effective technology integration examples, it may bring about the reverse effect on pre/in-service teachers' attitudes and practice (Kay, 2006). Thus, having models that can provide meaningful technology integration examples is an important task for teacher education programs and PDPs.

Hands-on technology experiences. According to participants, hands-on learning experiences contributed to perceived changes in beliefs, knowledge, skill, and confidence for technology integration. The learning sources described by participants that included meaningful hands-on experiences were discipline-specific coursework within their undergraduate and graduate PETE programs. Some of the experiences described were instructor-directed and others student-directed; nonetheless having time to experience and explore the technologies within discipline-specific contexts appeared optimal.

Participants described hands-on technology experiences in sport and exercise science coursework. For example,

"In Exercise Physiology class, we used a ton of technology...... I was like 'man, this stuff that I can actually use because it's so scientific. There's a lot of method behind it.....that [VO2 Max machine] was the most incredible piece of equipment I've ever seen. It was amazing” (Daniel)

Although hands-on experiences can contribute to increase awareness and beliefs about technology's value itself, merely having experiences do not necessitate the integration of such tools within one's professional practice. When Daniel was asked about his knowledge and confidence regarding technology integration after the aforementioned hands-on technology experience in the exercise physiology, he described:

"I was exposed to it, but having only the chance of using it only once during undergrad, I felt like I hadn't practiced enough...... I know that it was meaningful, but in terms of me using it, I wasn't just confident. If I had gone through more training, then I would've definitely been more active to use it in class right off the bat" (Daniel). 
Rather, hands-on experiences that allowed participants to explore technology were more influential. According to the participants, in the discipline-specific technology course (graduate program) they were required to select and explore the features, functions, and potential uses of a specific technology within physcial education, then were tasked with planning and delivering a technology-enhanced teaching episode to their peers. This learning activity challenged participants to develop a deep understanding of the technology itself (TK). For example, one participant stated:

"I really liked the class activities (e.g. self-exploration of technology) because instead of just learning about 1-2 technologies, she made us become the expert of one [technology] and teach [the technology] our peers. So I became the expert of the flip camera and taught all my peers how to use it, where to buy it, how much it cost, so and so forth...... I had to do some previous research and had to really dive into what all it takes to use a flip camera." (Ethan)

In other words, the combination of participants' technological knowledge and application of the technology within a teaching and learning scenario, maximized their learning and appreciation of the value of the technological tools. Participants had to create technologyintegration plan using the technology self-explored and present a sample technology-integrated PE lesson to their peers. For example, Christopher described:

"we were given an opportunity to select a piece of technology......My technology was Fitbit which is a calorie counter, step counter, etc. I researched it and then I had to prepare a presentation to show my peers and my peers had the opportunity to learn technology through me" (Christopher).

Along with a technology-integrated PE lesson presentation, participants had to complete a technology action research project, which required them to use a technology in one of their PE units in their school. This learning activity allowed them to observe firsthand the benefits of technology integration in PE class, which greatly influenced participants' beliefs and teaching practice. For example, Joseph stated: 
"In the one credit follow-up class, we applied it [technology] in our schools, which was the most beneficial part. It forced me to go back and look at what I already did, and pick a technology. She said do not pick a lot. Pick one and focus on that one. Apply that technology into what I do [in my PE class]. That was beneficial because it changed my teaching. I could see my students get better because of the activity." (Joseph)

Overall, participants described positive hands-on technology use and application experience in discipline-specific mediated learning situations, specifically the sport and exercise science coursework and discipline-specific technology coursework. Participants described the hands-on experiences positively influenced their knowledge, beliefs, and attitudes toward technology integration.

The findings of this current study imply that hands-on technology expereinces (e.g. selfexploration of technology and its application) have a positive impact on participants' knowledge and beliefs toward technology use. However, hands-on experiences that do not include technology application within teaching and learning scenarios appear to be less effective in influencing teachers' knowledge and beliefs about technology in teaching. Certainly, having positive beliefs, knowledge, and comfort with technology are important elements of technology integration, but technology integration does not rely on only one specific knowledge type. Rather, it relys on the interaction of knowledge types within the context where they function. To successfully incorporate technology, teachers need to have an understanding of how a particular technology influences content and pedagogy within the discipline specific setting. Such understanding is difficult to develop in an isolated, non-contextualized environment. However, Lawless and Pellegrino (2007) suggested that teachers' learning to integrate technology frequently occurs in isolated environments. Learning that occurs in an isolated environment may make it difficult for pre/in-service teachers to extend knowledge and learned skills to contextspecific situation and practices, thus, making it difficult to make appropriate "decisions about when to use technology, what technology to use, and for what purposes" (Lawless \& Pellegrino, 
2007, p.581). These decisions cannot be made without the consultion of theory and research on learning, instruction, and assessment (Lawless \& Pellegrino, 2007). Instead, the knowledge dimensions of TPACK can only be developed through active engagement in the process of technology application and integration.

Change in knowledge, self-efficacy, and pedagogy. The observation and hands-on experiences played a positive role in changing participants' knowledge, skill, and pedagogy. Notably, participants consistently described the influence of peer observation and the learning activity (self-exploration, modeling of technology integration, and action research) on their knowledge, confidence, and pedagogy. For example, Jacob described his change in knowledge and beliefs regarding technology use in physical education. He stated:

"I am now more advanced. I know a lot more information and a lot more resources that I can use. I know how to use it. I definitely have that knowledge now. I definitely know now that technology in PE is definitely something that's going to happen. It's definitely something really good, and it's definitely going to improve overall quality PE."

Similarly, Mathew depicted his change in confidence and teaching practice. He said:

"I am an advanced technology user in my PE classroom. I'm more confident than I have ever been in implement those [technology] because I've had that practice. I've been able to do it on a daily basis or weekly basis in my classes."

William described a change in his teaching behavior as well as his firsthand observation of

benefits of technology use in PE class. He described:

"When teaching dance, instead of me standing up in front of the class and teaching the class and having them [students] watch me, I use the technology [projector]. They watch the technology and I give feedback and walk around while they're watching it...... This year, I did a QR Code lesson to where I put QR Codes around campus. I did like a scavenger hunt thing to where they would go scan the QR Code. I would come up with the exercises that I want them all to do. They would video themselves doing it, and then they would text it to me. And then when I saw them all doing what they were supposed to do, I would send them to the next one. That was kind of fun and the kids like it too. They got excited when they got to use it. There was so much from that class and so much where you could see the application process of the technology that it made you want to use it because I can see where the benefit is, and I can see how to use it, where to use it." (William) 


\section{Implications}

Teachers are at various levels in their knowledge and use of technology and these levels are developmental when attempting to incorporate technology into their classroom (Holland, 2001). Holland (2001) described characteristics of teachers with a different level of knowledge and use of technology and five developmental stage of technology integration. a) non-readiness, b) survival, c) mastery, d) impact, e) innovation. These stages may prove helpful to teacher educators and professional development coordinators as they provide insight to what experiences, training, and supports are necessary for teachers with varying degrees of knowledge and technology use.

The characteristics of teachers at the first stage of technology use, non-readiness, is a lack of technological knowledge and skills. The absence of TK and skills often make them afraid of using technology. Although it may be believed that today's pre/in-service teachers are fairly knowledgeable about technologies (Ertmer \& Ottenbreit-Leftwich, 2010), there are still teachers who do not have enough knowledge and skills about using technology. For those teachers at the non-readiness stage, opportunities to develop technological knowledge and skills to overcome their fear and insecurities are needed. Two learning activities, including self-exploration of technology with guidance and formal training showing how to operate technology, would be appropriate to help them develop. In particular learning activities allowing teachers to focus only on a particular technology would be more beneficial for teachers to increase familiarity with technology and enhance TK, rather than having them learn a broad range of new technologies.

Teachers at the survival stage demonstrate a limited level of knowledge and skills regarding technology and have little to no knowledge about how to utilize the technologies as instructional tools in education (TPK), which is consistent with the findings of the current and 
previous studies (Ertmer \& Ottenbreit-Leftwich, 2010; Holland, 2001). The lack of TPK makes teachers to see a technology as a thing in itself, rather than as a tool to support their current pedagogy (Holland, 2001), which makes it difficult to connect technology to teaching. In the current study, participants articulated their inability to make the conceptual link between technology, pedagogy, and content, which led to beliefs and value statements reflecting that technologies are "unnecessary tools in PE." Such negative belief can be a serious threat to technology integration. Thus, teacher educators and PDP coordinators need to provide learning activities that could positively influence the view of teachers about technology use in teaching. Proper learning activities to change their beliefs and perspective of technology integration would be a) reflection on current pedagogical beliefs, b) interaction with others who support innovative instruction with technology, c) observations of a good example of technology use in PE setting, d) use of co-teaching model to provide immediate help and assistant for technology integration, and e) providing accessbility of technology throughout PETE program. These learning activities not only provide teachers with opportunities to develop knowledge about how technologies can be used as instructional tools, but also provide them with opportunities to challenge their existing beliefs and practice by examining new beliefs and practice (Ertmer, 2005). However, teacher educators and professional development coordinators have to be careful in providing examples of technology integration because if a model does not demonstrate successful and meaningful technology integration, it may have the reverse effect on teachers' beliefs.

Teachers at the mastery stage demonstrate a considerable level of knowledge about a particular technology, but do not have sufficient knowledge and skills to use technologies effectively as instructional tools (Holland, 2001). According to Holland (2001), teachers at this stage use technology a somewhat limited way. Teachers at this stage primarly use technology to 
deliver information (command style teaching: teacher-centered), rather than as a tool to enhance higher order thinking (student-centered). If teachers know only one particular way to integrate technology, then they may not be able to utilize the full potential of technology as an instructional tool. Thus, training that helps teachers understand various instructional strategies with technology (TPK) is needed. For teachers to understand and use technologies in variety ways to enhance teaching and learning, teachers need first to understand diverse instructional strategies and their advantages and disadvantages in teaching. That is, teachers should have sufficient pedagogical knowledge (PK) which is “teacher's knowledge about the basic principle of instruction, classroom management, and the aims and purpose educccation" (Cox, 2008, p.7). Chai, Koh, and Tsai (2010) stressed the importance of PK to develop TPACK. According to them, PK is the most influential and foundational knowledge for technology integration so if teachers do not have solid PK, they cannot utilze technology to the maximum to enhance students' learning. Thus, acquisition of strong PK should occur prior to the development of TPK and TPACK. Several strategies should be used to help teachers understand a variety of instructional methods with technology. First, formal training showing various of technology integration examples would broaden teachers' perspective of using technology. Second, matching pre/in-service teachers with a trusted peer who are expert in technology integration would help teachers think various ways to integrate technology and think beyond the common use of technology. Lastly, providing pre/in-service teachers with a supportive environment (e.g. micro-teaching/simulation) where they can practice technology integration.

Teachers at the impact stage show sufficient knowledge about several technologies and are comfortable with integrating technologies as instructional tools, but often demonstrate difficulty in using technology to enhance students' learning and in managing students during 
class (Holland, 2001). Management of students' behaviors during technology integration is a concern frequently reported by beginning teachers as the biggest challenge in the process of technology integration (Choy, Wong, \& Gao, 2009). The issue is also related to teachers' lack of PK. As stated previously, PK is teacher's knowledge about classroom management and organization (Cox, 2008; Shulman, 1987). If teachers lack PK, they experience difficulty in managing and organizing the classroom, particularly when technology is incorporated (Choy, Wong, \& Gao, 2009). Thus, teacher educators and PDP developers should be aware that development of PK is prerequisite for effective technology integration, although PK is not directly related to technology integration (Chai et al., 2010). For those teachers who experience difficulty managing students in the technology-integrated class, providing opportunities to discuss about classroom management and technology integration strategies with other teachers would be helpful for them to expand their perspective. Action research (problem-based learning) which allows teachers to plan, implement, and evaluate their technology integration idea would also help them develop TPK and TPACK.

Teachers at the innovation stage have sufficient knowledge to use a variety of technologies in efficient ways to maximize the potential in their exisiting pedagogy for student learning, but they still need to refine their current pedagogy with technology. Helping teachers at this stage create a learning community where teachers can share their ideas and plan technology integration together would be beneficial. The members of the learning community should have a similar level of knowledge and technology use to maximize the benefits. Along with creation of learning community, training on how to conduct research and how to read and use the research findings would help pre/in-service teachers become teachers and scholar. This training would help them understand how research informs and improves teaching practice. 
In summary, teachers' levels of knowledege and use of technology vary. To address these differences, teacher educators and PDP coordinators need to be aware of the differences of teachers and provide appropriate training and supports according to their levels of knowledge and use of technology. Considering the unique characteristics of content and context of PE, the training and supports have to be content and context-specific to PE. The developmental stage of technology integration theory could provide teacher educators and PDP developers with good insight as to what trainings and supports are needed for teachers at different stage of technology integration.

\section{Conclusion}

Findings from this study contribute to the limited body of knowledge relative to how PE teachers have learned to teach with technology and their perceptions of the learning experiences. Understanding types of technology-related learning experiences that PE teachers had through mediated learning situations and their perceptions of the learning experiences provide those involved in teacher education and PDPs with valuable information on what trainings and supports are needed for teachers to integrate technology. Although there are many factors influencing technology integration, this study found that many courses or PDPs primarily focus on technological skills and knowledge, which is consistent with the finding from previous studies and not very effective in helping teachers integrate technology. To help PE teachers use technology in their classroom, teacher educators and PDP developers should provide systematic and various learning experiences, which address the multitude of barriers that teachers need to overcome. The developmental theory of technology integration (Holland, 2001) could provide useful information on what training and supports are appropriate for teachers who are at various stage of technology integration. 
Table 3

Developmental Stage of Adoptation of Technology

\begin{tabular}{|c|c|c|c|}
\hline SAT & Characteristics & $\begin{array}{c}\text { Suggested Strategies } \\
\text { (Holland, 2001) }\end{array}$ & $\begin{array}{c}\text { Suggested Strategies } \\
\text { (Current Study) }\end{array}$ \\
\hline $\begin{array}{l}\text { Non- } \\
\text { readiness }\end{array}$ & $\begin{array}{l}\text { - Lack of technological } \\
\text { knowledge and skill } \\
\text { - Often afraid of using technology }\end{array}$ & $\begin{array}{l}\text { Formal training on how } \\
\text { to operate technology } \\
\text { and how to use it in } \\
\text { classroom } \\
\text { - Formal training which } \\
\text { can spark teachers' } \\
\text { interest }\end{array}$ & $\begin{array}{l}\text { - TK training } \\
\text { O Self-exploration of technology } \\
\text { o Formal training on operation and function } \\
\text { of technology } \\
\text { - Observation of best technology use in } \\
\text { teaching to spark teacher's interest }\end{array}$ \\
\hline Survival & $\begin{array}{l}\text { - Limited technological knowledge and } \\
\text { skill } \\
\text { - Inability to connect technology to } \\
\text { teaching } \\
\text { - Limited perspective of technology use } \\
\text { in teaching } \\
\text { - Easily discouraged to use technology } \\
\text { in teaching } \\
\text { - May have negative beliefs and attitude } \\
\text { toward technology use in teaching }\end{array}$ & $\begin{array}{l}\text { - Immediate and } \\
\text { continuous assistance to } \\
\text { help them solve } \\
\text { technological problem } \\
\text { - Development of personal } \\
\text { knowledge and use of } \\
\text { technology } \\
\text { - Co-teaching model } \\
\text { - Situated professional } \\
\text { development }\end{array}$ & $\begin{array}{l}\text { - TPK \& TCK training } \\
\text { O Reflection on current beliefs } \\
\text { ○ Interaction with others who support } \\
\text { innovative instruction } \\
\text { o Vicarious experience of meaningful } \\
\text { technology use } \\
\text { o Access to technology throughout PETE } \\
\text { program } \\
\text { o Encouragement of small change of } \\
\text { teaching with technology }\end{array}$ \\
\hline Mastery & $\begin{array}{l}\text { - Proficient in one technology } \\
\text { - Tend to focus on technology, rather } \\
\text { than its application in teaching } \\
\text { - Insufficient knowledge to effectively } \\
\text { utilize technology in teaching } \\
\text { - Limited use of instructional } \\
\text { technology }\end{array}$ & $\begin{array}{ll}\text { - } & \text { Formal training } \\
\text { - } & \text { Personal } \\
\text { assistance } \\
\text { - } & \text { Peer coaching }\end{array}$ & $\begin{array}{l}\text { - PK development as a prerequiste } \\
\text { knowledge } \\
\text { - TPACK training } \\
\text { O Access to wide variety of technology } \\
\text { integration examples (Observation of } \\
\text { other teachers who have used technology } \\
\text { effectively) } \\
\text { o Peer coaching (trusted peers) } \\
\text { o Micro-teaching with technology in }\end{array}$ \\
\hline
\end{tabular}




\begin{tabular}{|c|c|c|c|}
\hline & & & $\begin{array}{l}\text { college classroom / supportive } \\
\text { environment }\end{array}$ \\
\hline Impact & $\begin{array}{l}\text { - Often experience difficulty in managing } \\
\text { student behaviors when technology is } \\
\text { integrated } \\
\text { - Experience difficulty in finding best way } \\
\text { to use technology for students' learning }\end{array}$ & 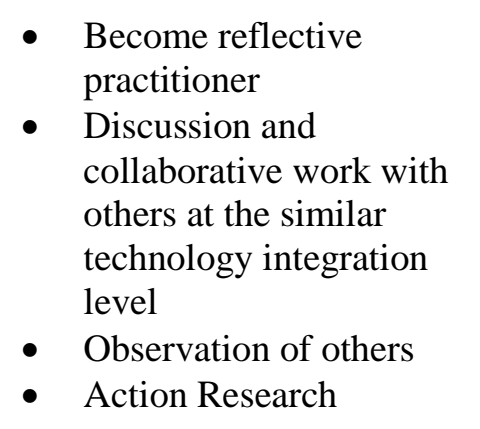 & $\begin{array}{l}\text { - TPACK training } \\
\text { O Discussion with others about successful } \\
\text { classroom management stories } \\
\text { O Action research with guidance } \\
\text { o Self-reflection in the process of technology } \\
\text { integration } \\
\text { - Collaborative work for design technology } \\
\text { integration plan }\end{array}$ \\
\hline Innovation & $\begin{array}{l}\text { - Pursue refining their pedagogy with } \\
\text { technology }\end{array}$ & $\begin{array}{l}\text { - Collaboration with others } \\
\text { for technology integrated } \\
\text { curriculum design }\end{array}$ & $\begin{array}{l}\text { - Creation of leanring community to share ideas } \\
\text { - Teacher as scholar and researcher }\end{array}$ \\
\hline
\end{tabular}


There were several limitations in this current study. First, participants' memories might be affected by time, which may have influenced participants' interpretation of their learning experiences. Thus, examining pre/in-service PE teachers' feelings and perceptions immediately after the courses or PDPs is recommended in future studies. Second, the small sample size of this study may make it difficult to generalize the findings to other settings. Third, this current study was an exploratory study. Thus, this study was not able to find causality. Future study needs to empirically investigate how the suggested learning activies influence pre/in-service teachers' beliefs, knowledge, and professional practice. 


\section{References}

Abbitt, J. T. (2011). An investigation of the relationship between self-efficacy beliefs about technology integration and technological pedagogical content knowledge (TPACK) among preservice teachers. Journal of Digital Learning in Teacher Education, 27(4), 134-143.

Beighle, A., Morgan, C. F., \& Pangrazi, R. P. (2004). Using pedometers in elementary physical education. Teaching Elementary Physical Education, 15, 17-18.

Bernstein, M.B. (2009). At the desk and on the nightstand: Reading as a mediating artifact in teachers' professional and personal lives. (Unpublished doctor dissertation). Northwestern University, Evansdale, IL.

Block, B. A. (2008). Using iPods in dance pedagogy. Journal of Physical Education, Recreation \& Dance, 79, 25-28.

Bold, C. (2011). Using narrative in research. Thousand Oaks, CA: SAGE Publications.

Brush, T., Glazewski, K., Rutowski, K., Berg, K., Stromfors, C., Van-Nest, M. H., ... \& Sutton, J. (2003). Integrating technology in a field-based teacher training program: The PT3@ ASU project. Educational Technology Research and Development, 51, 57-72.

Christensen, R. (1997). Effect of technology integration education on the attitudes of teachers and their students. (Unpublished doctoral dissertation). University of North Texas, Denton, TX.

Christensen, R. \& Knezek, G. (2001). Instruments for assessing the impact of technology in education. Computer in Schools: Interdisciplinary Journal of Practice, Theory, and Applied Research, 18, 5-25. 
Chai, C. S., Koh, J. H. L., \& Tsai, C. C. (2010). Facilitating preservice teachers' development of technology pedagogical, and content knowledge (TPACK). Educational Technology \& Society, 13, 63-73.

Choy, D., Wong, A.F.L., \& Gao, P. (2009). Student teachers' intentions and actions on integrating technology into their classrooms during student teaching: A Singapore study, Journal of Research on Technology in Education, 42, 175-195.

Clandinin, D. J. (2006). Narrative inquiry: A methodology for studying lived experience. Research Studies in Music Education, 27, 44-54.

Corbin J, \& Strauss J (2008) Basics of qualitative research: Techniques and procedures for developing grounded theory. (3rd edition). Thousand Oaks, CA: Sage Publications.

Cox S. (2008). A conceptual analysis of technological pedagogical content knowledge. (Unpublished doctoral dissertation). Bringham Young University, Provo, UT.

Cuban, L., Kirkpatrick, H., \& Peck, C. (2001). High access and low use of technologies in high school classrooms: Explaining an apparent paradox. American Educational Research Journal, 38, 813-834.

Elo, S., \& Kyngas, H. (2008). The qualitative content analysis process. Journal of Advanced Nursing, 62, 107-115.

Ertmer, P. A. (1999). Addressing first-and second-order barriers to change: Strategies for technology integration. Educational Technology Research and Development, 47, 47-61.

Ertmer, P. A., Paul, A., Molly, L., Eva, R., \& Denise, W. (1999). Examining teachers' beliefs about the role of technology in the elementary classroom. Journal of Research on Computing in Education, 32, 54-72. 
Ertmer, P. A. (2005). Teacher pedagogical beliefs: The final frontier in our quest for technology integration?. Educational Technology Research and Development, 53, 25-39.

Ertmer, P. A., \& Ottenbreit-Leftwich, A. T. (2010). Teacher technology change: How knowledge, confidence, beliefs, and culture intersect. Journal of Research on Technology in Education, 42, 255-284.

Gibbone, A., Rukavina, P., \& Silverman, S. (2010). Technology integration in secondary physical education: Teachers' attitudes and practice. Journal of Educational Technology Development and Exchange, 3, 27-42.

Glaser, B. \& Strauss, A. (1967). The discovery of grounded theory. Hawthorne, NY; Aldine Publishing Company.

Harris, J., Mishra, P., \& Koehler, M. (2009). Teachers' technological pedagogical content knowledge and learning activity types: Curriculum-based technology integration reframed. Journal of Research on Technology in Education, 41, 393-416.

Hixon, E., \& Buckenmeyer, J. (2009). Revisiting technology integration in schools: Implications for professional development. Computers in the Schools, 26, 130-146.

Holland, P. (2001). Professional development in technology: Catalyst for school reform. Journal of Technology and Teacher Education, 9(2), 254-267.

Hutchinson, G. E. (1993). Prospective teachers' perspectives on teaching physical education: An interview study on the recruitment phase of teacher socialization. Journal of teaching in Physical Education, 12, 344-344.

International Society for Technology in Education. (2008). ISTE standards teachers. Retrieved from http://www.iste.org/docs/pdfs/20-14_iste_standards-t_pdf.pdf 
Jones. E.M., Bulger, S.M., \& Wyant, J. (2012). Moving beyond the stopwatch and whistle: Examining technology use in teacher training. The Global Journal of Health and Physical Education Pedagogy, 1, 210-222.

Juniu, S., Shonfeld, M., \& Ganot, A. (2013). Technology integration in physical education teacher education programs: a comparative analysis. Actualidades Investigativas Enducación, 13, 218-240.

Kay, R. H. (2006). Evaluating strategies used to incorporate technology into preservice education: A review of the literature. Journal of Research on Technology in Education, 38, 383-408.

Koehler, M., \& Mishra, P. (2009). What is technological pedagogical content knowledge (TPACK)? Contemporary Issues in Technology and Teacher Education, 9, 60-70.

Lawless, K. \& Pellegrino, J.W. (2007). Professional development in integrating technology into teaching and learning: Knowns, unknowns, and ways to pursue better questions and answers, Review of Educational Research, 77, 575-614.

Legrain, P., Gillet, N., Gernigon, C., \& Lafreniere, M. A. (2015). Integration of information and communication technology and pupils' motivation in a physical education setting. Journal of Teaching in Physical Education, 34, 384-401.

Liang, G., Walls, R. T., Hicks, V. L., Clayton, L. B., \& Yang, L. (2006). Will tomorrow's physical educators be prepared to teach in the digital age? Contemporary Issues in Technology and Teacher Education, 6, 143-156.

Lortie, D.C. (1975). School-teacher: A sociological study. Chicago, IL: The University of Chicago Press. 
Marra, R. M. (2004). An online course to help teachers "use technology to enhance learning": Successes and limitations. Journal of Technology and Teacher Education, 12, 411-429.

Melton, B., Bland, H., Harris, B., Kelly, D., \& Chandler, K. (2015). Evaluating a physical activity app in the classroom: A mixed methodological approach among university students. Physical Educator, 72, 601.

Mishra, P., \& Koehler, M. (2006). Technological pedagogical content knowledge: A framework for teacher knowledge. The Teachers College Record, 108, 1017-1054.

Mishra, P., Koehler, M. J., Zellner, A., \& Kereluik, K. (2012). Thematic considerations in integrating TPACK in a graduate program. Developing technology-rich teacher education programs: Key issues, 1-12

National Association for Sport and Physical Education. (2008). National initial physical education teacher education standards. Reston, VA: Author

National Center for Education Statistics (2010). Teachers' Use of Educational Technology in U.S Public Schools: 2009. Retrieved from http://nces.ed.gov/pubs2010/2010040.pdf/

Pamuk, S. (2012). Understanding preservice teachers' technology use through TPACK framework, Journal of Computer Assisted Learning, 28, 425-439.

Pitney, W., \& Parker, J. (2009). Qualitative research in physical activity and the health professions. Champaign, IL: Human Kinetics.

Phillips, A., Rodenbeck, M., \& Clegg, B. (2014). Apps for physical education: Teacher tested, kid approved! Strategies, 27, 28-31.

Shulman, L. S. (1987). Knowledge and teaching: Foundations of the new reform. Harvard Educational Review, 57, 1-23. 
Wyant, J.D., Jones, E.M. \& Bulger, S.M. (2015). A mixed methods analysis of a single-course strategy to integrate technology into PETE. Journal of Teaching in Physical Education, $34,131-151$.

Zhao, Y., \& Cziko, G. A. (2001). Teacher adoption of technology: A perceptual control theory perspective. Journal of technology and teacher education, 9, 5-30. 


\section{Appendix A \\ Extended Method}

\section{Participants}

Second and third-year students $(\mathrm{n}=19)$ enrolled in the Master's PETE program at a rural, mid-Atlantic university, were invited to participate in the study. Participants were required to register for a graduate course focused on instructional technology in sport and physical education. The course was designed to a) introduce students to a variety of instructional technologies in sport and physical education settings, and b) demonstrate technology integration strategies that enhance instructional efficiencies, and student learning, and professional engagement. All participants completed the instructional technology in sport and physical education course before the study was conducted. Therefore, each had the potential to provide rich information regarding their technology-related learning experiences within the graduate program.

Of the 19 students enrolled in the course, twelve (11 males and one female) were selected for the current study based on their responses to a stage of adoption of technology (SAT) survey (Christensen, 1997) (Table 1). The SAT survey was used to select participants indicating a wide range in their use of instructional technology. The reliability of the SAT survey has been tested and demonstrated a high test-retest reliability estimate (.91) (Christensen \& Knezek, 2001). The use of SAT survey was reasoned that differing levels of technological usage might provide a broader, more diverse range of perspectives on participants' technology-related learning experiences. All participants graduated from an undergraduate PETE program between 2007 and 2012. At the time of the interviews, all participants were concurrently employed in public schools across the United States and enrolled in the PETE master's program. Teacher's average age was 31 years old, and the mean teaching experience was 3.8 years. 
Table 1.

Participant Demographics

\begin{tabular}{ccccccc}
\hline Participant & Gender & $\begin{array}{c}\text { Undergraduate } \\
\text { Graduation } \\
\text { Year }\end{array}$ & $\begin{array}{c}\text { Years of } \\
\text { Teaching }\end{array}$ & Age & $\begin{array}{c}\text { Stage of } \\
\text { Adoption of } \\
\text { Technology }\end{array}$ & $\begin{array}{c}\text { Geographic } \\
\text { Region }\end{array}$ \\
\hline Jacob & Male & 2009 & 5 & 29 & 1 & South \\
Daniel & Male & 2009 & 2 & 26 & 2 & South \\
Ethan & Male & 2013 & 3 & 25 & 3 & South \\
Annie & Female & 2014 & 1 & 25 & 4 & South \\
Michael & Male & 2007 & 7 & 29 & 4 & South \\
William & Male & 2011 & 2 & 43 & 4 & South \\
Alexander & Male & 2010 & 3 & 27 & 5 & South \\
Joseph & Male & 2012 & 3 & 45 & 5 & West \\
Matthew & Male & 2012 & 2 & 26 & 6 & South \\
Ryan & Male & 2010 & 7 & 38 & 6 & South \\
Christopher & Male & 2010 & 5 & 27 & 6 & Northeast \\
Anthony & Male & 2009 & 5 & 27 & 6 & Northeast \\
\hline
\end{tabular}

Note. Geographic region designation was informed by the United States Census Bureau (Retrieved from http://www.census.gov/econ/census/help/geography/regions_and_divisions.html)

\section{Setting}

This study was conducted in the PETE master's program at a public land-grant research university, which is located in a mid-Atlantic region of United States. The PETE master's program is a hybrid PETE master's program which is designed for current PE professionals with demanding schedules. In the PETE master's program, courses are delivered in a hybrid format: online courses during the school year (fall and spring) and two weeks on-campus courses during the summers. One of the required courses in the PETE master's program is an instructional technology in sport and physical education, which is designed a) to introduce students to variety of instructional technologies that can be meaningfully use in sports and physical education setting and b) to help them understand various ways to integrate instructional technologies in sports and physical education setting. A faculty member who is expertise in instructional technology in sports and physical education has instructed this course for several academic years and have secured various instructional technologies for the course, including handheld devices 
(e.g.IPad) and applications used in sports and PE setting, video/digital cameras, GPS units, active video game systems, and physical activity trackers (e.g. pedometer, heart rate monitors, physical activity watch). These technologies are available for the master's students to explore while in the campus.

\section{Data Collection Instrument}

Two data sources were used to answer the research questions: the Stage of Adoption of Technology survey (Christensen, 1997) and narrative interview.

Stage of Adoption of Technology Survey. The Stage of Adoption of Technology survey [SAT] was used to identify the participants' current stage of technology adoption (Christensen, 1997). This survey describes six different developmental stages of technology adoption that teachers move through in order to be confident technology user: a) awareness, b) learning the process, c) understanding and application of the process, d) familiarity and confidence, e) adaptation to other contexts, and f) creative application to new contexts (see Appendix B). The reliability of the survey has been tested, and it demonstrated a high test-retest reliability estimate (.91) (Christensen \& Knezek, 2001). Participants were asked to read the description of each stage of technology adoption and select one stage that best describe them. They were also required to describe the reason why they selected a particular stage of technology adoption.

Narrative Interview. The narrative interview was the primary source of this current study. The narrative interview was used to understand, describe, and explain particular events of participants' story about their past technology-related learning experience from three learning situations (undergraduate and graduate PETE program as well as PDPs). The use of narrative interview was reasoned that it allows researchers to understand, describe, and explain particular 
events or experiences of participants over a period and to capture the meaning that participants assign to the events or experiences (Bernstein, 2009; Bold, 2011).

Twelve master's students participated in individual, audio-recorded, structured narrative interviews (see Appendix A), which lasted approximately 60 - 90 minutes. An interview guide including 20 open-ended questions was used to explore participants' technology-related learning experiences in their undergraduate and PETE graduate programs as well as PDPs. A narrative interview guide was created with careful consideration given to the elements of a "narrative" interview as described by Bold (2011), including a particular focus on people, action, certainty, and context. Such elements are crucial considerations when attempting to understand participants' experiences and perceptions regarding the issue at hand in a deep and meaningful manner (Bold, 2011). For instance, when asking follow up or probe questions, participants were asked to describe their experiences in detail, "like exactly when it happened, where it happened, what happened, who was involved, what you did with the technology, and what you were thinking and feeling at that moment?". These detailed descriptions helped the researcher understand critical factors (e.g. social and cultural factors) (Clandinin, 2006) influencing participants' experiences with and values, beliefs, and attitudes towards technology integration in their PE classes. Prior to the narrative interview, the validity of interview questions was performed by experts in qualitative research methodology and piloted with three physical education teachers to check for clarity and understanding. Based on a result of the pilot testing, interview questions were slightly revised.

\section{Data Collection Procedures}

After IRB permission had been obtained, the lead researcher sent out a cover letter describing the study aims amd confidentiality procedures to potential participants via email. A 
list of all PETE master's students was obtained from the professor teaching the instructional technology in sport and physical education course. Individuals agreeing to participate in the study were asked to first complete the SAT survey. The results of the SAT survey revealed that all participants' SAT level were well distributed across the six levels outlined on the instrument. Based on the results of the SAT survey the researcher purposefully selected 12 participants across all stages of technology adoption. The purposefully selected participants were then contacted by email, and one-on-one structured interviews were scheduled. The interview guide was attached to the introductory email for participant review. Prior to the interviews, a research assistant with experience in qualitative research was recruited to assist with data collection and analysis. Thus, two researchers were trained to conduct the narrative interviews.

At the commencement of each interview, the researchers reiterated the purpose of the study and, reminded participants that all responses were confidential and anonymous and attempted to build rapport to ensure comfort and allow for an open dialogue and discussion. To established positive atmosphere during the interview, the researchers used soft voice tone and dynamic questions. For example, “can you start by telling me about your experience with technology?" The interviews lasted approximately 1-2 hours for each participant and were audio recorded. . The interviewer concluded the interview by summarizing important information (e.g. feeling and meaning that participants assigned to the experience) and verifying whether the interviewer understood the information correctly. Follow-up with individual participants was initiated by the researcher in the event clarification on particular points arose during data analysis. In return for study participation, participants received a \$20 gift card. 


\section{Data Analysis and Trustworthiness}

Data was analyzed through two phases. The followings table describes each phase of data analysis.

Phase One. The SAT survey data was analyzed by the description of each stage in the SAT survey to identify PE teachers' current technology adoption stages. Twelve participants who are in a various stage of technology adoption were selected based on the results of SAT survey.

Phase Two. All interviews were transcribed verbatim by a professional transcriber to ensure the accuracy of the interview transcript. The transcribed interviews were analyzed using inductive content analysis to identify patterns or themes emergent from the data (Elo \& Kyngas, 2008). Three levels of analyses including a) open coding, b) axial coding, and c) selective coding, were performed in order to gather a detailed picture of the information obtained during data collection process (Corbin \& Strauss, 2008). For example, researchers first began to read through the transcripts without judging the content in order to gain general sense of the data. In the second reading, the researchers identified important information related to the research questions by highlighting, bracketing, or underlining. In the third reading, the researchers began assigning codes to the important information (e.g. events related to learning about technology or technology integration and participants' perception and feeling of such learning experiences). Two theories (Technological Pedagogical Content Knowledge [Mishra \& Koehler, 2006] and first and second order barriers to technology integration theory [Ertmer, 1999]) influenced the coding. After labeling approximately ten percent of the interview data, the researchers met to compare and contrast initial coding. If there is agreement between the researchers, the researchers went back and continued to code the remaining data. This process repeated until 
thirty percent of interview data were coded. After coding, the researchers began to examine the pattern of data and grouped codes with similar meaning together to create categories. For example, codes related to beliefs (e.g. irrelevance to teach PE, negative attitude toward the use of technology in PE, and positive beliefs about use of technology) were categorized as beliefs. The categories were organized by using Excel software. After creating several categories, researchers established connections between categories and created themes emerged from the data. A constant comparative technique was utilized for the purpose of examining the consistency and relatedness of the data (Glaser \& Strauss, 1967). After creating several categories, researchers established relationships between categories and created themes emerged from the data.

To enhance the trustworthiness of the data several recommended strategies, namely a) member checks, b) investigator triangulation, and c) peer debriefing, were employed (Pitney \& Parker, 2009). Member checks were accomplished by sending participants a transcription of their interview and asking them to indicate the extent to which the transcript accurately represented their experiences, perceptions, feelings, and thoughts regarding the research questions. Multiple analyst triangulation and peer debriefing session were also performed to establish trustworthiness. 


\section{Appendix B}

\section{Extended Review of Literature}

Although there are various PE specific technologies available for PE teachers to use to teach PE contents, studies (Gibbone et al., 2010; Juniu et al., 2013) found that PE teachers have reported that they are struggling to integrate technology in their class. Teachers including PE teachers frequently reported that there are some barriers hindering their technology integration. Thus, understanding what factors are hindering teachers' technology use and what teacher educators have done to help teachers overcome the hindering factors are important.

The following section will review literature related to following topics: a) available physical education specific technologies and their use in physical education, b) literature on factors influencing teachers' use of instructional technology for teaching, c) literature on technology integration strategies to train teachers to use technology, d) literature on PE teachers' learning, and e) literature on developmental stages of teachers' technology integration. These literature will help understand: a) what PE specific technologies are available in the field of physical education and how they are suggested to integrate in PE class, b) what challenges teachers (including PE teachers) face when attempting to integrate technology into their teaching, c) what technology integration strategies have been used by teacher educators to help teachers navigate the challenges, d) how teachers learn to teach, and e) how differently teachers use technology in terms of developmental stages of technology integration.

\section{Instructional Technology in Physical Education}

Physical education teachers have been encouraged to use a variety of instructional technology tools in physical education classes to enhance student learning and teaching effectiveness (ISTE, 2008; NASPE, 2008). While effective teaching in PE class is possible 
without technology integration, the supplementary role of technology, such as providing visual aids and demonstration, verbal cuing and skill-related feedback, and others could enhance students learning and teaching effectiveness (Jones et al., 2012). Over the past two decades, variety of instructional technologies have been introduced and suggested by many teachers and scholars who are involved in the field of physical education (Beighle, Morgan, \& Pangrazi, 2004; Block, 2008; Gibbone, Perez, \& Virgilio, 2014; Pillips, Rodenbeck, \& Clegg, 2014). The use of technology has been changed the ways PE teachers to teach physical education subject matters.

Physical education teachers have integrated technologies in physical education for various purposes, which range from as assessment tools to as physical activity tracking. The following section will discuss various technologies available in physical education and its application in physical education.

Video games. Various video games have been suggested for PE teachers to use in physical education classes as means to enhance students' motivation, confidence, physical activity levels, motor skills, and comprehensive understanding of sports and physical and sports activities (Day, Winfred, and Gettman,2001; Hayes \& Silberman, 2007; Fiorentino \& Gibbone, 2005). Largely, there are two types of video games, sports video games and active video games. Two different types of video games will be discussed in the below section.

Sports video games. Sport video games are video games emulating the playing of traditional popular sport games, such as basketball, soccer, football, ice hockey, tennis, or skateboarding, etc. (Wikipedia, 2014). Several researchers proposed use of sport video games to increase students' motivation and comprehensive understanding of sports and physical and sports activities (Hayes \& Silberman, 2007). However, there is a lack of empirical evidence supporting 
the effectiveness of video games on students learning and teacher's teaching effectiveness. Due to the lack of empirical evidence on the positive impact of video games as instructional tools on student learning, many people tend to hold a persistent belief that sports video games decrease youths' physical activity rather than increasing physical activity (Hayes \& Silberman, 2007). According to a study (Marshall, Biddle, Gorely, Cameron, \& Murdey, 2004), no relationship between video games and physical inactivity was found. The study suggested that if a video game is used in educationally appropriate ways, sport video games have a potential to increase students' learning in PE class.

Simulated environments and situation within sport video games are very similar to real sport games so that they have the potential to enhance physical performance by having players to create mental images of successful performance (Hayes \& Silberman, 2007). Because of the environmental similarity, sport video games are often used for college level athlete, professional athletes, or military as a purpose of part of on-going training (Hayes \& Silberman, 2007). Scholars such as De Lisi and Wolford (2002), Day et al. (2001), and Hayes and Silberman (2007) have claimed the effectiveness of video gaming on spatial awareness ability, motor skills, comprehension of game tactics and strategies. These researchers suggested simulated video games can be a useful tool to enhance spatial awareness, motor skills, and comprehension of game strategies.

Hayes and Silberman (2007) suggested several meaningful ways that sports video games can be integrated in PE class as educational tools. According to Hayes and Silberman (2007), use of simulated video games can help players develop mental imagines of successful performance. Sport video games provide players with a wide range of virtual environments that players can perform the skill and develop game strategies and use them. Within the diverse virtual 
environments, players can acquire and develop skills and new game strategies. The newly developed skills and game strategies are applied in video games. While applying the skills and game strategies, players can have opportunities to explore various game strategies they developed and to analyze them. The exploration and analysis of their skills and strategies help players understand a wide range of game strategies and use them successfully in future (Hayes \& Silberman, 2007).

Use of sport video games can be a useful tool to teach sport or physical activity terminologies. Understanding sports terminologies are important because they are used as a communication mean in sports (Hayes \& Silberman, 2007). When playing a video game, players encounter sports terminologies naturally. This experience enables them to understand what and when sports-specific terminologies are used and how people communicate in sports.

Hayes and Silberman (2007) also suggested that sport video games can also be utilized when teaching various positions of player in sport games. For example, in Madden NFL or NBA Street games, video game players need to see entire court to control the virtual players. By controlling game and virtual players, video game players can understand virtual players' different positioning and how a team functions (Hayes \& Silberman, 2007). Although several ways to integrate sport video games in PE classes have been introduced by several researchers, there are a lack of empirical evidence supporting the effectiveness of these on students' learning in PE class.

Active video games. Another type of video game that can be effectively utilized in physical education class is active video games. Active video games are often called differently, such as exergames, interactive video games or active games depending on people (Fiorentino \& Gibbone, 2005; Mears \& Hansen, 2009; Meckbach, Gibbs, Almqvist, Ohman, \& Quennerstedt, 
2013; Sheeban \& Katz, 2010). Active video games combine physical activity and video games to create an enjoyable and appealing way for students to be physically active (Hicks \& Higgins, 2010). Many types of active video games are available in the market which includes X-Box Kinect sports, Wii Fit, Dance Dance Revolution, sports walls, and XR board (Mears \& Hansen, 2009; Trout \& Christie, 2007).

Unlike the traditional sedentary video games that are described in the previous section, the active video game requires its players' active involvement and the exertion of physical force (Sheeban \& Katz, 2010). PE teachers have used these active video games as means to provide students with the opportunity to increase their physical activity, to experience various movements, and to have fun (Meckbach et al., 2013). A study (Meckbach et al., 2013) found that PE teachers who use of active video games in their teaching believe there is great potential to encourage students' physical activity.

Students' physical activity level is increased when they are motivated to engage in movement tasks. Sheehan and Katz (2010) explained the reason why the active video games increase students' motivation to participate in physical activity. According to Sheenhan and Katz (2010), there are five components which are essential for students' intrinsic motivation; a) control, b) challenge, c) curiosity, d) creativity, and e) constant feedback. These components can be easily found in video games.

Sheehan and Katz (2010) described that active video games provide players with freedom. When playing active games, players are free to start, stop, and restart the game. Also, players are given several choices to select games and level of difficulties. This characteristic of video games allows players to the choice appropriate level of games based on their ability. The challenge is another essential component of intrinsic motivation. Appropriate challenge increase 
students motivation to participate in a task for a prolonged period. As described in the previous paragraph, video game provides players with the choice to select game levels appropriate for players. This characteristic of video games plays an important role in enhancing one's motivation. Curiosity helps keep students engaged and motivated. When students are curious about the next activity, they are motivated to achieve a given task to see next activity (Sheehan \& Katz, 2010). Sheehan and Katz (2010) also talked about creativity. During engaging in active video games, students create strategies to solve or overcome the challenge. Lastly, constant feedback is one of a key feature of active video games. All video games have a built-in system which provides personal, accurate, and immediate feedback through the scoring system (Hicks \& Higgins, 2010). Knowing how they are doing at all time is an important component having students keep engaged and focused (Sheehan \& Katz, 2010).

Although there is little empirical research on impact of active video games on motor skill development (Mears \& Hansen, 2009), several physical educator have claimed that active video game can be used to help children develop fundamental motor skills such as hopping, throwing, catching, kicking and jumping (Sheehan \& Katz, 2010). These fundamental motor skills are important skills that students should develop to successfully participate in more complex movement tasks, such as game plays. If students do not develop these abilities, they face difficulties engaging in complex movement task. Robison (n.d) said that active video games such as Dance Dance Revolution help to develop complex movement patterns. By exploring various movements in active video games such Wii Fit and DDR, students can develop their movement skills. 
Physical activity trackers. Various physical activity trackers, such as pedometer, heart rate monitor, and other devices, have drawn the attention of physical education teachers. In this session, I am going to review studies talking about these devices and the use of these devices.

Pedometer. A pedometer is a device measuring steps or steps/min (Scruggs, Mungen, \& Oh, 2010). It has been used as one of the popular tools to measure individuals' physical activity levels by PE teachers (Beighle et al., 2004). Beighle et al. (2004) claimed that use of pedometers enables PE teachers to teach students about physical activity (PA), enhance PE teachers' instruction, and provides students with accountability for their physical activity. The advantage of using pedometer is that it provides PE teachers with a valid and reliable data about students' step counts. The data obtained from pedometer allows PE teachers to give students immediate feedback about their PA levels, and also can be used as a tool measuring students' fitness levels (Beighle, Pangrazi, \& Vincent, 2001; Beighle et al., 2004).

Beighle et al. (2001) mentioned that one of biggest reasons that PE teachers use this technology is to promote a physically active lifestyle for students. According to Beighle et al. (2001), effective use of pedometer has a potential to increase students' understanding of the importance of all physical activities, which in turn increase their physical activity participation. Information on the amount of physical activity and distance that students the accumulated during class and free time can help students understand how different sports and physical activity influence their steps and their daily calorie consumptions during PE class and free time (Beighle et al., 2001;2004). Thus, a pedometer can be a great tool to promote students' healthy lifestyle.

Beighle et al. (2004) also suggested that pedometer can be utilized to evaluate PE teachers' teaching effectiveness. PE teachers' teaching effectiveness can be assessed by measuring students' PA levels during PE (Beighle et al., 2004). By checking students'step 
counts over the course of several PE classes, PE teachers can understand whether their instruction was effective enough to increase students' PA levels. However, it should be remembered that pedometer is not the best way to assess teaching effectiveness (Beighle et al., 2004) because there are many other variables influencing students' steps, such as instruction time, management time, activity types, and teacher characteristic (Beighle et al., 2004). Thus, PE teachers should be aware that using pedometer is just one of tools that help them evaluate their teaching effectiveness.

Heart rate monitor. Heart rate monitor is another commonly used technology by $\mathrm{PE}$ teachers. This device can be seen in PE programs easily. Heart rate monitors have been largely used by PE teachers in three purposes: a) to supplement the physical education fitness curriculum, b) to motivate students to achieve higher intensity levels of physical fitness, c) to assess students' exercise intensity levels during physical education program (Nichols, Davis, McCord, Schmidt, \& Slezak, 2009). One of the advantage of using heart rate monitor in PE class is that PE teachers can give students more responsibility for their learning, which increases their motivation to exercise (Nichols et al., 2009).

Heart rate monitor allows PE teachers and students to measure the effort of students they put during exercise easily (Nichols et al., 2009). Students determine their target rate zone and work hard to stay in the target zone for a long period. If students' heart rate goes above or below the target heart rate, they adjust their activity intensity to meet the target heart rate. While students are engaging in activities, PE teachers can measure the effort of students by checking students' time in the target heart rate zone and encourage their exercise. This way of teaching with heart rate monitor gives students freedom to adjust their workout while maintaining higher accountability level (Nichols et al., 2009). 
Another advantage of using heart rate monitor is that students can learn about body's physiological response to the different intensity of exercise, as compared to other technology such as pedometer which simply measures steps (Nichols et al., 2009). Nichols et al. (2009) claimed that heart rate monitor can teach students about their heart, how it works, and why it is important to their health. Nichols et al. (2009) provided an example how physical education teachers can teach about students' heart and how different activities stress their heart in different ways by using heart rate monitor. According to Nichols et al. (2009), "by wearing heart rate monitor, it is extremely easy for your children to see that their heart beats fast the more they move around and slows when they stop. This can be done with the audio "beep, beep" sounds made by the monitor." (p.20).

The data from heart rate monitor allows students to understand what activity has cardiovascular component by comparing several different activities (Nichols et al., 2009). For example, PE teachers ask students to wear heart rate monitors while they are participating in an active video game and real sport games, and then have a discussion how different physical activities affect their heart rate by comparing and contrast to the data of real sports and video game sports (Hicks \& Higgins, 2010).

Information sharing technology. One of the technologies that can be used to share information with people is Podcast. The Podcast is relatively new technology that has been integrated into physical education classroom (Mikat, Martinez, \& Jorstad, 2007). Podcasting is a form of personal broadcasting through the internet, which drives from Apple's "iPod" and “broadcasting” (Mikat et al., 2007). This technology allows people to share information with others. 
One of standards in National Standards for Physical Education for K-12 students (NASPE) is that students demonstrate an understanding of movement concept, principles, and strategies (NASPE, 2009). To help students understand movement concepts, principles and game strategies, a considerable amount of time explaining the concepts and strategies should be spent in PE classes. However, considering one of important task of PE class today, (maintaining high level of physical activity during PE class) spending considerable amount of time for instructing movement concepts and strategies is not a good idea because if teacher spends lots of PE class time for instruction, the opportunity that students can be physically active during PE class is decreasing. Thus, PE teachers have been required to find effective way to reduce instructional time and increase PA time.

Podcast can be an effective supplementary instructional tool to reduce instructional time during PE class and to help develop students' understanding of movement concept and strategies because it allows PE teachers to deliver content to students outside of the classroom which enable students to participate in movement task for a longer period (Mears, 2009).

Several physical educators have suggested ways to integrate podcast into PE class. Mikat et al. (2007) and Mears (2009) suggested step by step podcast integration procedure in PE class. According to them, PE teachers need to create podcasts or recording of his/her teaching by using software programs such as PodProducer or Audacity. The recording should be e saved as MP3 or WAV files and then uploaded the files on the website for easy distribution. For example, physical education teacher creates an audio file and post the podcast link on their school's internet server (ex. Blackboard or E-campus) so that students can access the file at any time. Along with podcasting file, physical education teachers can add video and PowerPoint to a 
Podcast along with a document that students can utilize while listening to the podcast. One of example that Mikat et al. (2007) described in their paper was as follow:

A physical education teacher directs her students to the class web site. The web site contains a link to an audio file that the students can download and listen to at their leisure. The teacher instructs her students to listen to the file in preparation for their next class. The file contains information about the reduction of heart disease risk from increased physical activity. The file concludes by asking the students questions that they should be able to answer after listening to the recording. The next day, students arrive in class and immediately begin to engage in a discussion about the audio file and its contents (p.14).

It is not common to see PE teachers using the Podcast in their PE class. However, researchers claimed that use of podcast in PE class has a potential to enable students to become familiar with PE contents before classes and to understand the content and apply their knowledge better (Mikat et al., 2007). If the Podcast is used effectively, in-class instructional time can be more devoted to psychomotor domain development. Ultimately, use of podcast can help PE teachers achieve NASPE standards, which are students demonstrate not only competent motor skills, but also demonstrating an understanding of movement concepts, principals, and strategies (Mears, 2009).

Visual representation. Visual representation is another technology that can be integrated in physical education class. Visual representation technologies include a digital camera, video camera, PowerPoint, and video editing devices. In general education, teachers usually transmit information to students through visual representation, such as PowerPoint. One of benefits using visual representation is that it can help to enhance the learning of students who are visual learner (Heynen, 2008) and PE teachers' teaching effectiveness. PE is a discipline studying of physical movements. Human's physical movements occur in a very short period of the moment so our eyes and brain cannot capture quick and complex physical movements perfectly (Harris, 2009)., Because of this unique characteristic of PE discipline, PE teachers had difficult time processing 
and analyzing students' movements to provide appropriate feedback to students. Also, PE teachers in traditional PE class usually rely on physical demonstration to teach movement skills (Heynen, 2008). However, the introduction of innovative visual representation technology has helped PE teachers overcome the problem that just described. The following section will discuss various visual representation devices and their use in PE class.

Digital camera. Digital camera is one of visual representation technologies which can be used in PE class as a means of assessment or review of concepts. PE teachers can use a digital camera as a great tool to provide immediate feedback on students' performance (Haynen, 2008). Images chaptered by a digital camera provide PE teachers with useful information on students' performance, and the information can be an immediate visual reference that helps PE teachers continuously evaluate students' performance and provide students with immediate corrective feedback on their performance (Haynen, 2008). The immediate feedback helps students understand their performance and enhance analytical thinking (Haynen, 2008)

Video camera. Another visual representation technology that is popular among PE teachers is video cameras. A project by the Francophone Sector of the New Brunswick Development of Education found a positive impact of using the video camera on students' learning (Harris, 2009). According to Haynen (2008), video camera or motional analysis can be used mainly for two purposes: skill performance evaluation and document creation. One of the ways to integrate this device in PE class is for the purpose of skill performance evaluation (Haynen, 2008). Video camera enables PE teachers and students to slow down performers' real time performance and examine critical elements of their movement. With this device, PE teachers can encourage students to evaluate their performance or other's performance by using a video camera (Haynen, 2008). To effectively use a video camera, PE teachers can pair students 
up and have students to record each other's performance. The recorded video can be analyzed by students and students can provide feedback each other based on the data from the video. This form of peer assessment can be an excellent tool not only to help students visualize and analyze their but also to help PE teachers manage and evaluate whole class (Haynen, 2008).

Tablet and mobile device. Tablet and mobile technology (iPad, iphone, gallexy note or tab, etc.) recently added into PE class and became one of the popular technologies among PE teachers. The unique characteristic of these technologies is that there are a number of applications (apps) for people to use recreationally or educationally (Sinelnikov, 2012). The variety of educational applications have been introduced by physical educators and the applications are suggested to use to motivate students, to assess students learning, to help students understand of movement, to increase student-centered learning, and to help students move and keep track of their physical activity and fitness (Gibbone et al., 2014; Robinson, n.d.; Sinelnikov, 2012; Phillips et al., 2014). Diverse applications will be discussed and how they can be used in PE class in the following section.

Physical activity instruction supplementary applications. Several PE educators have introduced various instructional supplementary applications, such as Virtual Heart, Visual Anatomy Lite, Speed Anatomy Lite, Fitness HD, VSB physical education, iReferee HD, and YouTube, to help student understanding and learning (Gibbone et al., 2014, Phillps et al., 2014; Sinelnikov, 2012). Health-related applications such as Virtual Heart, Visual Anatomy, Speed Anatomy Lite, and Fitness HD can be usefully implemented in PE class when teaching human body and organs, and how they can be strengthened by which exercise. For example, when teaching human body, the PE teacher can use the Virtual heart to show students what a real heart look like and its motion in action (Phillips et al., 2014). Another example is use of Fitness HD. 
This application can be used to teach what exercise strengthens which muscle groups. The applications described above can help students understand complex information, such as human body and organ and their functions in our body.

Other applications such as Keynote app and Numbers app can be effectively utilized in PE class for student-centered learning (Sinelnikov, 2012). The Numbers app is a spreadsheet application that allows PE teachers to create tables and graphs and enters data into them (Sinelnikov, 2012). According to Sinelnikov (2012), this application can be used to teach students sports statistics. In professional sports, individual or team performances, for example, the number of wins and losses, the number of shot, pass, assist, or turn-over, are recorded in every game or practice. In a similar manner, students in PE class can use this application to keep tracking of individual performance and their team performance. By tracking students' performance, students can understand how professional sports keep tracking of the team and individual player's performance.

In summary, this section explored types of technologies available in physical education and how these technologies have been used or suggested to use in physical education. Although there are many literature introducing many instructional technologies and their use in PE, there is no empirical research examining the effect of these instructional technologies on student learning and PE teachers' teaching effectiveness. This finding demonstrates the needs of empirical research examining the effect of instructional technologies on student learning and teacher effectiveness.

Although various types of PE specific technologies are available, studies (Liang et al., 2006; Juniu et al., 2013) found that PE teachers are still struggling to integrate technology. The 
following section will explore factors negatively influencing teachers' technology integration effort.

\section{Variables Influencing Teachers' Use of Technology in Teaching}

There are a wide range of factors influencing teachers' decision and practice with technology. Barriers to technology integration are clearly identified and well documented in many studies. Ertmer (1999) suggested that there are two types of barriers to technology integration (first order and second order barriers), of which include understanding of effective integration (knowledge), skills to operate, confidence, accessibility (resource), technical and administrative support, time, pedagogical belief and value toward technology use in classroom, training, class size and etc. (Ertmer \& Ottenbreit-Leftwich, 2010; Ertmer, 1999; Ertmer, 2005; Gibbone et al., 2010; Hew \& Brush, 2007; Inan \& Lowther, 2010). These barriers can significantly limit teacher capacity to integrate technology in their teaching. Identifying and understanding the reasons teachers have struggled to integrate technology in their teaching can assist teacher educators as they develop and modify teacher training curricula and professional development experiences. Thus, the following section will review the existing literature on reported barriers to technology integration.

First order barriers. The term first-order barriers refer to "obstacles that are extrinsic to teachers" (Ertmer, 1999, p.50) and includes lack of equipment, insufficient time, lack of funding, inadequate training, and insufficient technical and/or administrative support (Ertmer, 1999; Ertmer et al., 1999). Although first-order barriers are manageable, pre/in-service teachers have reported difficulties in controlling and overcoming these technology-related barriers (Hixon \& Buckenmeyer, 2009). 
Pre/in-service teachers frequently reported a lack of access to technologies (resource) as one of the most significant barriers to technology integration (Barton \& Haydn, 2006; Choy et al., 2009; Kopcha, 2012; Gibbone et al., 2010). A study by Barton and Haydn (2006) reported that pre-service teachers felt that lack of resources is a great obstacle impeding their technology integration. Similary, Kopcha (2012) found that in-service teachers have the same perception regarding access to technology. When Kopcha (2012) examined 30 elementary teachers' perceptions regarding barriers to technology integration, participants reported that access to technology was the biggest obstacle, followed by belief, vision, and professional development. These findings are consistent with the ideas of Ertmer (1999), who stated that teachers believe that they can't initiate meaningful technology integration if sufficient technologies are not secured. The findings of these studies seem to show the importance of access to successful technology integration.

Researchers (Russell, Bebell, O’Dwyer, \& O’Connor, 2003) found a positive influence of technology access on teachers' attitudes and values. A study by Russell et al. (2003) compared the attitudes and values of two groups, those who have the technology and who do not. Russell et al. (2003) found that teachers who have access to technologies demonstrated positive attitudes and more strongly values about technology integration in teaching than do teachers who do not have access. Similar to Russell et al. (2003), Wyant et al. (2015) reported the importance of preservice PE teachers' technology access. He found that allowing pre-service PE teachers to access technologies in a supportive environment had a positive effect on teachers' attitude and confidence with technology skills. Wyant et al. (2015) suggested that allowing teachers to access technologies and to explore technologies is critical to change attitude and self-confidence of preservice PE teachers. 
Along with access to technology, inadequate training is another barrier to teachers' technology integration. Researchers (Juniu et al., 2013; Inan \& Lowther, 2010; ISTE, 2008) have stressed the importance of adequate training to shape teachers' technology use in their instruction. ISTE (2008) stated that continuous and quality training plays a significant role in enhancing teachers' skills and attitude necessary for meaningful technology integration. Similarly, teacher educators (Inan \& Lowther, 2010; Vannatta \& Nancy, 2004) found positive effects of technology training on teachers' technology skills and use in instruction. Vannata and Nancy (2004) suggested that teachers' technology integration is proportionate to the amount of technology training they receive. That is, the more time teachers receive technology training, the more likely the teachers are to integrate technology into their teaching. Although many teacher educators have suggested the importance of quality training about technology integration, physical education teacher education (PETE) programs haven't provided adequate training to pre-service PE teachers. Studies by Juniu et al. (2013) and Gibbone et al. (2010) found that pre/in-service PE teachers did not feel well prepared to use technology in their teaching. Pre/inservice PE teachers reported that they did not receive proper training to have adequate skills and competence to teach with technology in their classes (Juniu et al., 2013; Gibbone et al., 2010). Lack of proper training appears to inhibit pre/in-service PE teachers' technology use regarding skill, knowledge, and belief.

Lack of time is another barrier that has been most frequently mentioned by teachers. Researchers (Barton \& Haydn, 2006; Kopcha, 2012) stated that lack of time to navigate and explore the potential of the technologies was commonly cited by teachers. Kopcha (2012) suggested that if teachers do not have enough time to plan and examine technology, they are less likely to use technology even if they have access to technology and training. He continued to 
explain that considerable amount of time planning and thinking about new teaching and classroom management to integrate technology make in-service teachers have negative attitude toward technology integration. Thus, it is thought that providing pre/in-service teachers with more time to consider what to do with technologies and how to use available technologies in meaningful ways is important (Zhao \& Frank, 2003).

First order barriers significantly influence teachers' technology integration effort. If any one of first order barriers (time, training, equipment, and support) is not eliminated, teachers' meaningful integration will be difficult to achieve. However, when adequate funding, training, time, and support are secured, it is probable that teachers could overcome first order barriers (Ertmer, 1999; Ertmer et al., 1999). Therefore, teacher education programs and school administrators can help teachers overcome the first order barriers by providing enough budget, time, support, and training.

Although helping teachers eliminate first order barriers is critical to teacher education programs and school administrators, they should have in mind that merely providing pre/inservice teachers with enough resources, time, and training are not enough for them to effectively integrate technology into their teaching. Ertmer (1999) stated that "even if first-order barriers were removed, teachers would not automatically use technology to achieve the kind of meaningful outcomes advocated here" (p.51). Although teachers frequently indicate first order barriers to be most influential, researchers have found that second order barriers (which are internal factors such as knowledge, self-efficacy, attitude, and beliefs) have greater impact on technology integration (Ertmer, 1999; Ertmer \& Ottenbreit-Leftwich, 2010; Ertmer, 2005; Hew \& Brush, 2007; Hixon \& Buckenmeyer, 2009). Thus, teacher educators must understand second 
order barriers and work to develop experiences that can help teachers navigate and overcome these internal influencers.

Second order barriers. In addition to first order barriers, second order barriers also significantly influence teachers' technology integration. Second order barriers refer to internal barriers which include knowledge and skills, pedagogical belief about teaching and learning (teaching methods, organizational and management styles, and assessment procedure), belief about technology, and fear of using technology (Ertmer, 1999; Hew \& Brush, 2007; Hixon \& Buckenmeyer, 2009). Unlike first order barriers, second order barriers are not easily changed.

Knowledge (skill). Teachers' lack of knowledge and skills are the most frequently reported barriers to technology integration by teachers including PE teachers. According to the studies by Gibbone et al., (2010) and Juniu et al. (2013), PE teachers reported that lack of knowledge and skills as one of the obstacles, which affect PE teachers' use of technology. To help PE teachers successfully integrate technology, it is important for teacher educators to understand knowledge structure and what knowledge contributes to successful technology integration. Therefore, the following section will explore literature on teachers' knowledge necessary for effective teaching with technology and how such knowledge can be developed and applied within the field of physical education.

Teaching is a complex activity that requires many kinds of knowledge (Mishra \& Koehler, 2006). Teacher educators (Mishra \& Koehler, 2006; Koehler \& Mishra, 2009; Pierson, 2001) proposed a new type of knowledge: Technological knowledge (TK). According to Mishra and Koehler (2006), this type of knowledge interacts with other types of knowledge, such as pedagogical knowledge (PK) and content knowledge (CK) and together they create a new type of specialized knowledge: Technological Pedagogical Content Knowledge (TPACK) which 
teachers need to have in order to understand effective teaching with technology and to successfully integrate technology in their teaching. This knowledge has been viewed as a dynamic set of knowledge system which three different bodies of knowledge consistently interact with each other during instruction. (Mishra \& Koehler, 2006)

Pierson (2001) was the first person discussed TK and TPACK after examining characteristics of technologically and pedagogically competent teachers (Voogt, Fisser, Roblin, Tondeur, \& Braak, 2013). Although she discussed TPACK before Koehler and Mishra (2005), Koehler and Mishra were the first scholars who introduced TPACK framework and expanded each knowledge construct in detail. This knowledge structure has been discussed and referred to by scholars by many names, including information and communication technology-related PCK (Angeli \& Valanide, 2005; Chai, Koh, \& Tsai, 2010; Kovalik, Kuo, \& Karpinski, 2013), technology-enhanced Pedagogical Content Knowledge (Niess, 2005), and technological scientific pedagogical knowledge (Jimoyiannis, 2010). Throughout the various iterations of names, the principles remain constant that "effective technology integration depends on consideration of the interaction between technology, content, and pedagogy" (Ertmer \& Ottenbreit-Leftwich, 2010, p.259).

The TPACK framework stems from Shulman's (1986) idea of Pedagogical Content Knowledge (PCK). Koehler and Mishra (2005) added another type of knowledge (Technological Knowledge, TK) onto Shulman's PCK framework (1986). For Koehler and Mishra (2005), technology is not just a supplementary material to support teaching. They viewed technology as another distinct knowledge system, which teachers need to develop and understand for effective technology integration. 
According to Koehler and Mishra (2005), there are three types of teacher knowledge which are interacting with each other consistently to construct TPACK. Ideas in the TPACK framework are that teachers need; a) knowledge of the content they are teaching (CK), b) knowledge of pedagogical methods that facilitate students' learning (PK), c) knowledge of finding technologies that can support the pedagogical methods (TK) (Ertmer \& OttenbreitLeftwich, 2010). When the three types of knowledge described above interact with each other, TPACK is created. Information on TPACK will be specifically described later in this paper.

The TPACK framework has played an important role in helping teacher educators understand what teachers need to know to integrate technology in their teaching. Using the concept of TPACK framework, teacher educators has designed their programs to train pre/inservice teachers how to teach with technology (Archambault \& Barnett, 2010). Figure 1 provides a structure of TPACK and how the three distinguished type of knowledge work each.

Figure 1. The TPACK framework and its knowledge components.

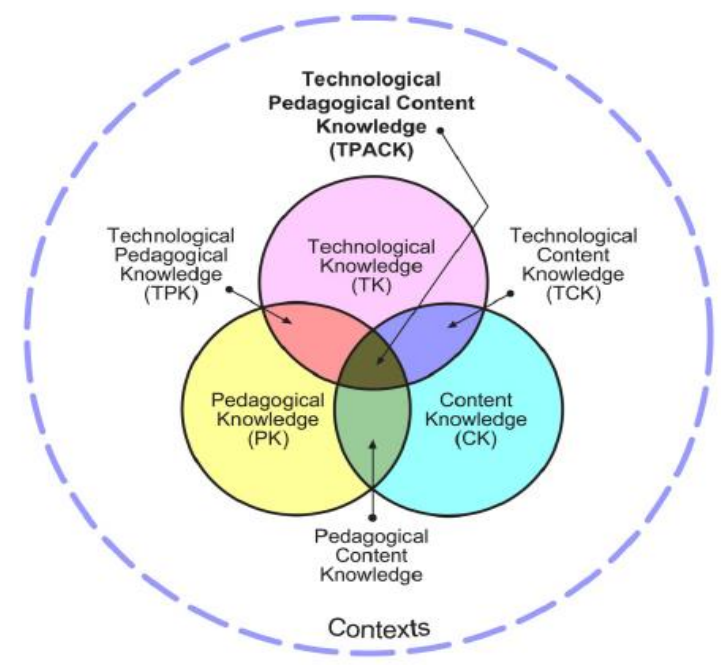

Note. Adapted from Mishra and Koehler (2009). What is technological pedagogical content knowledge (TPACK)?. Contemporary Issues in Technology and Teacher Education, 9, 60-70. 
Pedagogical content knowledge (PCK). Pedagogical content knowledge (PCK) is a combination of two types of knowledge (PK and CK), which teachers need to effectively teach a discipline specific content. According to Shulman (1987), "PCK represents the blending of content and pedagogy into an understanding of how particular topics, problems, or issues are organized, represented, and adapted to the diverse interests and abilities of learners, and presented for instruction" (p.8). PCK is different from general pedagogical knowledge (PK) in terms of content specific and context specific. Teachers' PCK is of particular importance because it helps teachers organize and represent the content to make it teachable which facilitates students' learning, and select multiple instructional strategies that fit the content to meet the diverse learners' interest and abilities (Shulman, 1987). In physical education, when teachers develop PCK, they can understand what makes motor skills or game concepts difficult or easy for learners to learn and understand and what common misconceptions they have. This knowledge type allows teachers to arrange skills or concepts in developmentally appropriate ways and to use various teaching strategies, which increase students' understanding and learning. Grossman (1990) expanded Shulman's idea of PCK and identified four important components of PCK: a) conceptions of purpose for teaching subject matter, b) knowledge of students' understanding including context, c) curricular knowledge, and d) knowledge of instructional strategies. First, the conception of the purpose of teaching subject matter is to know the purpose of teaching certain subject matters. Ayvazo (2007) said that PE teachers' knowledge about the purpose of teaching is to teach basic movement skills for elementary school students and to teach advanced skills and apply them in various sports games in secondary school students. Second, the knowledge of students' understanding is defined as teachers' understanding of students' age and development levels, motivation levels, skills and abilities, previous experience about the 
subject they are learning, and learning style (Shulman, 1986). Third, the knowledge of curriculum refers to teachers' knowledge about curricular materials that teachers may use to teach a particular content (Ayvazo, 2007). Ayvazo (2007) stated that based on the content students already have learned, teachers can decide content and sequence of the content in developmentally appropriate ways. The last component of PCK identified by Grossman includes knowledge of instructional strategies to teach specific content (teachers' ability to represent content). These four components are important for developing PCK.

Technological knowledge (TK). Technological knowledge refers to a teacher's ability to know "how to install and remove peripheral devices, install and remove software programs, and create and archive document" (Mishra \& Koehler, 2006, p.1027). According to Mishra and Koehler (2006), many things can be considered as technologies in the classroom, even devices such as textbooks, pencil, pen, and blackboard. However, since these technologies have not been considered innovative technologies for quite some time (Mishra \& Koehler, 2006), more advanced digital tools, such as the internet, digital camera, handheld devices (tablet, iPhone, iPad, etc.), and software programs, will be the focus of this research. A variety of technologies is available for PE teachers to use. Although all electronic technologies, such as computer software programs (Microsoft Word, PowerPoint, and Publisher), the internet, and podcasts, can be used to teach PE content, technologies related to human movements such as pedometers, heart rate monitors, physical activity watches, iPads, various mobile apps, video games and etc. are commonly seen in physical education classroom (Beighle et al., 2004; Block, 2008; Phillips et al., 2014) because physical education deals with physical movements. Technological knowledge (TK) includes knowledge of available technologies, awareness of the tools' functions, and how to troubleshoot effectively/operate the technology. 
Technological pedagogical knowledge (TPK). Technological pedagogical knowledge (TPK) is another knowledge type advanced from general TK by adding pedagogical knowledge. According to Mishra and Koehler (2006), TPK is "knowledge of the various technology existences, components, and capabilities of various technologies as they are used in teaching and learning setting” (p.1028). Teachers who have this knowledge type are aware of technologies that could fulfill a particular task, understand the related constraints and affordances of using certain tools, and how a particular technology can influence instruction and student learning (Mishra \& Koehler, 2006).

Most technologies are not devised for educational purposes. Many technologies, such as the Micro-software program (Word, Publisher, Excel, and PowerPoint), blog, podcast, twitter, etc. were designed for business, entertainment, and social networking (Mishra \& Koehler, 2006). Teachers with TPK can modify these tools into innovate devices to enhance student learning experiences. When applying this concept in the physical education setting, teachers with TPK are aware of various technologies (ex. pedometer, heart rate monitor, physical activity watches, iPod, various mobile apps, video games, etc) on the market and view them as instructional tools to teach PE content. For example, PE teachers with TPK know there are software programs (ex. FITNESSGRAM) that can keep track of students' health-related fitness levels. The PE teachers use this software program to help students understand their fitness levels and to motivate them to participate in physical activity.

Technological content knowledge (TCK). Technological content knowledge is teachers' knowledge of the various technologies, which can represent subject matters being taught better (Mishra \& Koehler, 2006). This knowledge requires teachers to not only master their subject matter they teach but also have a deep understanding of how subject matter can be affected by 
the implementation of particular technologies (Mishra \& Koehler, 2006). Teachers with TCK understand how technologies can assist their way to present their subject matter. Technologies have unique affordances and constraints that can help make certain tasks easy or difficult to understand (Koehler \& Mishra, 2009). Teachers with TCK are aware of various technologies that can enhance subject matter content in more effective and/or innovative ways. For example in PE, animation and visual aid tools can be helpful for students to see and analyze skill performance. Another example could be the use of heart rate monitors. Teachers can use heart rate monitor to communicate the effect of different intensity of exercise on heart rate.

Technological pedagogical content knowledge (TPACK). Technological pedagogical content knowledge (TPACK) is the combination of the three types of knowledge which emerged from the interactions among pedagogical knowledge (PK), content knowledge (CK), and technological knowledge (TK) (Mishra \& Koehler, 2006). TPACK refers to "knowledge of using various technologies to teach, represent, and facilitate knowledge creation of specific subject content” (Chai, Koh, \& Tsai, 2013, p.33). According to Mishra and Koehler (2006), merely knowing how to use technology, subject matter, or instructional methods does not mean that teachers have TPACK. In order for teachers to have TPACK, teachers have to understand various technologies and their constraint and affordance, appropriate discipline-specific teaching strategies, representations, and the complex relationships between the three types of knowledge (technology, content, and pedagogy) and use them wisely when integrating technology into teaching. According to Koehler and Mishra (2009), teachers with TPACK understand representation of concept using technology, teach the concept with technology, understand what makes the concept difficult or easy to learn, and understand how technologies can help to teach or learn the concept better. That is, teacher with TPACK know how technologies can be used to 
teach a particular subject matter in pedagogically effective ways and implement appropriate technologies when needed to teach the subject matter better.

In physical education, teachers with TPACK can understand what factors facilitate or hinder students' performance; what errors or misconceptions students usually display when performing certain motor skills; what technologies are available to help to solve the problems; and how technologies can be implemented pedagogically to correct students' performance errors or misconceptions. For example, a PE teacher understands if there is a problem in his/her students' skill performances regarding biomechanics. He found that it is difficult for him to explain skill performance in terms of biomechanics in traditional method. He decided to use motion capturing devices, such as iPad apps and video cameras, which can help him detect students' performance errors and effectively explain the errors to his students. He can show what performance errors students demonstrated during the skill execution, and effectively explain what caused the errors and how students can correct the errors by using motion capturing devices. This use of technology can help students understand the PE teacher's instruction better which increase student learning.

Along with TPACK, Mishra and Koehler (2006) stated that teachers need to consider educational contexts where teachers are asked to incorporate technologies. For successful technology integration, teachers continuously interact with content, pedagogy, technology, and teaching and learning environments. Integrating technology in teaching is complex and requires teachers' understanding of the connection between the three types of knowledge and application of TPACK in the dynamic classroom context (Mishra \& Koehler, 2006). Mishra and Koehler (2006) stated that "there is no one best way to integrate technology into the curriculum. Rather, integration efforts should be creatively designed or structured for particular subject matter ideas 
in specific classroom contexts" (p.62). That is, teachers need to develop the flexible knowledge necessary to incorporate technology successfully into teaching according to their educational environments.

In summary, the combination of three teacher knowledge (TK, PK, and CK) constructs a specialized knowledge (TPACK), which is an integral element of meaningful technology integration in teaching. Each type of teacher knowledge plays an important role in shaping teachers' teaching behavior with technology. Even when first barriers are removed, if teachers do not have the appropriate knowledge to integrate technology, effective technology integration cannot be seen (Ertmer, 1999). However, there is an assumption that teachers' technology knowledge of technology is the most important element for successful technology integration. This assumption should be rectified. Merely knowing how to operate technologies such as hardware (e.g. camera, heart rate monitor, and pedometer) and software programs (e.g. fitnessgram, and applications) is not enough to enable the teachers to infuse technologies into their instruction (Ertmer \& Ottenbreit-Leftwich, 2010). Teachers must deeply understand the content being taught, teaching and learning processes (pedagogy), and technologies (Mishra \& Koehler, 2006), but also understand the complex relationships between these three concepts and their education setting.

Self-efficacy. Having high knowledge is not enough for teachers to successfully integrate technology, even if they have good understanding of technology, content, pedagogy, and their relationship (Mueller, Wood, Willoughby, Ross, \& Specht, 2008). If teachers do not feel confident using all three types of knowledge for effective teaching with technology, successful technology integration of the teachers may be difficult to expect. 
Self-efficacy is a belief about one's abilities to perform specific tasks and goals (Bandura, 1990). People's beliefs about their ability to complete tasks significantly influence their behaviors. According to Bandura (1990), behaviors (e.g. effort and duration of pursuance) are influenced by one's self-efficacy level. For example, if a person has high self-efficacy the amount and duration of effort is likely to be greater than a person with low self-efficacy in the face of difficulty. Bandura (1990) said that "when people lack a sense of self-efficacy, they do not manage situation effectively, even though they know what to do and possess the requisite skills. Self-inefficacious thinking creates discrepancies between knowledge and action” (p.9). That is, if people do not have a certain level of self-efficacy, it seems that people may not integrate technology effectively even if they have enough knowledge to use technology in their instruction.

Research has suggested that teachers' self-efficacy regarding technology use for instruction is directly related to their instructional practice (Ertmer \& Ottenbreit-Leftwich, 2010). They suggested that developing self-efficacy may be more important than knowledge or skills for successful technology integration because if teachers do not feel confident in using their knowledge for their instruction, they are less likely to use it. Studies (Barton \& Haydn, 2006; Lai, 2008) supported the idea of Ertmer and Ottenbreit-Leftwich (2010). The studies found a relationship between teachers' self-efficacy and level of technology integration and success. Barton and Haydn (2006) and Lai (2008) suggested that when teachers do not have high selfefficacy, they are less likely to successfully and meaningfully use technology in their instruction.

According to Bandura (1995), people's self-efficacy can be developed by four sources: a) mastery experience, b) vicarious experience, c) social persuasion, and d) physiological and emotional states. Among these sources, mastery experience is reported as the most powerful 
source to develop one's personal self-efficacy. According to Bandura (1995), people increase their self-efficacy through successful experiences. If teachers have successful experiences with the use of technology, their self-efficacy is more likely to be increased. However, success which comes without effort may not positively influence one's self-efficacy. Bandura (1995) mentioned that when people experience and expect easy success, they are easily discouraged by failure. That is, if a task is too easy for people to complete and people can expect that they can easily accomplish, when they face difficult task to complete, they are more likely to quit their work which impacts self-efficacy. Thus, Bandura (1995) said that certain levels of success and difficulty are important factors influencing self-efficacy.

The second most powerful source to help teachers develop their self-efficacy is vicarious experience (Ertmer \& Ottenbreit-Leftwich, 2010). Viewing other people who perform a task successfully can be a positive source to increase observer's self-efficacy to perform a similar task (Wang, Ertmer, \& Newby, 2004). That is, observing others who integrate technology successfully can positively influence the observer's self-efficacy to integrate technology. A study (Wang et al., 2004) demonstrated a positive effect of vicarious learning experience on pre/inservice teachers' self-efficacy for using technology in their teaching. Wang et al. (2004) conducted a study with 280 pre-service teachers who enrolled in an introductory educational technology course to examine the impact of vicarious learning experience on pre-service teachers' self-efficacy for technology integration. The pre-service teachers were randomly assigned to either control or experimental groups. The experimental group who watched videos through multimedia demonstrated higher self-efficacy than the control group. Although vicarious experience through observation of successful others can be a good source to increase teachers' self-efficacy, the effect of this experience would be limited unless pre/in-service teachers have 
opportunities to perform the tasks the way model did (Albino, 1999). That is, if pre/in-service teachers do not have opportunity to apply the concepts they have seen into teaching, the experience may have a limited effect on pre/in-service teachers' self-efficacy. Therefore, it is recommended that allowing pre/in-service teachers to have hand-on experiences to enhance selfefficacy.

In conclusion, teachers' confidence in integrating is another barrier reported by pre/inservice teachers when they try to integrate technology. As Ertmer and Ottenbreit-Leftwich (2010) said, even if teachers have appropriate knowledge related to technology, self-efficacy belief about their capability to integrate technology is another importance element for successful technology integration. However, efficacy itself may not be enough if teachers do not have positive attitude toward technology integration or do not view technology as a valuable instructional tools to increase student learning and teacher teaching effectiveness. Thus, the following section will explore how teachers' beliefs and value about technology integration influence teachers' practice.

Beliefs and attitude toward technology integration. Several researchers (Ertmer, 2005; Ertmer \& Ottenbreit-Leftwich, 2010; Russell et al., 2003) suggested that teachers' beliefs and attitude about technology use in classroom is the most influential factor in teachers' technology integration because teachers' beliefs have a strong relationship with teacher planning and teaching. Some teachers often consider technology as an unnecessary tool in teaching because they believe technology use in class may disrupt their instruction and require time to train and plan (Kopcha, 2012). If teachers do not see technology as a valuable instructional tool to enhance their teaching and students' learning, teachers are less likely to use technology in their teaching. 
In order for teacher educators to change one's personal belief, teacher educators should understand how beliefs are formed. Ertmer (2005) suggested that "beliefs are created through a process of enculturation and social construction." (p.30). That is, what people see, hear, and do influences their belief system. Person's previous experiences tend to influence his later experience. Depending on one's previous experiences, the one views later experience either positively or negatively (Ertmer, 2005). Researchers (Ertmer, 1999; Hixon \& Buckenmeyer, 2009) suggested that teachers' attitude and belief about technology integration are personal and more deeply rooted in their belief system. Thus, people may receive only when the information is corresponding to their belief, or they may manipulate the information to fit into their belief system. Changing teachers' existing attitude and belief about teaching and learning process is not an easy task. As described above, a person's attitude and belief are not easily changed or revised because they are deeply personal, highly engrained, and extremely resistant to change (Ertmer, 2005). However, it is not impossible to change them (Ertmer, 2005). Teachers' beliefs can change when they are not satisfied with their current instructional practice (Ertmer, 2005). Ertmer (2005) suggested that if teacher education programs want to be successful at changing pre/in-service teachers' belief about technology integration, teacher education programs should provide pre/in-service teachers with opportunities to challenge their current teaching, and provide opportunity to examine, elaborate, and integrate new information into their current belief system.

Ertmer (2005) suggested various learning activities that can help pre/in-service teachers challenge their existing beliefs and examine new beliefs. According to her, personal experience, vicarious experience, and social cultural influence can play a role in promoting change in teacher's attitude and beliefs. She said that through those experiences, teachers can experience 
new teaching practice and examine their own and others' practice. These experiences have impact on reshaping one's belief.

Beliefs are formed through personal experience (Ertmer, 2005). If a teacher has a new experience which is successful, the successful experience helps the teacher build confidence, which positively influence the teacher's belief system (Ertmer, 2005). Ertmer (2005) suggested that teacher education programs can introduce relatively simple use of technology to pre/inservice teaches, which allow pre/in-service teachers to have successful experience. However, other strategies, such as reflection and examination of other beliefs, should be used in combination with other strategies such as reflection and examination of other teachers' practice with technology (Ertmer, 2005). Questioning one's own beliefs and practice and the practice of others can also play a role in changing one's belief system. Through these experiences, teachers can reflect their own belief systems and compare them with others. If they see the value of others' beliefs and practice, they gradually replace their beliefs with more relevant beliefs. Ertmer (2005) suggested that these activities would promote changes of one's deeply rooted beliefs, knowledge, and teaching practice.

Individual's vicarious experience is another powerful tool to promote pre/in-service teachers' change in beliefs and practice. Observing others teaching with technology can not only provide pre/in-service teachers with information about how certain strategy and technology is used in classroom, but also provide them with opportunity to increase confidence integrating technology and to generate same instructional behaviors (Ertmer, 2005). Similiarly, Zhao and Cziko (2001) suggested that observing others successfully integrating technology might increase teachers' perception of the needs of technology integration. Finding from the study of Barton and Hayton (2006) support the idea. Barton and Hayton (2006) found that when pre-service teachers 
see someone doing something with technology that they wanted to do, they are more motivated to integrate technology. Thus, it is suggested that teacher education programs should provide pre/in-service teachers with opportunity for them to have vicarious experience through modeling. Teachers' practice and beliefs are shaped and revised continuously through on-going experiences as teachers and interaction with society and others around them, such as students, colleague, significant others, and professions (Ertmer, 2005). Putnam and Borko (2000) suggested that engaging in professional communities can help teachers change their beliefs and practice. In the professional communities, teachers interact with other teachers by sharing or discussing new materials, methods, and strategies (Putnam \& Borko, 2000; Zhao \& Frank, 2003). When having discussion with others who have different opinion and perception about teaching and learning, teachers can explore other perspective and practice which help them learn new teaching methods, tools, and beliefs about teaching and learning. Thus, providing teachers with enough time to interact with others (e.g. teachers, administrators, parents) and explore perspectives are recommended for teacher education programs to use (Ertmer, 2005).

Eliminating first order and second order barriers is a challenging task not only for teachers themselves but also teacher educators. However, there is a false assumption that if first order barriers are removed, technology integration will automatically follow. However, removing second order barrier would be more important to teachers' technology integration than first order barriers. Study by Ertmer, Ottenbreit-leftwich and York (2006) found that in-service teachers perceived first order barriers as significantly more influential factors than first order barriers. First order barriers can be easily eliminated by securing funding and support of school, but second order barriers are not simply removed because individuals' beliefs, attitude, and selfefficacy are deeply rooted in their belief system and they are not easily changed. It is believed 
that effective teacher education programs and PDP can prepare per/in-service teachers to overcome the two types of barriers through strategic planning when facing these barriers (Ertmer, 1999; Wyant et al., 2015). Therefore, the following section will be devoted to investigating strategies that teacher education programs and professional development programs (PDP) have used to train pre/in-service teachers to integrate technology into their teaching.

\section{Strategies to Train Technologically Literate Teachers}

Since International Society for Technology in Education (ISTE) established standards in 2008 for evaluating the skills and knowledge teachers need, strategies to effectively prepare teachers is an issue of interest to teacher educators. The ISTE standards describe skills and knowledge teachers must possess in order to help digital-age students engage in learning activity, and to improve their learning (ISTE, 2008). The standards of ISTE have helped teacher education programs and PDPs to effectively design their programs to produce technologically literate teachers.

Several teacher educators (Bai \& Ertmer, 2008; Barton \& Haydn, 2006; Brush et al., 2003; Brown, 2006; Chai, Koh, \& Tsai, 2010; Choy, Wong \& Gao, 2009; Ertmer, 2005; Harris, Mishra, \& Koehler, 2009; Hur, Cullen, \& Brush, 2010; Kay, 2006; Polly, 2011; Russell et al., 2003; Wyant et al., 2015) have suggested several strategies that have been used in teacher training programs or PDPs to train pre/in-service teachers who can integrate technology in their teaching in pedagogically sound ways. The strategies were mostly used to develop teachers' knowledge and skills necessary for successful technology integration. The following section will describe what strategies teacher educators have implemented in their teacher education programs and PDPs to prepare pre/in-service teachers who are competent and confident in integrating 
technology in their classroom. The table 1 describes the advantages and disadvantages of each strategy.

Kay (2006) and other researchers (Bai \& Ertmer, 2008; Barton \& Haydn, 2006; Brush et al., 2003; Brown, 2006; Choy, et al., 2009; Ertmer, 2005; Harris et al., 2009; Hur et al., 2010; Koehler \& Mishra, 2005; Kopcha, 2012; Lawless \& Pellegrino, 2007; Marra, 2004; Mouza, 2011; Polly, 2011; Russell et al., 2003; Thompson, Schmidt, \& Davis, 2003; Wang et al., 2004; Wyant et al., 2015) have reported several strategies that they have used to introduce instructional technologies to pre/in-service teachers. The identified strategies include: a) single course, b) access to technology, c) integrated, d) modeling, e) field-based, f) mentor teachers, g) collaboration, h) educate faculty, i) multimedia, j) workshops, k) combination, and l) other strategies. The following table provides a description of characteristics of each strategy (See table 1). These have been used to help pre/in-service teachers get familiarized with technology, increase technological knowledge and skills, and change their values and attitudes regarding technology use in teaching.

Strategies to Introduce Technology to Pre/In-service Teachers

\begin{tabular}{|c|c|c|}
\hline Strategy & Advantages & Disadvantages \\
\hline Integrated & $\begin{array}{l}\text { - Improvement of confidence and } \\
\text { technology skills } \\
\text { - Provides authentic experience with } \\
\text { technology }\end{array}$ & $\begin{array}{l}\text { - Amount of technology available in } \\
\text { teacher education program } \\
\text { - Limited faculty expertise and time to } \\
\text { integrate technology } \\
\text { - Difficulty to transfer learned skills to } \\
\text { real school setting }\end{array}$ \\
\hline Multimedia & $\begin{array}{l}\text { - Accessibility } \\
\text { - Modeling through online video } \\
\text { - Help pre/in-service teachers } \\
\text { understand how technology is } \\
\text { actually integrated in teaching }\end{array}$ & $\begin{array}{l}\text { - Difficult to achieve constructive } \\
\text { learning (hand-on experience) } \\
\text { - Lack of empirical evidence to support } \\
\text { effectiveness of the strategy }\end{array}$ \\
\hline Education & $\begin{array}{l}\text { - Creating cohesive and coordinated } \\
\text { environment for introducing }\end{array}$ & $\begin{array}{l}\text { - Faculty's acceptance and motivation to } \\
\text { integrate technology }\end{array}$ \\
\hline
\end{tabular}




\begin{tabular}{|c|c|c|}
\hline faculty & $\begin{array}{l}\text { technology and modeling its } \\
\text { effective use in classroom }\end{array}$ & $\begin{array}{l}\text { - Lack empirical evidence that the skill of } \\
\text { faculty can transfer to pre/in-service } \\
\text { teachers }\end{array}$ \\
\hline Single course & $\begin{array}{l}\text { - Introduce a wide range of } \\
\text { technology } \\
\text { - Provides good overview of } \\
\text { technology use in classroom } \\
\text { - Improve foundation of technology } \\
\text { skills } \\
\text { - Improve self-efficacy } \\
\text { - Can be used with other strategies }\end{array}$ & $\begin{array}{l}\text { - Learning occurs in an isolated } \\
\text { environment making it difficult to } \\
\text { transfer learned skills to real school } \\
\text { settings }\end{array}$ \\
\hline Modeling & $\begin{array}{l}\text { - Provides good examples of } \\
\text { technology use in real school } \\
\text { settings } \\
\text { - } \\
\text { Allows leaners to transfer skills } \\
\text { directly to real school settings } \\
\text { - }\end{array}$ & $\begin{array}{l}\text { - Faculty's ability to demonstrate } \\
\text { meaningful example of technology use } \\
\text { - Lack of hands-on experience of learner }\end{array}$ \\
\hline Collaboration & $\begin{array}{l}\text { - Opportunities to explore and } \\
\text { practice in supportive environments } \\
\text { - Collaborative work which allows } \\
\text { teachers to learn from each other } \\
\text { - Develop positive relationships } \\
\text { between university and schools } \\
\text { - Increase the comfort level of } \\
\text { teachers' technology use }\end{array}$ & $\begin{array}{l}\text { - Requires considerable time to organize } \\
\text { and develop effective learning } \\
\text { community } \\
\text { - Motivation of all members to participate }\end{array}$ \\
\hline
\end{tabular}

Field-based $\quad-$ Constructive learning

- Allows to transfer learned skill into real school settings

- Help to change attitude and beliefs about technology use in teaching

- Needs other strategies to help develop learners' technology skills

Workshops - Time efficient

- Can combine other strategies

- May not provide enough time to develop technology skills

- Lack of empirical evidence of long-term effects on attitude and teaching behavior regarding technology use in class

- On-going support following the workshop is critical

Access - Extensive technology support

- Allows learners to explore

- Needs other strategies for meaningful technologies

- Improves technology skills 
- Help to change attitudes and beliefs about technology use in class

$\begin{array}{ll}\text { Mentor teachers } \quad \text { - } & \text { Potential to promote learner's } \\ & \text { effective technology use in } \\ & \text { classroom } \\ & - \text { Takes less time to organize than } \\ & \text { collaboration strategy }\end{array}$

- Limited empirical evidence of its effectiveness on teachers' instructional behavior regarding technology use in class

Note. Adapted from Kay, R. (2006). Evaluating strategies used to incorporate technology into pre-service education: A review of the literature, Journal of Research on Technology in Education, 38, 383-408. 
Integrated. One strategy teacher education programs have used to train teachers to use technologies is an integrated strategy. This strategy integrates technologies across teacher education program curriculum (Kay, 2006) so that pre/in-service teachers can have plenty of experience using technology for their learning while they are in teacher education programs (Lawless \& Pellegrino, 2007). This strategy is found to be effective when improving pre/inservice teachers' technology skills and confidence (Kay, 2006). Since pre/in-service teachers have hands-on experiences using technologies for an extended period of time, it is believed that their actual experience with technology can have a positive impact on pre/in-service teachers' ability to transfer the learned knowledge and skills to teaching situations (Choy, Wong, \& Gao, 2009), and on their attitudes toward integrating technology in their teaching (Bai \& Ertmer, 2008). However, access to technologies and faculty members who have sufficient skills to integrate technology in their courses in meaningful ways should be secured for this strategy to be effective (Kay, 2006). In addition, enough curriculum space and time for faculty members to plan technology-integrated lessons should be secured. Wyant et al (2015) suggested that lack of curriculum space and time for faculty members to plan technology-integrated courses make teacher education programs difficult to train pre/in-service teachers.

Multimedia. Multimedia strategy is another technology integration training strategy that has been used in teacher education programs (Kay, 2006). Pre/in-service teachers are educated to integrate technology in several forms, such as online courses (Marra, 2004), technology case studies, and portfolios (Wang et al., 2004; Hur et al., 201). Marra (2004) suggested that online courses can be a convenient tool to teach important skills and demonstrate adequate ways to integrate technology. With this strategy, pre/in-service teachers can easily access professional development regardless of time and place (Kay, 2006). However, the problem of this strategy is 
that if teachers do not have fundamental technology skills and knowledge before taking online courses, students' focus will be on learning technology skills rather than developing a deep understanding and practicing application of the technology skills into teaching (Marra, 2006). For example, Marra (2004) found that students who took online classes focused on how to use Blackboard and how to download software programs instead of using the programs to teach a certain content. The result of this study implied that learning through online programs without proper technological skills interferes with learners' ability to achieve constructive learning.

Hur et al. (2010) used a multimedia strategy in different way. They implemented online case studies to help pre-service teachers view technology-integrated classrooms and evaluate them critically. They required pre-service teachers to analyze and critique the technologyintegrated classrooms. This strategy was found to be effective for pre-service teachers to critically see technology-integrated classrooms and giving them a better idea of how to integrate technology when teaching. Another study by Wang et al. (2004) used multimedia (video and web-based technologies) to show pre-service teachers how technologies are actually implemented in classroom. The study found that teachers' ideas and self-efficacy about technology integration were increased through multimedia learning. However, there is a lack of empirical evidence supporting the effectiveness of multimedia on teachers' technology integration. Thus, more research on this topic is needed to support the effectiveness of this strategy.

Faculty education. Faculty education is another strategy that teacher education programs have used to train pre/in-service teachers' adoption of integrated uses of technology. There is a belief that faculty members' positive attitude toward technology integration in teaching and their ability to integrate technology in their instruction have a positive impact on shaping pre/in- 
service teachers' attitudes toward technology use (Kay, 2006). Wyant et al. (2015) stated that if faculty members are not trained to use technology and do not accept the value of technology integration, faculty members are unlikely to allow pre/in-service teachers to use technology for instruction. Wyant et al. (2015) continued to suggest that when faculty members meaningfully use and reinforce technology, technology-related learning experiences can be woven across teacher education curriculum so that pre/in-service teachers can both observe technology use in the classroom and gain hands-on experiences for their learning. However, the problem of this strategy is that there is no clearly empirical evidence of effectiveness on pre-service teachers' technology use. Despite the lack of empirical evidence of this strategy, several researchers have implemented this strategy to educate faculty members to improve their attitude and technology skills (Kay, 2006). A study by Milken Exchange on Education Technology (MEET) (Moursand \& Talbot, 1999) found that student technology skills are comparable to the technology skills demonstrated by the faculty. That is, the higher faculty members have technology skills, the more likely their students have high technology skills. This study indicated the importance of faculty members' technology skills to enhance pre-service teachers' technology skills. However, in order for this strategy to be effective, faculty members must see educational benefits of technology use and agree to integrate them in their classes. If faculties don't, they are unlikely to learn and use technology in their courses.

Single course. A single course is one of the widely used strategies across teacher education programs to introduce a wide range of technologies and to teach and develop pre/inservice teachers' technology skills and knowledge (Kay, 2006). A technology course can help pre/in-service teachers develop basic knowledge and skills about technology and change pre/inservice teachers' attitudes and self-efficacy (Ertmer, 2005; Kay, 2006). Wyant et al. (2015) 
contended that implementation of a single course strategy in physical education teacher education (PETE) program is effective in developing teachers' knowledge, technology skills, and self-efficacy. However, single course alone is not enough for pre-service PE teachers to pedagogically integrate technology in their teaching (Wyant et al., 2015) because short-term exposure to technology is not enough for teachers to develop skills and knowledge related to technology integration (Choy et al., 2009). Another problem with this strategy is that pre/inservice teachers learn to teach with technology in an isolated environment (Kay, 2006). Learning skills in an isolated environment does not allow pre/in-service teachers to have an opportunity to use technology in an authentic setting, which makes them extend the learned skills in an authentic classroom environment. The lack of authentic experience makes teachers fully understand complexity of teaching and learning with technology (Kay, 2006; Lawless \& Pellegrino, 2007; Wyant et al., 2015). Thus, several other strategies (ex. field-based and modeling) are suggested to be combined with a single course.

Modeling. Many researchers (Barton \& Haydn, 2006; Brush et al., 2003; Choy et al., 2009; Ertmer, 2005) have suggested modeling to enhance pre-service teachers' use of technology in their teaching and learning. This strategy is found to be effective to enhance pre/in-service teachers' knowledge, skill, confidence, practice, motivation, and belief (Barton \& Haydon, 2006; Kopcha, 2012; Hur et al. 2010; Marra, 2004).

Teachers teach the way they were taught, and what teachers see and experience plays an important role in shaping their own beliefs and behaviors (Choy et al., 2009). Ertmer (2005) suggested that pre-service teachers' knowledge about teaching is often limited to their own experience. The limited experience often constraints their view of teaching and learning. Researchers (Brown \& Warschauer, 2006; Niess, 2005) contended that pre-service teachers have 
a limited opportunity to see teachers demonstrating effective technology integration. This limited opportunity for pre/in-service teachers makes it difficult to picture how technologies are integrated in pedagogically sound manners, which decrease likelihood of teachers' technology use in teaching (Marra, 2004).

Observing good example of technology integration can increase teachers' self-efficacy with regarding to technology integration and expand their view of teaching and learning with technology (Ertmer, 2005; Hur et al., 2010). Teachers' vision and self-efficacy on technology use in teaching significantly influence their own instructional practice with technology (Ertmer, 2005). When teachers can see others who effectively and meaningfully integrate technology, their confidence for generating the same teaching behavior is more likely to occur.

Along with improvement of self-efficacy and vision on teaching with technology, pre/inservice teachers can a) understand how different or various technology can be implemented and how these technologies can be managed or organized in classroom, and b) find potential problems of the observed technology integration and possible solutions to how they can be minimized when they are integrating technology in their teaching through observation (Kovalik et al., 2013). However, if the model does not demonstrate meaningful and effective technology integration examples, it may cause negative impact on pre/in-service teachers' attitudes and practice (Kay, 2006). Thus having models that can provide meaningful technology integration examples is an important task for teacher education programs and PDPs.

Collaboration. Another strategy that has been used in teacher education programs and PDPs is collaboration. (Hur et al., 2010; Thompson, Schmidt, \& Davis, 2003). The purpose of this strategy is to create learning community so that teachers in the learning community share ideas and support each other. This strategy is usually used in two ways: partnership with other 
parties such as university and public schools and collaborative work with classmates. When it is used in conjunction with partnership with public schools, pre/in-service teachers are placed in public schools and matched with technologically expert teachers. In addition, this strategy is usually used alongside with field-based experience. Thompson et al. (2003) suggested that a teacher education programs must provide students with quality technology-rich field experiences.

In the study by Thompson et al. (2003), a collaborative strategy was implemented. In their study, pre-service teachers were placed in public schools and they collaboratively worked with their peers and site teachers to identify possible ways to create technology-rich field experience. The study found that both parties (pre and in-service teachers) can benefit from collaborative work. Thompson et al. (2003) suggested that the collaborative work not only helped pre-service teachers to plan technology-integrated lesson with support, but also help inservice teachers to reflect and evaluate their own teaching. The study (Thompson et al., 2003) found that as a result of collaborative work, in-service teachers viewed technologies as instructional tools and used them for instruction rather than recreational tools (game). These results are consistent with the idea of Ertmer (2005). Ertmer (2005) suggested that observation of other teachers' classes and ongoing interaction with other teachers can help teachers change their beliefs and values toward technology integration.

Study by Barton and Haydn (2006) also suggested another way to use collaborative work with classmates in teacher education program to enhance pre-service teachers' planning skills. Barton and Haydn (2006) found that small group work and changing composition of working group helped pre-service teachers get benefits from gaining insight from many individuals. Another study by Kay (2007) found that pre-service teachers preferred collaboration with other 
pre-service teachers, and when pre-service teachers worked together with other pre-service teachers, their technology skills seemed to be increased. However, in order for this strategy to be effective, lots of time and effort to organize and design an effective learning community are needed (Kay, 2006). Also, both parties (university and public schools) involved in the learning community must be motivated (Kay, 2006).

Field-based. Field-based strategy is a technology integration strategy that is strongly supported by teacher educators (Baert, 2011; Hur et al., 2010; Lim, Chai, \& Churchill., 2011) because it is believed that "decisions about when to use technology, what technology to use, and for what purposes cannot be made in isolation of theories and research on learning, instruction, and assessment (Lawless \& Pellegrino, 2007, p.581).” Teacher educators believe that fieldbased strategy provides pre/in-service teachers with opportunity to have authentic and practical experience to make sense of theoretical knowledge and practice through planning, practicing, and evaluating their own technology-integrated lessons (Baert, 2011; Brush et al., 2003; Hur et al., 2010; Lim et al., 2011). Situating pre/in-service teachers in the school-based learning environment rather than an isolated environment would help them better transfer their knowledge and skills to a school context and help them take more ownership of their resource and instruction with technology (Choy et al., 2009; Lawless \& Pellegrino, 2007).

As discussed in the previous section, Ertmer (2005) stated that teachers' beliefs and values regarding technology integration play an important role in shaping their teaching practice with technology. Successful experience of technology integration in real school setting can have a positive impact on teachers' beliefs and values (Ertmer, 2005). A study by Kay (2007) conducted a study to examine effectiveness of technology integration strategies on pre-service teachers' technology skills and knowledge to integrate technology. In his study, field-based 
strategy was the most effective strategy among four other strategies used for pre-service teachers to learn how to teach with technology. The survey he used revealed that pre-service teachers perceived the field-based experience as the most helpful. He continued to say that active engagement in assignments using technologies and planning for instruction helped pre-service teachers receive a full benefit of authentic experience. Other study by Brush et al. (2003) also found effectiveness of field-based strategy to overcome barriers impeding the use of technology in teaching and learning such as knowledge and skills. Although authentic experience allows teachers to link theory to practice and increase technology integration skill, other strategies, such as project based, reflection, or modeling, have been recommended to use the field-based experience (Choy et al., 2009; Kay, 2006).

Workshop. Workshop is the most common strategy that PDPs usually use to provide for pre/in-service teachers to introduce new contents or teaching methods (Lawless \& Pellegrino, 2007). The workshops are usually short-focused seminars or labs helping pre/in-service teachers teach technology integration. In workshop, in-service teachers spend as little as 1 hour to 1 day to learn about new technologies and how to operate those (Lawless \& Pellegrino, 2007). This type of technology integration training approach is often criticized by researchers because of its ineffectiveness to train teachers to integrate technology in teaching. Harris, Koehler and Mishra (2009) said that PDPs tend to focus on affordances and constraints of technologies and how to use them rather than how to integrate them in classroom. This may be because workshop is too short for teachers to fully understand effective technology integration. Similarly, researchers (Ince, Goodway, Ward, \& Lee, 2006; Kay, 2006) suggested that one-time workshop is not enough for teachers to develop technology skills and understand how they can be used in instruction. Ince et al. (2006) found that workshop was not enough to change PE teachers' 
behavior related to technology use. Ince et al. (2006) suggested that on-going support along with workshop is critical in PDPs to help in-service teachers change their practice with technology.

Access to technology. Allowing pre/in-service teachers to access particular technology is a critical element influencing teachers' technology use. Kay (2006) suggested that access to technology is a very important element of teachers' use of technology. As mentioned in the previous section, teachers have reported that lack of resources and accessibility to technologies is factors that negatively influence their technology integration the most (Choy et al., 2009). If pre/in-service teachers have limited access to technology, it is difficult for teachers to have a positive attitude about teaching with technology and to implement technology integrated lessons (Kay, 2006). Study by Russell et al. (2003) found that teachers who could access to a particular technology demonstrated a positive attitudes and values toward technology use in education. The study found that the more time teachers are exposed to a particular technology, the teachers become more likely to have positive attitudes and values about technology use in education, which in turn positively influences their technology use in their instruction. Similarly, Wyant et al. (2015) contended the importance of technology access in pre-service PE teacher education programs. He found that allowing pre-service PE teachers to explore a particular technology could have a positive effect on attitudes and confidence of pre-service PE teachers. One of his participants mentioned that "I've enjoyed the fact that we have got to use some of pieces [of technology] outside of the classroom and really get comfortable with the technology" (Wyant et al., 2015, p.41).

However, merely exposing teachers to particular educational technologies are not enough for teachers to effectively integrate technology into their teaching (Harris, Mishra, \& Koehler., 2009). Juniu et al. (2013) suggested that even if pre-service PE teachers have easy access to 
technology, merely providing technologies to pre-service PE teachers without effective modeling and instruction does not help those teachers to bring technology into the classroom and use it for student learning. Thus, other strategies (e.g. modeling or field-based) have to complement with this strategy in order to help pre/in-service teachers deeply understand meaningful technology integration for teaching and learning.

Mentor. Several researchers have suggested a mentoring strategy (Brush et al., 2003; Lawless \& Pellegrino, 2007; Thompson et al., 2003; Polly, 2011). Mentor teacher strategy is usually used in combination with field-based or collaboration strategy in teacher education programs and PDPs (Brush et al., 2003; Lawless \& Pellegrino, 2007; Thompson et al., 2003; Hur et al., 2010). Pre/in-service teachers are usually placed in schools and matched with other teachers who can provide advice or feedback about technology integration. Mentor teachers usually provide support and feedback to pre/in-service teachers when it is needed and also share ideas together (Brush et al., 2003; Thompson et al., 2003). This strategy can not only help pre/inservice teachers reflect on their teaching practice and re-evaluate their personal beliefs, which can help them see a new vision of technology use in teaching, but also increase confidence with using technology.

A study by Kopcha (2012) found a positive influence of mentor teacher on in-service teachers' vision and their technology use. One participant from her study stated that "I got over my fear of technology by doing it with a mentor. This changed by beliefs about myself most. I could see what I could do" (p.1116). Another participant mentioned "after working with the mentor, I'm more able to come up with programs that fit the curriculum. I'm no longer looking for what I can do, but choosing from what I know is available (p.1116).” In the study of Thompson et al. (2003), this strategy was not used only for pre-service teacher development. The 
strategy was also used for faculty development. Faculty members were matched with technology scholars. Technology scholars shared ideas with faculty members and demonstrated effective uses of technology. Thompson et al. (2003) found that "the opportunity to share and learn from others is extremely important to them as they integrated technology into their courses." (p.82).

Similarly, Polly (2011) stated that mentor's feedback and assistant during the planning and implementation period is important because they played a positive role in developing inservice teachers' TPACK and their technology use in their instruction. One of his participants commented that "I really feel that my strongest lessons were the ones that I got feedback on. I just needed help during planning to help me move in the right direction" (p.91). This comment appeared to show a positive influence of mentoring on in-service teachers' technology use in the classroom. However, no clear relationship between planning support and implementation were found although there was some evidence that co-planned lessons resulted in high level technology use than planned independently. Polly (2011) concluded that teachers need an extensive time and support to pedagogically integrate technology in their class and need to coplan lesson with more knowledgeable others before they are independently designing and implementing technology-integrated lessons. This help to increase teachers' TPACK.

Although several studies implemented mentor strategy to educate pre/in-service teachers or faculty members, this strategy is usually used in conjunction with other strategies. Thus, it is difficult to conclude that the mentoring strategy is the sole factor in increasing pre/in-service teachers' technology integration. However, this strategy has a potential to promote and create effective technology integration lesson planning (Kay, 2006).

Combination. Teacher educators do not use only one strategy to teach pre/in-service teachers how to integrate technology in teaching. Instead, multiple strategies are usually 
implemented to offset the weakness of each strategy (Chai et al., 2010; Hur et al., 2010; Mouza, 2011; Polly, 2011; Wyant, 2012). Mouza (2011) implemented several strategies (single course, modeling, collaboration, field-based experience (case development in her study), and reflection) to help in-service teachers enhance their knowledge and skills related to technology integration. This strategy was found to be effective helping in-service teachers develop TK and TPK. She stated that in-service teachers' ability to connect technology with lesson content and pedagogy was strengthened as a result of the combination strategy. Another study by Hur et al. (2010) also implemented multiple strategies (single course, modeling, collaboration, hands-on experience, authentic experience, and reflection) in a systematic order to help pre-service teachers improve knowledge, skills, and understanding of technology integration. In their study, pre-service teachers reported that their comfort level of using technology was increased, and they were able to identify appropriate technologies for effective technology integration as a result of the combination strategy. Hur et al. (2010) stated that reflection is a critical component of teacher learning to technology. As discussed in the previous section, Ertmer (1999) stated that teachers evaluate their beliefs and practice when reflecting their beliefs and practice. Through reflection, teachers can change their beliefs and practice when they are not satisfied with their existing teaching and beliefs. Thus, reflection with other strategies is recommended by researchers because they are more likely to evaluate their practice and redesign their teaching to better meet diverse students' needs and differences when they reflect on their teaching.

Wyant et al. (2015) conducted a study examining the effectiveness of a single course focusing on instructional technology in PE. Within the single course, several strategies such as single course, modeling, and project-based learning were implemented. Wyant et al. (2015) found that the single course using multiple strategies was effective at increasing pre-service PE 
teachers' self-efficacy and their TK and TPK. He suggested that allowing pre-service teachers to experience a variety of technologies throughout curriculum may help to enhance pre-service teachers' perceived value and usefulness of technology use in instruction.

Other strategies. In addition to ten strategies, Kay (2006) identified, Harris et al. (2009) introduced a new strategy (learning activity type), which was developed based on TPACK framework, to help pre/in-service teachers develop their knowledge regarding technology integration. According to Harris et al. (2009), depending on curricular, student learning style, contexts, and contents, teachers need to understand different pedagogical strategies and technologies that can help to increase student learning. Merely using technology in teaching does not mean that the instruction has quality (Juniu, 2011). The quality instruction requires teachers to understand the goal of the lesson and contents and then select appropriate technologies to support their lesson goal rather than planning instruction according to technologies they selected (Harris \& Hofer, 2009). Thus, Harris and Hofer (2009) introduced a learning activity type model. This model is a systematic instructional design model which requires pre/in-service teachers a) to identify a range of possible learning activities within a particular content area based on curriculum and standards, b) to identify possible technologies and match them with learning activities to support each type of learning activity, and c) to select appropriate teaching methods and implement the teaching methods (Harris et al., 2009). Juniu (2011) said that when using learning activity types for teaching with technology, the following four questions can help teachers plan technology-integrated lessons: a) "what do the individual students need to reach their goal?, b) what strategies are appropriate for this particular lesson?, c) what teaching strategies are being used?, and d) what digital technologies are pedagogically appropriate?" (p.42). Juniu (2011) suggested that this model can be used in the "learning technology by 
design" model (Koehler \& Mishra, 2005). According to Juniu (2011), the following steps can help pre-service PE teachers come up with learning activity using technology in pedagogically sound ways: a) give pre-service PE teachers a problem to solve, b) ask them to work as groups to brainstorm and find solution for the problem, c) ask them to investigate their subject matter, d) organize their ideas, e) find effective ways to represent their content, and f) select appropriate technology. She suggested that through these steps, pre-service PE teachers can develop their technology skills and have an authentic experience related to technology integration.

In summary, various ways to train pre/in-service teacher to integrate technology into their instruction have been introduced and studied by several researchers. This review of the literature found that a few strategies (workshop, mentoring, access to technology, and combination) had been implemented in PDPs. Although the strategies described above are available for teacher education programs and PDPs, pre/in-service teachers are not adequately prepared to integrate technology into their teaching. This may be because of the teacher educators' assumption that just exposing teachers to particular educational technologies and possible curriculum-based uses of those tools and resources can help pre/in-service teachers integrate technology, and because of the techno-centric approach of teacher education programs and PDPs (Harris, Mishra, \& Koehler, 2009).

Pierson (2001) stated that teachers need appropriate knowledge and skills regarding technology integration to optimize their instruction and their students' learning. In order for teacher education programs and PDPs to appropriately train per/in-service teachers to use technology in classrooms, teacher educators should understand not only variety of strategies to teach pre/in-service teachers how to integrate technology but also how teachers learn to teach. 
Therefore, the next section will be devoted to exploring studies on how teachers and coaches learn to teach.

\section{Teacher Learning}

Teaching involves a combination of complex and dynamic skills. Specific to physical education, teachers must acquire content-specific knowledge and skills related to sport, physical activity, and movement (Cushion, Armour, \& Jones, 2003). Those involved in teacher training understand the developmental process of learning to teach; therefore, this section will describe what is known about how teachers (and coaches) learn. Studies reviewed in this section focused on how coaches learn to coach. The reason why this section focused on coaches' learning was that I believed the coaching and teaching PE shares same concepts and context. While coaching majorly deals with sports, PE deals with sports and physical activity. Although the focus of these two may be subtly different, it is assumed that the knowledge and skills needed for coaches and PE teachers are very similar.

Teachers learn to teach from a variety of sources. Moon (2004) identified that teachers learn to teach their contents through three major learning situations: mediated, unmediated, and internal situations, which influence teacher's cognitive structure. Mediated learning situations refer to a learning situation where learning occurs directly by another person or through materials, which simplify the materials of teaching (Moon, 2004). In this view of learning situation, Moon (2004) views learning as unable to be separated from instruction because there is no learning without instruction. Teachers play an important role because they are the source of knowledge for students. They design classes with clear intention and goals to instruct students. Through their instruction, students acquire new information and new behaviors. Mediated learning situation may include university courses, workshops, conferences, distance learning 
programs, or printed materials (book or textbook) that have been created by an instructor or professor.

Another form of teachers' learning is through unmediated learning situation. Unlike mediated learning, there is no instructors or professors who direct students' learning. Instead, the students (PE teachers in this study) choose what to learn about something and initiate their own learning (Moon, 2004). In this view of learning, people can learn from everyday activities they do without the direct guidance of the instructor. The unmediated learning situations may include conversation and discussion with other teachers, searching the Internet, watching videos, or reading articles.

The last learning situation is the internal learning situation, otherwise known as reflection, which refers to "learning situation where there is no new material of learning coming from either a mediated or unmediated learning situation (Werther \& Trudel, 2006, p.204)”. This way of learning is found to be effective and has potential to improve coaches' knowledge (Gilbert \& Trudel, 2005). The following figure describes three types of learning situations and how teachers/coaches learn to teach. Although learning situations are distinguished in here, teachers can learn to teach through a number of different learning situations at the same time (Werther \& Trudel, 2006). 
Figure 2. Model of Coach Learning in Different Learning Situations

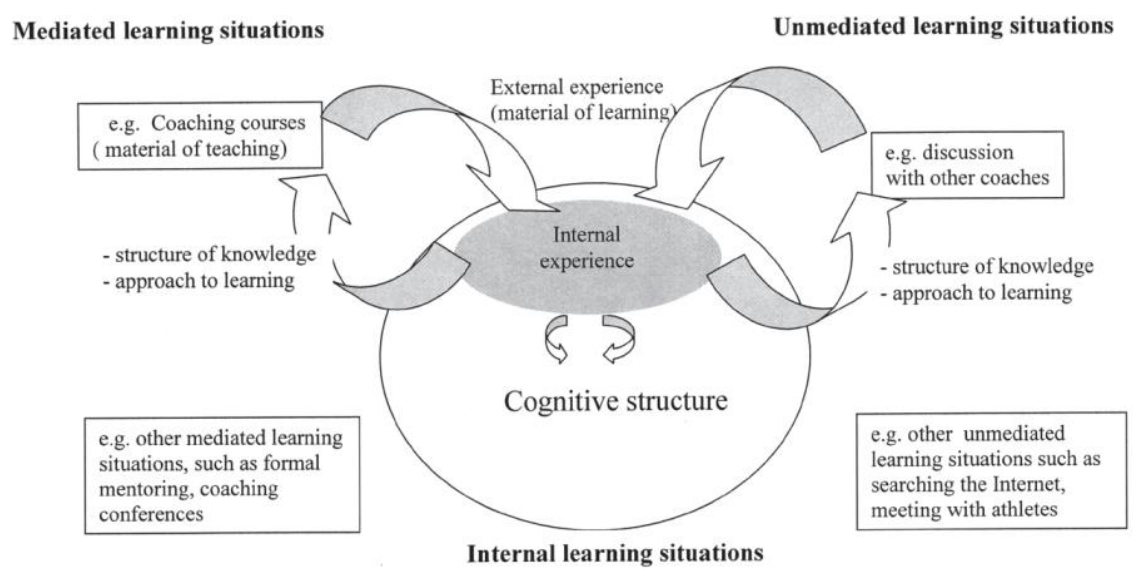

Adapted from Werther and Trudel (2006). A new theoretical perspective for understanding how coaches learn to coach. The Sport Psychologist, 20, 198-212.

In the field of sports, researchers (Lemyre, Trudel, \& Durand-Bush, 2007; Wright, Trudel, \& Culver, 2007) found that coaches learn to coach through three different mediated learning situations such as coaching clinics, formal mentoring, and National Coaching Certification Programs (NCCP), which is PETE program in the case of physical education teachers. Wright et al. (2007) suggested that even if coaches reported that these are the sources where they can learn to coach, their perception regarding the importance of each source varied. Also, even if coaches received the same formal education or had the same mediated learning situations, their perception toward mediated learning situations can be different (Werther \&Trudel, 2006). This is because their cognitive structures, internal experiences (previous experiences), understanding of the nature of the learning process, and conceptions of the structure of knowledge are very different, which influences their approach to learning (Werther $\&$ Trudel, 2006). For example, in the study of Werther and Trudel (2006), a participant reported that he 
perceived his university course as a helpful learning experience, but he did not receive the information delivered by the course instructor passively. The participant listened to what the instructor said and saw if it made sense to him, and then make changes to him if he believed the information was useful and appropriate for his coaching. His conception of the process of learning and structure of knowledge influenced his approach to learning. Rather than passively understanding information delivered by the instructor without relating it to his previous experience and knowledge, he sought the meaning and understanding of the information and connected the information to his previous experience and knowledge. This is consistent with a constructivist view of learning. People's cognitive structures guide us what to pay attention to, what to learn, and how we modify what we know already (Moon, 2004). "The process of learning is not about the accumulation of material of learning, but about the process of changing conceptions" (Moon, 2004, p. 17).

With respect to teachers' preferred learning source, Christensen (2014) found interesting information. She examined expert coaches' preferred learning situations. She found that expert coaches considered mediated learning situations (formal coaching programs) as a minimum importance source of their knowledge development because they perceived that the programs underestimated how differently coaches develop and expand their knowledge. That is, the programs do not consider each coaches' different abilities and needs. Meta-analysis study of Cushion et al. (2010) found that coaches' experience and perception of formal coaching programs were as followings: a) the courses provide little more than basic concept of coaching, b) coaches already know what the courses cover, c) some of the theoretical materials in the course is not practical or too abstract, and d) too much information is covered in short period of time. However, coaches in Christensen's study (2014) said that formal education programs are 
important because they provide coaches with opportunities to meet others and share ideas and thoughts. This finding is interesting because the coaches did not perceive their formal coaching programs as places providing them with useful information and helping them develop coaching knowledge. Rather, they considered the coaching programs as places where they can meet other coaches and share ideas. This is consistent with the finding of Lemyre, Trudel, and Durand-Bush (2007). Coaches perceived formal coaching programs as places that allow them to interact with others and develop friendships. However, Erickson, Bruner, MacDonald, and Cote (2008) found that coaches perceived formal coaching education programs as a top source of knowledge in coaches' knowledge development. Erickson et al. (2008) provided two possible explanations for this conflicting result. According to them, the coaches in their study are level two or three coaches, which means that they are not coaching elite athletes. When teaching non-elite or preathletes, the formal education can be a good source for coaches to develop their knowledge and skills. Another explanation is that coaches may have learned to coach too much by trial and error so that they would prefer more guided learning opportunities.

A study by Lemyre et al. (2007) may in part support the opinion of Erickson et al. (2008). Lemyre et al. (2007) found that coaches' experience as athletes and coaches influence their perception regarding the importance of formal education program. If coaches do not have previous coaching or athletic experiences, formal coaching education programs can be a very good source for them to learn the basic notion of coaching and teaching. It seems that the learning source of coaches may be different based on their coaching level, previous experience, and contexts. These studies may show that formal education programs can be very informative for coaches who just start coaching or work at low-level of coaching, but the course may not effective for those who coach at a higher level because the programs may fail to cover complex 
contextual factors (Lemyre et al., 2007). Thus, more research on coaches' perception about formal coaching education is needed.

Unmediated learning situations can be considered as another important source for teachers to learn how their subject matters because the experience they have can be very meaningful to them (Werther \& Trudel, 2006). This type of learning is often referred to informal learning or self-directed learning and takes place in many forms in a wide variety of contexts. According to the meta-analysis study of Cushion et al. (2010), unmediated learning situations may include discussion with others teachers or students, observation of others, mentoring, reading coaching manuals and articles, watching sport science videos, recording other coaches and athletes, and exploring the Internet (Cushion et al., 2010). Studies found that coaches prefer this type of learning to mediated learning situation. A study by Christensen (2014) found that expert coaches learned important skills and had important experiences through unmediated learning situations such as informal networking, mentoring, and observation of other coaches and players. Learning from mentors has been discussed by many researchers (Lemyre et al., 2007). Christensen (2014) found that expert coaches preferred to learn from their role models and networking with them. Similarly, Lemyre et al. (2007) found that many novice coaches have access to some kind of mentoring and perceive this as an important source of learning to coach. Christensen (2014) found that observation of role model played an important role in developing coaches' view of themselves. By observing their role model, coaches reflect on their current practice in the practice of their role model. However, a study by Erickson et al. (2008) found conflicting results. They said that coaches in their study perceived that the formal education setting was a primary source of the coaches' knowledge. Erickson et al. (2008) explained that the conflict results from previous studies might be due to the characteristics of participants in their 
study. While previous studies focused on elite level coaches, the participants of Erickson et al.'s study included coaches ranging from 2 to 43 years so some of the coaches were a novice and some of them were expert. These different characteristics of participants might cause the conflicting results.

Observing a role model and working with the role model and receiving feedback from $\mathrm{him} / \mathrm{her}$ can be a good source to develop knowledge to teach. It seems that learning can occur best when one interacts with others who are more experienced and knowledgeable than him/her. However, coaches should keep in mind that "there is a danger in being limited to only one way to learn how to coach (Werther \& Trudel, 2006, p. 199)”.

Another type of learning within unmediated learning situation is experimental learning, or learning through experience. This type of learning is consistent with the concept of constructivism: Learning is most effective when one use knowledge and skills they learned, and one construct meanings for himself/herself in the context of socializing with others (Cushion et al., 2010). This type of learning situation often works with internal learning situation (reflection). Erickson et al. (2008) suggested that the primary source of coach's learning is through experience. Erickson et al. (2008) said following:

"mechanism of knowledge gain through participating in coaching (learning by doing) may in fact be reflection in and on these experiences. By consciously monitoring what behaviors, decisions, or strategies are successful or unsuccessful and why, coaches may discern components of personally effective coaching practice. (p.534)”.

Similary, Gilbert and Trudel (2005) reported that coaches learn from their own experiences: experience from their teaching or experience with other coaches. Through their own experiences, coaches take the time to reflect on their techniques, training programs, and their students (athletes) (Werther \& Trudel, 2006). Literature has said that one's reflection can also be occurred through dialogue with others such as other teachers or students (Werther \& Trudel, 
2006). Sometime, coaches ask advice to solve coaching issue they face. During a conversation with other coaches, coaches reflect on what issues were, what caused the issues, and jointly construct a solution to solve coaching issues (Lemyre et al., 2007). This idea is consistent with the idea of Cushion et al. (2010). They suggested that learning, thinking, and activing are not separate activities (Cushion et al., 2010). That is, people are learning while they are doing. Although these unmediated learning situations are an important source for teacher development, time and space to meet others to share their knowledge are a limiting factor for coaches (Lemyre et al., 2007). Also, the level of ability to learn by oneself, openness and eagerness to create new learning opportunities, and looking for information are other important characteristics that teachers must possess for their continuous learning (Werther \& Trudel, 2006). Although researchers identified three major learning situations that teachers learn to teach, teachers can learn to teach through a number of different learning situations at the same time (Werther \& Trudel, 2006).

In summary, this section was devoted to examining how coaches learn to coach. The literature on coach learning have demonstrated that coaches learn to coach through three major learning situations: mediated, unmediated, and internal learning situations. Although these learning situations are distinguished in this literature review, coaches use a variety of sources to learn to teach, rather than seeking for one source to learn to coach. According to studies, coaches perceive each learning situations differently due to their individual differences, such as cognitive structure, previous experience, understanding of the nature of the learning process, and conception of the structure of knowledge (Moon, 2004; Werther \& Trudel, 2006).

This concept can be applied to PE teachers' learning to integrate technology in PE classes. Since PE teachers' cognitive structure, knowledge, skill, and experiences are different, 
their preferred sources will be different. Next section will describe teachers at different stages of technology integration and what sources, educations, and supports are needed for those who at a variety of developmental stage of technology integration.

\section{Teachers' Developmental Stages of Technology Integration}

Several researchers suggested that teachers are at various stages in their knowledge and use of technology when attempting to integrate technologies, and these stages are developmental (Holland, 2001; Russell, 1995). According to Russell (1995), teachers move through six developmental stages to be confident technology users: a) awareness, b) learning to process, c) understanding and application of the process, d) familiarity and confidence, e) adaptation to other contexts, and f) a creative application to new context. Teachers may move from any stage and progress to each stage at their own pace. The descriptions of each stage are as followings:

a) Awareness (stage 1): the teachers at this stage understand the existence of technology, but have not used technologies. Sometimes, the teachers actively avoid using technologies.

b) Learning the process (stage 2): the teachers at this stage are trying to learn basic technology skills but are often easily frustrated when using technology. Also, the teachers at this stage do not feel comfortable using technologies.

c) Understanding and application of the process (stage 3): the teachers at this stage are starting to understand the use of technology and think of specific tasks for which technology might be useful. The teachers feel much more comfortable using technology than the previous stage and no longer needs constant help.

d) Familiarity and confidence (stage 4): the teachers have developed a sense of confidence using a specific technology. The teachers do not need to follow the steps meticulously to use technology. 
e) Adaption to other contexts (stage 5): the teachers are no longer concerned about how to use technology. The teachers are starting to understand about the potentials of technology for learning and focus on their possibilities. The teachers can use many technologies and use them as instructional tools but in limited ways.

f) Creative application to new contexts (stage 6): the teachers can use technologies for learning processes in their classroom and integrate them in their curriculum in multiple ways.

More recently, a similar concept was reported by Holland (2001). She described that teachers learn to integrate technology in teaching through five developmental stages: nonreadiness, survival, mastery, impact, and innovation. While the ideas of Holland (2001) were not exactly corresponding to the model of Russell (1995), the general idea and underlying principles of the two models are the same. The five technology integration levels are described below.

a) Non-readiness (stage 1): teachers at this stage exhibit fear of using technology because they are afraid of breaking machines or damaging programs. Their lack of knowledge of how to use a technology causes this problem and makes them avoid using the technology. Teachers perceive technology as too difficult or complex to learn and use in teaching and do not view technology neither as a useful tool for a daily living nor for learning.

b) Survival (stage 2): teachers at this stage focus on their personal learning and use of technology. Teachers may have a certain level of proficiency in one or more technologies, but have not developed sufficient skills to use them in their teaching. Thus, their level of confidence is low. Teachers may be able to teach the technologies they know to students, but cannot use them to help their instruction and students' learning. Teachers at this stage demonstrate limited knowledge of technology and lack of 
understanding regarding how technology can improve their instruction and students' learning.

c) Mastery (stage 3): teachers at this stage are competent in one technology, but not competent in other technologies. Teachers master how to use technology, but do not master how to use technology as an instructional tool. They may be able to use technology in their teaching, but their way of technology use for instruction is teachercentered. Teachers use technology merely to provide information to students. That is, technology is the object of instruction, not a support tool for learning.

d) Impact (stage 4): teachers at this stage are familiar with several technologies and are working on integrating technology in their instruction and curriculum. Teachers now understand and recognize technology is best used as an instructional tool rather than a separate tool. However, they are still trying to find the best ways to use technology for instruction. Teachers at this stage shift their focus from their own personal use of technology to instructional use. Teachers are concerned about the effect of technology use on students' learning. Teachers often create an environment where students can use technology for problem solving (more learner-centered teaching). They need little technical assistance from technology specialists in planning and trouble shooting. Teachers at this stage may be able to use several teaching strategies to integrate technology in order to meet diverse students' needs, but often feel difficulty in managing and monitoring students' work during instruction.

e) Innovation (stage 5): teachers at the innovation stage can use a variety of technologies in their teaching and can use complex technologies to teach their subject matter. They create learning environments where students can learn through discovery and facilitate students' 
own learning by integrating technology.

When learning to teach with technology, teachers advance through the developmental stages, but can come back to an earlier stage at any time. This is because teachers may have high knowledge and experiences in some technologies, but not in other technologies.

As described above, teachers are at various levels in their knowledge and use of technology and these levels are developmental when attempting to use technology in their teaching (Holland, 2001). Teachers have different needs and require different support depending on their technology integration stages. According to Holland (2001), different supports and tactics should be provided to teachers who are at a variety of developmental stages in order to help them successfully integrate technology. Holland (2001) suggested the following supports and training for teachers who are in different developmental stages. The following table describes strategies and supports for teachers at various stages of technology integration to help them integrate technology. 
Table 2

Developmental Stages of Adoption of Technology (SAT)

\section{SAT Suggested Strategies}

Non-readiness $\quad$ - Formal training on how to operate technology and how to use it in classroom

- Formal training which can spark teachers' interest

Survival

- Immediate and continuous assistance to help them solve technological problem

- Development of personal knowledge and use of technology

- Co-teaching model

- Situated professional development

Mastery

- Formal training

- Personal assistance

- Peer coaching

Impact

- Become reflective practitioner

- Discussion and collaborative work with others at the similar technology integration level

- Observation of others

- Action Research

Innovation

- Collaboration with others for technology integrated curriculum design

Note. Adapted from Holland, P. (2001). Professional development in technology: Catalyst for school reform. Journal of Technology and Teacher Education, 9(2), 254-267.

\section{Summary}

To date, there is lack of the consolidated idea of what strategies are the most effective to train PE teachers. Studies have reported barriers that teachers face when attempting to integrate technologies, such as lack of access to technologies, time, inadequate technical and administrative support, class size, knowledge, self-efficacy, and pedagogical beliefs. These barriers to technology integration are largely categorized into two: First order barriers and second order barriers. These barriers significantly influence teachers' technology integration effort. 
Ertmer (1999) maintain that teachers can overcome first order barriers if they have adequate funding, support, training, and time. However, overcoming the first order barriers do not mean that teachers will meaningfully integrate instructional technology into their teaching because the second order barriers hinder teachers' meaningful technology integration. Researchers suggested that the second order barriers have more impact on teachers' meaningful technology integration (Ertmer, 1999, 2005; Ertmer \& Ottenbreit-Leftwich, 2010; Hew \& Brush, 2007; Hixon \& Buckenmeyer, 2009). Therefore, there are many efforts to eliminate these barriers among teacher educators.

Many technology integration strategies that have been used in teacher training programs and PDPs are introduced by teacher educators (Kay, 2006). These strategies range from single course to combination and have found to be effective to prepare pre/in-service teachers who can effectively integrate technology in their classroom. However, these studies are from general education. Thus, there is a lack of research what technology integration strategies PETE programs use and their effect on pre/in-service PE teachers' technology integration. To date, only one study by Wyant et al. (2015) demonstrated technology integration strategy that a PETE program has implemented to train pre/in-service PE teachers. This limited evidence makes PE teachers educators difficult to effective design their program to prepare PE teachers to use technology. This lack of evidence and study in the field of PE may make PE teacher educators to provide courses focusing only on technology skills and its function or courses using 'one size fit for all' strategies. These courses have found to be ineffective because these courses do not consider individual differences. Researchers (Holland, 2001; Russell, 1995) suggested that teachers differ in their knowledge, skills, beliefs, and experiences. Therefore, they are at various stages of technology integration when beginning to use technology in their teaching. Teachers in 
different stages of technology integration need different supports and training. In spite of this fact, many teacher training programs and PDPs provide techno-centric courses or courses using one-size-fit-for all approaches. These courses are not appropriate to teachers who are in different stages of technology integration. 


\section{References}

Angeli, C., \& Valanides, N. (2005). Preservice elementary teachers as information and technology designers: An instructional systems design model based on an expanded view of pedagogical content knowledge. Journal of Computer Assisted Learning, 21, 292-302.

Albino, P. (1999) Self-efficacy beliefs as an indicator of teachers' preparedness for teaching with technology. In: 10th International Conference of the Society for Information Technology \& Teacher Education (SITE 1999). Retrieved from https://eprints.usq.edu.au/6973/1/Albion_SITE_1999_AV.pdf

Ayvazo, S. (2007). Exploring the pedagogical content knowledge of effective teachers in physical education (Unpublished doctoral dissertation). Ohio State University, Columbus, $\mathrm{OH}$.

Archambault, L. M., \& Barnett, J. H. (2010). Revisiting technological pedagogical content knowledge: Exploring the TPACK framework. Computers \& Education, 55, 1656-1662.

Baert, H. (2011). The integration of technology within physical education teacher education: Perceptions of the faculty. (Unpublished doctoral dissertation). University of Arkansas, Fayetteville, AR.

Bai, H., \& Ertmer, P. (2008). Teacher educators' beliefs and technology uses as predictors of preservice teachers' beliefs and technology attitudes. Journal of Technology and Teacher Education, 16, 93-112.

Bandura, A. (1990). Perceived self-efficacy in the exercise of control over AIDS infection. Evaluation and Program Planning, 13, 9-17.

Bandura, A. (1995). Self-efficacy in changing societies. New York, NY; Cambridge University Press 
Barton, R. \& Haydn, T. (2006). Trainee teachers' views on what helps them to use information and communication technology effectively in their subject teaching. Journal of Computer Assisted Learning, 22, 257-272.

Beighle, A., Pangrazi, R. P., \& Vincent, S. D. (2001). Pedometers, physical activity, and accountability. Journal of Physical Education, Recreation \& Dance, 72(9), 16-19.

Beighle, A., Morgan, C. F., \& Pangrazi, R. P. (2004). Using pedometers in elementary physical education. Teaching Elementary Physical Education, 15, 17-18.

Bernstein, M.B. (2009). At the desk and on the nightstand: Reading as a mediating artifact in teachers' professional and personal lives. (Unpublished doctor dissertation). Northwestern University, Evansdale, IL.

Block, B. A. (2008). Using iPods in dance pedagogy. Journal of physical education, Recreation \& Dance, 79, 25-28.

Bold, C. (2011). Using narrative in research. Thousand Oaks, CA: SAGE Publications.

Brown, D., \& Warschauer, M. (2006). From the university to the elementary classroom: Students' experiences in learning to integrate technology in instruction. Journal of Technology and Teacher Education, 14, 599-621.

Brush, T., Glazewski, K., Rutowski, K., Berg, K., Stromfors, C., Van-Nest, M. H., ... \& Sutton, J. (2003). Integrating technology in a field-based teacher training program: The PT3@ ASU project. Educational Technology Research and Development, 51, 57-72.

Chai, C. S., Koh, J. H. L., \& Tsai, C. C. (2010). Facilitating preservice teachers' development of technology pedagogical, and content knowledge (TPACK). Educational Technology \& Society, 13, 63-73. 
Chai, C. S., Koh, J. H. L., \& Tsai, C. C. (2013). A Review of technological pedagogical content knowledge. Educational Technology \& Society, 16(2), 31-51.

Choy, D., Wong, A.F.L., \& Gao, P. (2009). Student teachers’ intentions and actions on integrating technology into their classrooms during student teaching: A Singapore study, Journal of Research on Technology in Education, 42, 175-195.

Christensen, R. (1997). Effect of technology integration education on the attitudes of teachers and their students. (Unpublished doctoral dissertation). University of North Texas, Denton, TX.

Christensen, R. \& Knezek, G. (2001). Instruments for assessing the impact of technology in education. Computer in Schools: Interdisciplinary Journal of Practice, Theory, and Applied Research, 18, 5-25.

Christensen, M. K. (2014). Exploring biographical learning in elite soccer coaching. Sport, Education and Society, 19(2), 204-222.

Clandinin, D. J. (2006). Narrative inquiry: A methodology for studying lived experience. Research Studies in Music Education, 27(1), 44-54.

Cushion, C. J., Armour, K. M., \& Jones, R. L. (2003). Coach education and continuing professional development: Experience and learning to coach. Quest, 55 (3), 215-230.

Cushion, C., Nelson, L., Armour, K., Lyle, J., Jones, R., Sandford, R., \& O’Callaghan, C. (2010). Coach learning and development: A review of literature. Leeds: Sports Coach, UK.

Day, E. A., Winfred, A., \& Gettman, D. (2001). Knowledge structures and the acquisition of a complex skill. Journal of Applied Psychology, 86(5), 1022 - 1033.

De Lisi, R., \& Wolford, J. L. (2002). Improving children's mental rotation accuracy with computer game playing. The Journal of Genetic Psychology,163, 272-282. 
Elo, S., \& Kyngäs, H. (2008). The qualitative content analysis process. Journal of Advanced Nursing, 62(1), 107-115

Erickson, K., Bruner, M. W., MacDonald, D. J., \& Cote, J. (2008). Gaining insight into actual and preferred sources of coaching knowledge. International Journal of Sports Science and Coaching, 3(4), 527-538.

Ertmer, P. A. (1999). Addressing first-and second-order barriers to change: Strategies for technology integration. Educational Technology Research and Development, 47, 47-61.

Ertmer, P. A., Paul, A., Molly, L., Eva, R., \& Denise, W. (1999). Examining teachers' beliefs about the role of technology in the elementary classroom. Journal of Research on Computing in Education, 32, 54-72.

Ertmer, P. A. (2005). Teacher pedagogical beliefs: The final frontier in our quest for technology integration?. Educational Technology Research and Development, 53, 25-39.

Ertmer, P. A., Ottenbreit-Leftwich, A., \& York, C. S. (2006). Exemplary technology-using teachers: Perceptions of factors influencing success. Journal of Computing in Teacher Education, 23(2), 55-61

Ertmer, P. A., \& Ottenbreit-Leftwich, A. T. (2010). Teacher technology change: How knowledge, confidence, beliefs, and culture intersect. Journal of Research on Technology in Education, 42, 255-284.

Fiorentino, L.H., \& Gibbone, A. (2005). Using the virtual gym for practice and drill, Teaching Elementary Physical Education, 16, 14-16.

Gilbert, W. D., \& Trudel, P. (2005). Learning to coach through experience: Conditions that influence reflection. Physical Educator, 62, 32 
Gibbone, A, Perez, S.L. \& Virgilio, S.J. (2014). Using mobile devices in physical education to enhance learning and physical activity for at-risk girls, Strategies, 27, 13-17.

Gibbone, A., Rukavina, P., \& Silverman, S. (2010). Technology integration in secondary physical education: Teachers' attitudes and practice. Journal of Educational Technology Development and Exchange, 3, 27-42

Grossman, P. L. (1990). The making of a teacher: Teacher knowledge and teacher education. New York, NY: Teachers College Press.

Harris, J., Mishra, P., \& Koehler, M. (2009). Teachers' technological pedagogical content knowledge and learning activity types: Curriculum-based technology integration reframed. Journal of Research on Technology in Education, 41, 393-416.

Harris, J. \& Hofer, M. (2009). Instructional planning activity types as vehicles for curriculumbased TPACK development. In Society for Information Technology \& Teacher Education International Conference, 1, 4087-2095.

Harris, F. (2009). Visual technology in physical education using Dartfish video analysis to enhance learning: An overview of the Dartfish project in New Brunswick. Physical \& Health Education Journal, 74, 24-25

Harris, J. \& Hofer, M. (2011). Technological pedagogical content knowledge (TPACK) in action: A descriptive study of secondary teachers' curriculum-based, technology-related instructional planning, Journal of Research on Technology in Education, 43, 211-229.

Hayes, E., \& Silberman, L. (2007). Incorporating video games into physical education. Journal of Physical Education, Recreation \& Dance, 78, 18-24.

Heynen, C (2008). Viewing and visual representation in the physical education classroom, Strategies, 22, 25-30. 
Hew, K. F., \& Brush, T. (2007). Integrating technology into K-12 teaching and learning: Current knowledge gaps and recommendations for future research. Educational Technology Research and Development, 55, 223-252.

Hicks, L., \& Higgins, J. (2010). Exergaming: Syncing physical activity and learning, Strategies, $24,18-21$

Hixon, E., \& Buckenmeyer, J. (2009). Revisiting technology integration in schools: Implications for professional development. Computers in the Schools, 26, 130-146.

Holland, P. (2001). Professional development in technology: Catalyst for school reform. Journal of Technology and Teacher Education, 9(2), 254-267.

Hur, J.W., Cullen, T., \& Brush, T. (2010). Teaching for application: A model for assisting preservice teachers with technology integration, Journal of Technology and Teacher Education, 18, 161-182.

Inan, F. A., \& Lowther, D. L. (2010). Factors affecting technology integration in K-12 classrooms: A path model. Educational Technology Research and Development, 58, $137-154$.

Ince, M. L., Goodway, J. D., Ward, P., \& Lee, M. A. (2006). The effects of professional development on technological competency and the attitudes urban physical education teachers have toward using technology. Journal of Teaching in Physical Education, 25(4), 428-440.

International Society for Technology in Education. (2008). ISTE standards teachers. Retrieved from http://www.iste.org/docs/pdfs/20-14_iste_standards-t_pdf.pdf 
Jimoyiannis, A. (2010). Designing and implementing an integrated technological pedagogical science knowledge framework for science teachers professional development. Computers \& Education, 55, 1259-1269.

Jones. E.M., Bulger, S.M., \& Wyant, J. (2012). Moving beyond the stopwatch and whistle: Examining technology use in teacher training. The Global Journal of Health and Physical Education Pedagogy, 1, 210-222.

Juniu, S., Shonfeld, M., \& Ganot, A. (2013). Technology integration in physical education teacher education programs: a comparative analysis. Actualidades Investigativas en Educación, 13, 218-240.

Juniu, S. (2011). Pedagogical use of technology in physical education, Journal of Physical Education, Recreation \& Dance, 82, 41-49.

Kay, R. H. (2006). Evaluating strategies used to incorporate technology into preservice education: A review of the literature. Journal of Research on Technology in Education, $38,383-408$.

Kay, R. H. (2007). A formative analysis of how pre-service teachers learn to use technology, Journal of Computer Assisted Learning, 23, 366-383.

Koehler, M.J., \& Mishra, P. (2005). What happens when teachers design educational technology? The development of technological pedagogical content knowledge. Journal of Educational Computing Research, 32, 131-152.

Koehler, M., \& Mishra, P. (2009). What is technological pedagogical content knowledge (TPACK)? Contemporary Issues in Technology and Teacher Education, 9, 60-70. 
Kopcha, T.J. (2012). Teachers' perceptions of the barriers to technology integration and practices with technology under situated professional development. Computer \& Education, 59, 1109-1121.

Kovalik, C., Kuo, C, \& Karpinski, A., (2013). Assessing pre-service teachers' information and communication technologies knowledge, Journal of Technology and Teacher Education, 21, 179-202.

Lai, M. L. (2008). Technology readiness, internet self-efficacy and computing experience of professional accounting students. Campus-Wide Information System, 25, 18-29.

Lawless, K. \& Pellegrino, J.W. (2007). Professional development in integrating technology into teaching and learning: Knowns, unknowns, and ways to pursue better questions and answers, Review of Educational Research, 77, 575-614.

Lemyre, F., Trudel, P., \& Durand-Bush, N. (2007). How youth-sport coaches learn to coach. The Sport Psychologist, 21(2), 191-209.

Liang, G., Walls, R. T., Hicks, V. L., Clayton, L. B., \& Yang, L. (2006). Will tomorrow’s physical educators be prepared to teach in the digital age?. Contemporary Issues in Technology and Teacher Education, 6, 143-156.

Lim, C.P., Chai, C.S., \& Churchill, D. (2011). A framework for developing pre-service teachers' competencies in using technologies to enhance teaching and learning. Educational Media International, 48, 69-83.

Marra, R. M. (2004). An online course to help teachers "use technology to enhance learning": Successes and limitations. Journal of Technology and Teacher Education, 12, 411-429. 
Marshall, S. J., Biddle, S. J., Gorely, T., Cameron, N., \& Murdey, I. (2004). Relationships between media use, body fatness and physical activity in children and youth: a metaanalysis. International Journal of Obesity, 28, 1238-1246.

Mears, D. (2009). Technology in physical education: Article \#4 in a 6-part series: Podcasts and Wiki's: Delivering content information to students using technology, Strategies, 23, 2934.

Mears, D., \& Hansen, L. (2009). Technology in physical education article\# 5 in a 6-Part series: Active gaming: Definitions, options and implementation. Strategies, 23, 26-29.

Meckbach, J., Gibbs, B., Almqvist, J., Ohman, M., \& Quennerstedt, M. (2013). Exergames as a teaching tool in physical education?. Sport Science Review, 22, 369-386.

Mikat, R. P., Martinez, R. D., \& Jorstad, J. A. (2007). Podcasting for your class. Journal of Physical Education, Recreation \& Dance, 78, 14-16.

Mishra, P., \& Koehler, M. (2006). Technological pedagogical content knowledge: A framework for teacher knowledge. The Teachers College Record, 108, 1017-1054.

Moon, J. (2004). A handbook of reflective and experiential learning: Theory and practice. New York, NY: Routledge Falmer.

Moursand, D. \& Talbot, B. (1999). Will new teachers be prepared to teach in a digital age? A national survey on information technology in teacher education. Santa Monica, CA: Milken Family Foundation, Milken Exchange on Education Technology. Retrieved from http://asucoefoundationsandtechnology.pbworks.com/f/Will\%2520teachers\%2520be\%25 20prepared\%2520to\%2520teach\%2520in\%2520the\%2520digital\% 2520age.pdf 
Mouza, C. (2011). Promoting urban teachers' understanding of technology, content, and pedagogy in the context of case development. Journal of Research on Technology in Education, 44, 1-29.

Mueller,J., Wood, E., Willoughby, T., Ross, C., \& Specht, J. (2008). Identifying discriminating variables between teachers who fully integrate computers and teachers with limited integration. Computer and Education, 51, 1523-1537.

National Association for Sport and Physical Education. (2008). National initial physical education teacher education standards. Reston, VA: Author.

National Association for Sport and Physical Education. (2009). Appropriate use of instructional technology in physical education [Position statement]. Reston, VA: Author.

Nichols, R., Davis, K. L., McCord, T., Schmidt, D., \& Slezak, A. M. (2009). The use of heart rate monitors in physical education. Strategies, 22, 19-23.

Niess. M. L. (2005). Preparing teachers to teach science and mathematics with technology: Developing a technology pedagogical content knowledge. Teaching and Teacher Education, 21, 509-523.

Phillips, A., Rodenbeck, M., \& Clegg, B. (2014). Apps for physical education: Teacher tested, kid approved!. Strategies, 27, 28-31.

Pierson, M. E. (2001). Technology integration practice as a function of pedagogical expertise. Journal of Research on Computing in Education. 33, 413-430.

Pitney, W., \& Parker, J. (2009). Qualitative research in physical activity and the health professions. Champaign, IL: Human Kinetics. 
Polly, D. (2011). Developing teachers' technological, pedagogical, and content knowledge (TPACK) through mathematics professional development, International Journal for Technology in Mathematics Education, 18, 83-95.

Putnam, R. T., \& Borko, H. (2000). What do new views of knowledge and thinking have to say about research on teacher learning?. Educational Researcher, 4-15.

Russell, A.L. (1995). Stages in learning new technology: Naive adult email users. Computer Education, 25 (4), 173-178.

Russell, M., Bebell, D., O'Dwyer, L., \& O'Connor, K. (2003). Examining teacher technology use implications for preservice and inservice teacher preparation. Journal of Teacher Education, 54, 297-310.

Scruggs, P.W., Mungen, J.D., \& Oh, Y. (2010). Quantifying moderate to vigorous physical activity in high school physical education: A pedometer steps/minutes standard. Measurement in Physical Education and Exercise Science, 14, 104-115.

Sinelnikov, O. A. (2012). Using the iPad in a sport education season. Journal of Physical Education, Recreation \& Dance, 83, 39-45.

Sheehan, D., \& Katz, L. (2010). Using interactive fitness and Exergames to develop physical literacy. Physical \& Health Education Journal, 76. 12- 19.

Shulman, L. S. (1986). Those who understand: Knowledge growth in teaching. Educational Researcher, 4-14.

Shulman, L. S. (1987). Knowledge and teaching: Foundations of the new reform. Harvard Educational Review, 57, 1-23 
Thompson, A. D., Schmidt, D. A., \& Davis, N. E. (2003). Technology collaborative for simultaneous renewal in teacher education. Educational Technology Research and Development, 51, 73-89.

Trout, J., \& Christie, B. (2007). Interactive video games in physical education. Journal of Physical Education, Recreation \& Dance, 78, 29-45

Vannatta, R. A., \& Nancy, F. (2004). Teacher dispositions as predictors of classroom technology use. Journal of Research on Technology in Education, 36, 253-271.

Voogt, J., Fisser, P., Pareja Roblin, N., Tondeur, J., \& van Braak, J. (2013). Technological pedagogical content knowledge: A review of the literature. Journal of Computer Assisted Learning, 29(2), 109-121.

Wang, L., Ertmer, P. A., \& Newby, T. J. (2004). Increasing preservice teachers' self-efficacy beliefs for technology integration. Journal of Research on Technology in Education, 36, $231-250$.

Werther, P. \& Trudel, P. (2006). A new theoretical perspective for understanding how coaches learn to coach. The Sport Psychologist, 20, 198-212.

Wikipedia (2014). Sport video game. http://en.wikipedia.org/wiki/Category:Sports_video_games

Wright, T., Trudel, P., \& Culver, D. (2007). Learning how to coach: The different learning situations reported by youth ice hockey coaches. Physical Education and Sport Pedagogy, 12(2), 127-144.

Wyant, J. D. (2012). A mixed methods analysis of a single course strategy to integrate technology into PETE. (Unpublished doctoral dissertation). West Virginia University, Morgantown, WV. 
Wyant, J.D., Jones, E.M. \& Bulger, S.M. (2015). A mixed methods analysis of a single-course strategy to integrate technology into PETE. Journal of Teaching in Physical Education, $34,131-151$.

Zhao, Y., \& Cziko, G. A. (2001). Teacher adoption of technology: A perceptual control theory perspective. Journal of Technology and Teacher Education, 9, 5-30.

Zhao, Y., \& Frank, K. A. (2003). Factors affecting technology uses in schools: An ecological perspective. American Educational Research Journal, 40, 807-840. 


\section{Appendix C}

\section{Participant Cover Letter}

\section{Dear Participant,}

This letter is a request for you to take part in a research project to examine physical education teacher's knowledge about technology integration in physical education as a result of masterlevel instructional technology focused course (instructional technology in physical education and a semester-long advanced laboratory). This project is being conducted by Jun-Hyung Baek, MS.Ed in the College of Physical Activity and Sport Sciences at WVU with supervision of Dr. Emily Jones, assistant professor in the College of Physical Activity and Sport Sciences, for completion of doctoral degree work. This study has been reviewed and acknowledged by IRB.

You will be asked to complete a survey four times, before and after the summer course and before and after your field experience. Along with the survey, several of you may be asked to participate in semi-structured interview. The survey will take approximately 30-40 minutes to complete, and interview will last for approximately 10-15 minutes. Your participation in this project is greatly appreciated.

You will be asked to report your identity when completing the survey, but your involvement in this project will be kept as confidential as legally possible. All data will be reported in the aggregate. Only primary researcher will be able to access data and all data (survey and audiotaping) will be stored and locked with a password in the primary researcher's computer. You must be 18 years of age or older to participate. Your participation is completely voluntary. You may skip any question that you do not wish to answer and you may discontinue at any time. Your class standing will not be affected if you decide either not to participate or to withdraw. West Virginia University's Institutional Review Board acknowledgement of this project is on file.

I hope that you will participate in this research project, as it could be beneficial for teacher educators in understanding what instructional approaches would be the best approach to prepare physical education teacher who can effectively and pedagogically use technology in physical education. Thank you very much for your time. Should you have any questions about this letter or the research project, please feel free to contact Jun-Hyung Baek at (815) 981-2374 or by email at jubaek@mix.wvu.

Thank you for your time and help with this project.

Sincerely,

Jun-Hyung Baek 


\section{Appendix D}

\section{Stages of Adoption of Technology}

Name: Date:

Instructions: Please read the descriptions of each of the six stages related to adoption of technology. Choose the stage that best describes where you are in the adoption of technology.

\section{Stage 1: Awareness}

I am aware that technology exists but have not used it-perhaps I'm even avoiding it.

\section{Stage 2: Learning the process}

I am currently trying to learn the basics. I am often frustrated using computers. I lack confidence when using computers.

\section{Stage 3: Understanding and application of the process}

I am beginning to understand the process of using technology and can think of specific tasks in which it might be useful.

\section{Stage 4: Familiarity and confidence}

I am gaining a sense of confidence in using the computer for specific tasks. I am starting to feel comfortable using the computer.

\section{Stage 5: Adaptation to other contexts}

I think about the computer as a tool to help me and am no longer concerned about it as technology. I can use it in many applications and as an instructional aid.

\section{Stage 6: Creative application to new contexts}

I can apply what I know about technology in the classroom. I am able to use it as an instructional tool and integrate it into the curriculum.

From: Christensen, R. (1997). Effect of technology integration education on the attitudes of teachers and their students. Doctoral dissertation, University of North Texas. Based on Russell, A. L. (1995). Stages in learning new technology. Computers and Education, 25(4), 173-178 


\section{Appendix E}

\section{Narrative Interview Guide}

Introductory comments

This is an interview to hear about your past technology-related learning experiences in formal education situations. I believe teachers learn to teach their subject matter with technologies through various learning situations. You may learn how to teach with technology from college courses, workshop, conference, or from discussion with your colleague. But for this present interview, I would like you to focus only on the time that you were in mediated learning situations. Mediated learning situations are learning situations where you learn something directly from another person or materials, such as teacher training courses, in-service workshop, conference, professional development, and graduate program. My goal is to understand what technology-related learning experiences you had in mediated learning situations, how you make sense of technology and how to develop your knowledge and skills through the situations, and how you interpret the experiences. Therefore, I am collecting and analyzing the stories of your experiences with instructional technology. There are no right or wrong answers to my questions. Instead, your task is simply tell me you about experiences in detail. Everything you say is voluntary, anonymous, and confidential. Therefore, your participation will not negatively or positive affect your class standing or grades. If at any time you wish to not respond to a question, it is ok. This interview will be audio-recorded.

Do you have any questions? If you don't, let's begin interview.

From now on, I would like to divide your mediated learning situations into three chapters. The first chapter will be your time in an undergraduate program. Second chapter will be your time as you work at a K-12 school as a PE teacher. Third chapter will be your time in a graduate program.

I would like you to focus on a few key events that stand out in bold print in each chapter. You do not need to tell me everything that has ever happened to you. You just need to select events or experiences that were significantly influential to you in terms of knowledge, skills, or confidence. Thus, please focus on a few events that were significant or influential to you. 
From now on, I am going to ask you about several specific events you experienced when you were in college. Please recall the time when you were in the undergraduate program.

1. Please describe your knowledge, skills, and confidence level related to technology when you first entered an undergraduate program (general technology skill, knowledge, confide nce).

2. At the time of entering PETE program, what were your beliefs about using technology in physical education class at that time?

3. What did you believe about using technology in PE at that time? Was it valuable?

4. Across your teacher education program, please list all technology-related learning experie nces you had while you were in teacher training program (Provide participants time to list the experiences).

5. Among the experiences you just listed, please tell me the learning experiences that was th e most influential to you. It would be courses or learning tasks that had a significant impa ct on your knowledge, skills, or confidence necessary to integrate technology. Please desc ribe the experiences in detail like exactly when it happened, where it happened, what hap pened, who was involved, what you did with the technology, and what you were thinking and feeling at that moment? (This is really fascinating). Were there any other significant events that were influential to you?

6. What technology-related learning experiences do you believe the least influential to you i $\mathrm{n}$ terms of knowledge, skills, or confidence? It would be courses or learning tasks that did not have any impacts on your knowledge, skills, or confidence integrating technology int o class. Please elaborate the learning experiences in detail like exactly when it happened, where it happened, what happened, who was involved, what you did with the technology, and what you were thinking and feeling at that moment?

7. Which of experiences were the least influential?

8. Can you think anything else you would like to share with me?

\section{As a PE teacher (Inservice examples)}

From now on, I am going to ask you about several specific events you experienced when you work at a K-12 schools as a PE teacher. Please recall the time when you are at your school.

1. Please describe your knowledge and skills related to technology when you just became a PE teacher. 
2. What was your perception about integrating technology in physical education class at that time?

3. Please list all technology-related learning experiences you had at your school, districts, na tionally. For example, school workshop, district workshop, state professional developmen $\mathrm{t}$, or state or national conference.

4. Among the experiences you just listed, please tell me the learning experiences that was th e most influential to you. It would be courses or learning tasks that had significant impact on your knowledge, skills, or confidence necessary to integrate technology. Please descri be the experiences in detail like exactly when it happened, where it happened, what happe ned, who was involved, what you did with the technology, and what you were thinking an $\mathrm{d}$ feeling at that moment? (This is really interesting). Were there any other significant eve nts that were influential to you?

5. What technology-related learning experiences do you believe the least influential to you $\mathrm{i}$ $\mathrm{n}$ terms of knowledge, skills, or confidence? It would be courses or learning tasks that did not have any impacts on your knowledge, skills, or confidence integrating technology int o class. Please elaborate the learning experiences in detail like exactly when it happened, where it happened, what happened, who was involved, what you did with the technology, and what you were thinking and feeling at that moment?

6. Can you think anything else you would like to share with me?

\section{Graduate Programs}

From now on, I am going to ask you about several specific events you experienced when you were in a graduate program. Please recall the time when you were in the graduate program

1. Please describe your knowledge and skills related to technology when you just entered th e graduate program.

2. What were your beliefs about using technology in physical education class at that time?

3. Please list all technology-related learning experiences you had while you were in the cour ses in graduate program.

4. Among the experiences you just listed, please tell me the learning experiences that was th e most influential to you. It would be courses or learning tasks that had significant impact on your knowledge, skills, or confidence necessary to integrate technology. Please descri be the experiences in detail like exactly when it happened, where it happened, what happe 
ned, who was involved, what you did with the technology, and what you were thinking an $\mathrm{d}$ feeling at that moment?

5. What technology-related learning experiences do you believe the least influential to you $\mathrm{i}$ $\mathrm{n}$ terms of knowledge, skills, or confidence? It would be courses or learning tasks that did not have any impacts on your knowledge, skills, or confidence integrating technology int o class. Please elaborate the learning experiences in detail like exactly when it happened, where it happened, what happened, who was involved, what you did with the technology, and what you were thinking and feeling at that moment?

6. Can you think anything else you would like to share with me?

Thank you for your time for this interview. I greatly appreciate your time and response. Can I follow up at another time if I have a question?

You are going to hear from me again in the future. I will transcribe the entire interview we did today and send it to you. I want you to look at the transcription and tell me. 